Provided for non-commercial research and education use. Not for reproduction, distribution or commercial use.

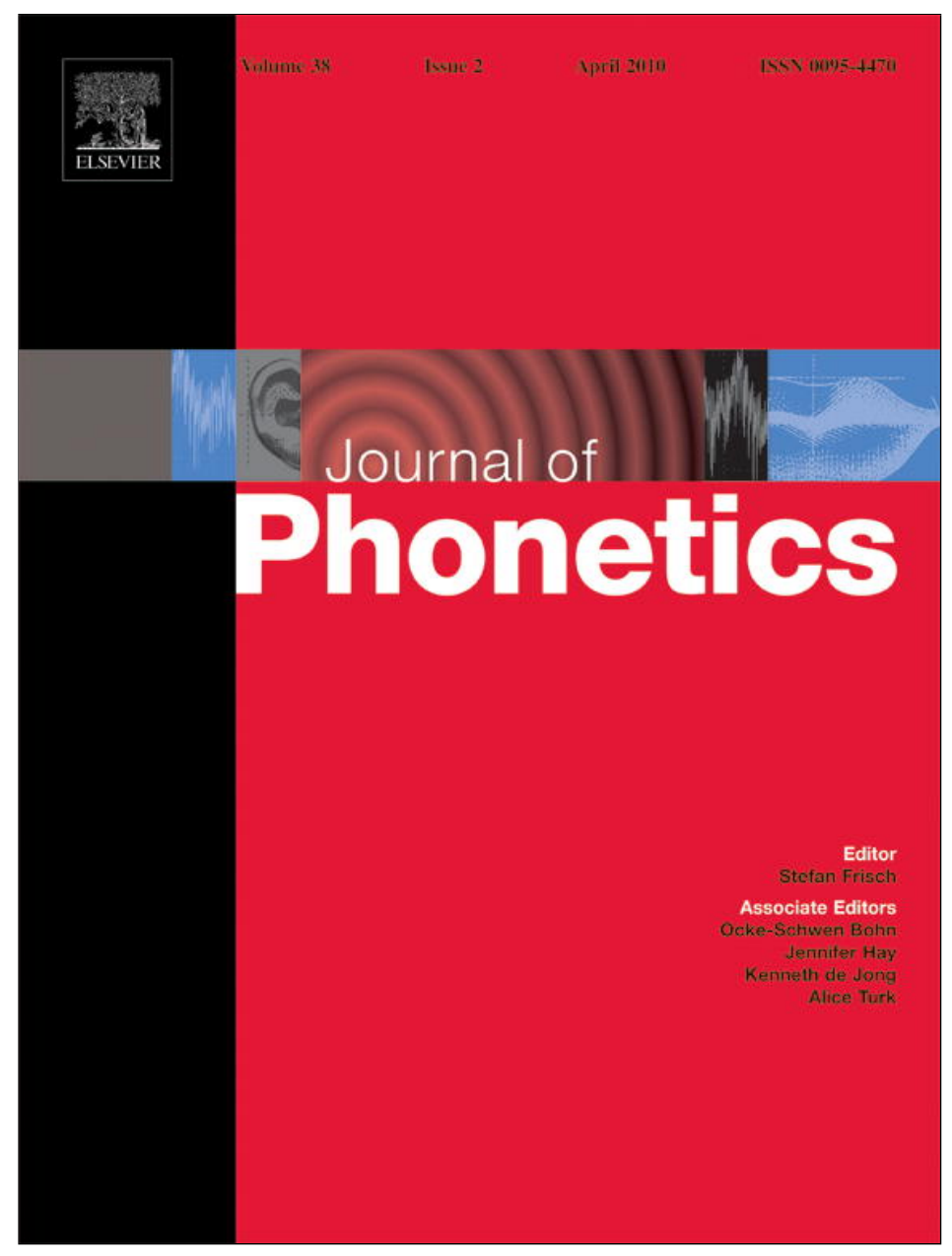

This article appeared in a journal published by Elsevier. The attached copy is furnished to the author for internal non-commercial research and education use, including for instruction at the authors institution and sharing with colleagues.

Other uses, including reproduction and distribution, or selling or licensing copies, or posting to personal, institutional or third party websites are prohibited.

In most cases authors are permitted to post their version of the article (e.g. in Word or Tex form) to their personal website or institutional repository. Authors requiring further information regarding Elsevier's archiving and manuscript policies are encouraged to visit:

http://www.elsevier.com/copyright 


\title{
Word-level prosody in Balsas Nahuatl: The origin, development, and acoustic correlates of tone in a stress accent language
}

\author{
Susan G. Guion ${ }^{\mathrm{a}, *}$, Jonathan D. Amith ${ }^{\mathrm{b}}$, Christopher S. Doty ${ }^{\mathrm{a}}$, Irina A. Shport ${ }^{\mathrm{a}}$ \\ ${ }^{a}$ Department of Linguistics, 1290 University of Oregon, Eugene, OR 97478-1290, USA \\ ${ }^{\mathrm{b}}$ Department of Anthropology, Gettysburg College, Campus Box 412, Gettysburg, PA 17325, USA
}

Received 4 April 2007; received in revised form 18 February 2009; accepted 25 March 2009

\begin{abstract}
Here we investigate the historical origins and acoustic correlates of a hypothesized tonal development in subdialects of the Nahuatl spoken in the Balsas River valley of central Guerrero state in Mexico. We hypothesize that some subdialects have developed high tone on a syllable preceding a syllable with a breathy-voiced coda $[\mathrm{h}](<* h)$. In subdialects retaining [h], coda [h] was found to slightly lower F0 on the tautosyllabic vowel, creating a high-low F0 contour beginning on the preceding syllable. We propose that tone was developed as a reanalysis of the F0 contour as a phonological tonal specification. Through this tonal development, hybrid stress and tone systems have arisen, as the historical penultimate stress accent described for Nahuatl generally has been retained in the tonal dialects. Though such systems are typologically rare, a comparison of the development of other such hybrid systems indicates that they follow a similar historical path. That is, a stress language develops tone through the reinterpretation of a coarticulatory F0 effect as a tonal specification. We suggest that hybrid stress and tone systems may be unstable: Our results indicate that the historical stress accent may be transitioning to tone in subdialects with innovated tone.
\end{abstract}

(C) 2009 Elsevier Ltd. All rights reserved.

\section{Introduction}

We propose that the word-level prosody of some varieties of Nahuatl has recently undergone a change. Classical Nahuatl and nearly all modern dialects are described as having a fixed penultimate stress accent (Andrews, 1975; Beller \& Beller, 1979; Brewer \& Brewer, 1971; Brockway, 1979; Lastra de Suárez, 1981; Munro, 1977; Ramírez de Alejandro \& Dakin, 1979; Sischo, 1979; Tuggy, 1979). We hypothesize that, in what is a historically fixed stress accent language, tone has developed as a reflex of a breathy coda segment in two subdialects of Nahuatl spoken along the Balsas River: Oapan, where the segment has been lost, and Ahuelicán, where the segment has been

\footnotetext{
${ }^{*}$ Corresponding author. Tel.: + 15413463682 ; fax: + 15413465961 .

E-mail address: guion@uoregon.edu (S.G. Guion).
}

maintained. While hybrid tone and stress accent systems are not unattested, they are unusual. The rarity of such systems may reflect a phonologically unstable situation or it may simply be that such systems rarely develop in languages. In either case, the Nahuatl varieties investigated here provide us with an opportunity to study the origin and development of a hybrid prosodic system. Our acoustic investigation revealed that the innovated tones are encoded primarily by $\mathrm{F} 0$. The penultimate stress accent, on the other hand, is encoded primarily by spectral balance (H1-H2 and H1-A2) and secondarily by duration. In the two subdialects that have developed tone, however, the penultimate stress accent may be transitioning to tone, as there are less stress-like acoustic correlates (i.e., reduced $\mathrm{H} 1-\mathrm{H} 2, \mathrm{H} 1-\mathrm{A} 2$, and/or duration effects) than found in non-tonal subdialects. Additionally, the historical stress accents have begun to interact phonologically with the innovated tone in certain environments, providing evidence for their incipient tonal status. 


\subsection{Typological background on stress, tone and hybrid systems}

Before detailing the current study, we locate our work within the typology of word-prosodic systems and change within those systems. This is no easy task, as various typologies have been proposed for word-level prosody. While not providing an exhaustive treatment, here we consider some of the main types of word-prosodic systems that have been proposed. One primary dividing line among typologies is how the category "accent" is defined and delineated from other prosodic types.

One view, proposed by Beckman (1986), is that accentual systems mark syntagmatic contrasts within a word. In other words, accented syllables stand out relative to unaccented syllables. Tonal systems, on the other hand, mark paradigmatic contrasts in which one tone can contrast with another tone in the same domain (e.g., word or morpheme). In Beckman's view, accent may be realized phonetically as either stress accent or non-stress accent. Stress accent is hypothesized to differ phonetically from non-stress accent. Although stress accent may have F0 as a correlate, it is thought to use acoustic correlates other than F0 more extensively than non-stress accent. The correlates of stress accent can include duration, amplitude, and vowel quality.

Hyman (2006) has recently proposed a different approach to word-level prosodic typology. Stress accent is the only accentual type admitted and it is defined by features of metrical prominence. A language with stress accent must meet the word-level metrical criteria of obligatoriness - every word must have at least one syllable marked with the highest degree of metrical prominence (primary stress) - and culminativity - every word must have at most one syllable marked with primary stress (Hyman, 2006 , p. 231). The only other category admitted is tone, which is defined as a language "in which an indication of pitch enters into the lexical realization of at least some morphemes" (Hyman, 2006, p. 229). In other words, a language is considered tonal if phonological specification at the lexical level is related to $\mathrm{F} 0$ in speech production, even if such specification is not found for all lexical items.

Languages like English and Dutch are categorized as stress accent by both of these typologies. Likewise, languages with multiple, lexically contrastive tones, such as Mandarin, are categorized as tone by both typologies. Where the typologies differ is in the categorization of languages that have tonal specifications for only some words or morphemes, especially in the case of a privative (i.e., present or absent) specification on a limited number of syllables in the word. Tokyo Japanese is a classic example of such a language (e.g., Pierrehumbert \& Beckman, 1988). Beckman's (1986) typology would classify these cases as non-stress accent, due to the syntagmatic nature of the contrast. Hyman's (2006) typology would classify these cases as tone because they violate the criterion of obligatoriness needed for stress accent but conform to the definition of tone by specifying "an indication of pitch" on the lexical realization of at least some morphemes. These sorts of cases have been the subject of much debate among typologists. Another approach has been to classify such cases as pitch accent, as do, for example, Van der Hulst and Smith (1988), who describe word-prosodic typology as a continuum between stress and tone, with pitch accent falling somewhere in the middle.

Our working hypothesis was that some of the varieties of Nahuatl studied here have developed privative specifications for pitch on some words and morphemes. In other words, we hypothesize the development of difficult-to-categorize patterns that have variously been termed non-stress accent, tone, or pitch accent. Here we will refer to these innovations as tones, following Hyman (2006), as well as other recent treatments of typologically similar prosodic phenomena (e.g., Gussenhoven, 2004). The varieties of Nahuatl studied here also exhibit the word-prosodic feature found in other extant varieties of Nahuatl, which may be uncontroversially termed stress accent in either of the typologies reviewed here. As will be presented below, this accentual prominence is historically located on the penultimate syllable of the word, although in the two tonogenetic variants the locus of this stress accent may shift in words that have innovated tone. Another purpose of this paper is to investigate the phonetic properties of the stress accent to determine whether they are typical of those found in stress languages generally and whether there are any variations in the acoustic correlates of the stress accent among the dialects.

Thus, some of the Nahuatl varieties treated here are hypothesized to be hybrid systems with both tone and stress accent (in Hyman's sense). Few such systems are documented in the literature. Indeed, as Remijsen and van Heuven (2005) have noted, some earlier views of word prosody disallowed hybrid systems (cf. Clements \& Ford, 1979; Haraguchi, 1988). However, languages with independent tone and stress systems have been attested. For example, Pike (1986) described Central Carrier, an Athabaskan language, as having word-final stress with three different word-level tonal patterns and Clark (1988) analyzed Zulu, a Bantu language, as having four tonal patterns which are independent of stress placement.

More recent studies have offered thorough phonetic investigations of hybrid systems. Everett (1998) described Pirahã, an Amazonian Mura language, as a tone language in which every vowel is specified for one of two tones. In addition, Pirahã has an independent stress accent that is assigned by syllable weight. Everett's acoustic investigation of the stress accent revealed that stressed syllables have greater peak amplitude, as well as a greater duration of the onset consonant. In contrast, vowel quality and fundamental frequency (F0) were not correlated with stress accent. Remijsen (2002) described Ma'ya, an Austronesian language, as having contrastive stress accent, as well as an independent three-way tonal contrast on final syllables. Stressed vowels were found to have longer duration, less centralization, and relatively more energy in the $1000-1750 \mathrm{~Hz}$ range than unstressed syllables, while F0 
was a relatively weak correlate of stress. In contrast, he found that the tonal contrasts were primarily correlated with F0 differences. Remijsen and van Heuven (2005) described Curaçao Papiamentu, a Caribbean Creole, as having contrastive stress that is independent of the tonal specification found on the penultimate syllable in some words. In an innovative design, Remijsen and van Heuven elicited words varying in stress and tone in multiple prosodic contexts. Specifically, they controlled for utterance position (medial and final), and focus (narrow focus, default focus, and out of focus). Though not a fully factorial design, the manipulation of prosodic condition revealed an F0 specification for tone, regardless of discourse context. In contrast, F0 was not correlated with stress. F0 specifications on stressed syllables could be attributed to intonational effects such as focus-induced prominence or an utterance-final fall. Stressed syllables were instead primarily correlated with greater duration, as well as greater intensity, and had more peripheral vowel nuclei, regardless of discourse context.

\subsection{Development of tone in stress accent systems}

In this paper, we present an investigation of the diachronic origin, as well as the synchronic realization, of a hybrid stress and tone system in two subdialects of Balsas Nahuatl. In this section we consider the historical development of similar prosodic systems cross-linguistically to determine whether there is a typical pathway of development. The studies on hybrid systems reviewed in the last section only describe synchronic systems. ${ }^{1}$ There are, however, a few studies that provide some discussion of the mechanics of development of tone in stress languages. Tones have developed from the loss of coda /h/ (in Jeh; Graden, 1966), the loss of onset /r/ (in Khmer; Wayland, \& Guion, 2005), or the loss of either coda $/ \mathrm{h} /$ or the preaspiration of a stop consonant in the following syllable onset (in Hopi; Manaster-Ramer, 1986). Graden (1966) describes the Mon-Khmer language Jeh as having stress on the 'main' syllable, which is the final of two syllables or the only syllable in the case of monosyllabic words. At the same time, some words have developed a rising tonal specification on final syllables that have lost a coda $/ \mathrm{h} /$. In one dialect, Dak Trap, the tone has a wider distribution and is also found on final syllables in which coda voiceless stops have become nasals. Wayland and Guion (2005) report that the Phnom Penh dialect of Khmer, also a MonKhmer language, has developed tonal specifications on some words conditioned by the loss of an onset $/ r /$. Like Jeh, Khmer has one stress per word in monosyllables or disyllables, with the exception of some compounds. The Uto-Aztecan language Hopi has also been described as a stress language that has developed tones. Manaster-Ramer (1986) compares modern Hopi to work done in the 1930s

\footnotetext{
${ }^{1}$ Remijsen (2002) writes that the tones in Ma'ya are a secondary development, but does not propose a specific account of their innovation.
}

and finds that where modern Hopi has a long vowel with high-to-low falling tone, earlier Hopi had a short vowel followed by either segmental coda $/ \mathrm{h} /$ or the pre-aspiration of a stop consonant in the following syllable onset. ${ }^{2}$ This development introduced independent tonal specifications on some words, although the historical stress falling on one of the first two syllables is apparently kept.

Given this rather limited set of data, a tentative developmental course can be proposed for stress systems developing into hybrid stress and tone systems. In such cases, a given segment has an effect on the F0 of a surrounding vowel. This effect is then reinterpreted as a phonological F0 specification. The original conditioning segment may then be lost, leaving only the F0 specification. In other words, a phonological specification that has $\mathrm{F} 0$ as a secondary perceptual cue is reinterpreted as a phonological specification for which F0 is the primary cue. Such a proposal is also made here for the Nahuatl subdialects under consideration. Specifically, we hypothesize that a coda [6] conditioned the development of a specification for F0 on some lexical items. The effect of breathy voicing on fundamental frequency and its role in the conditioning of tonal innovation will be discussed in the next section.

\subsection{Background on Balsas Nahuatl}

Nahuatl is the southernmost language of the UtoAztecan family, with variants spoken from the northern Mexican state of Durango (where it is known as Mexicanero) to the Cozcatlán province of El Salvador (where it is known as Pipil). To date, the variants of Nahuatl investigated in this paper are the only ones described as having developed tone.

Since the time of Classical Nahuatl in the seventeenth century, linguistic accounts of Nahuatl have described an "accent" or "stress" on the penultimate syllable in a word as the predominant prosodic pattern (see Andrews, 1975, for a summary of the Classical descriptions and Beller \& Beller, 1979; Brewer \& Brewer, 1971; Brockway, 1979; Lastra de Suárez, 1981; Ramírez de Alejandro \& Dakin, 1979; Sischo, 1979; Tuggy, 1979, for descriptions of modern Nahuatl dialects). ${ }^{3}$ Given that the earliest descriptions of Nahuatl from the seventeenth century, as well as those from modern times, describe a prosodic prominence on the penultimate syllable, we assume that the historical word prosody in the Balsas Nahuatl studied here is similar and, thus, that penultimate prosodic prominence is a

\footnotetext{
${ }^{2}$ Shaul (2000) also reports that Northern Tepehuan (Tepiman subfamily of Southern Uto-Aztecan) has developed tonal contrasts related to the loss of $/ \mathrm{h} /$. However, the exact nature of this development has not yet been fully described.

${ }^{3}$ Some dialects of Nahuatl exhibit different stress locations for some or all words, but these can be attributed to effects of historical processes such as cliticization or loss of a final vowel (Boas, 1917; Brockway, Brockway, \& Valdés, 2000; Munro, 1977; Wolgemuth, 2002). A fuller description of previous work on Nahuatl prosody is presented in Amith (unpublished ms.).
} 
continuation of the historical pattern. As mentioned above, the penultimate prosodic prominence would be classified as a stress accent in Hyman's (2006) typology, as it meets the criteria of obligatoriness and culminativity, and will be referred to as such here. No previous studies have investigated the phonetic aspects of this stress accent, and descriptions have been based on auditory impressions. Likewise, the numbered linguistic examples given in this paper are based on our fieldwork in the Balsas River area and reflect our auditory impressions, along with those of numerous nativespeaker consultants (including two who have been working on a documentation project for over 5 years) who have confirmed our auditory impressions and feel that the stress accents and hypothesized tones are correctly marked.

The domain of stress assignment, which can be termed a phonological word, may consist of many morphemes in this agglutinative language. For example, a noun or verb may have several prefixes and suffixes with just one penultimate stress (see (1) and (2) for examples from the nontonogenetic variety of Nahuatl spoken in Ameyaltepec).

(1) non $\overparen{t f a n a}$ makas

\begin{tabular}{|c|c|c|c|c|}
\hline n- & on- & tła & namaka & $-\mathrm{s}$ \\
\hline 1SG.S- & EXTRA.DIR- & NRefNHUM.O- & to.sell & -FUT.SG ${ }^{4}$ \\
\hline
\end{tabular}

(2) timi $\overparen{t s} w a: l p a l e: w i r s ' n e k i n$

$$
\begin{aligned}
& \text { ti- mits warl- palerwi: -s neki -n } \\
& \text { 1PL.S- 2SG.O- INTRA.DIR- to.help -FUT.SG- to.want -PRES.PL } \\
& \text { 'we want to come help you' }
\end{aligned}
$$

In this paper we demonstrate, through acoustic analysis, that stress accent in Nahuatl is realized by acoustic correlates typically found in stress accent languages such as duration and distribution of acoustic energy across the frequency range, i.e., spectral balance (Sluijter \& van Heuven, 1996a, 1996b). It is also possible that the stressed syllable will serve as a location for the alignment of intonational pitch accents (see, e.g., Ladd, 1996; Pierrehumbert, 1980). If this is the case, F0 effects may be associated with stressed syllables for some pragmatic functions, such as focus, or may be associated with stressed syllables occurring in particular positions within the utterance, such as initial vs. final position.

Recently, Amith (unpublished ms.) has put forth the claim that some varieties of Nahuatl along the Balsas River in Guerrero, Mexico, have developed new, lexical tonal specifications conditioned by coda [6], while maintaining

${ }^{4}$ The following abbreviations are used in the morphological parsing of the examples in the text:

1, 2, 3, 1st, 2nd, 3rd person; SG, singular; PL, plural; s, subject; o, object; POSSR, possessor; Ref, referencial; NRef, non-referencial; Hum, human; NHum, non-humam; ABS, absolutive (indicates a singular, unpossessed nouns); AGENT, agentive; ALIEN, alienable; COMPL, completive; DIMIN, diminutive; DUR, durative; EXTRA.DIR, extraverse directional; FUT, future; IMPERFV, imperfective; INTRA.DIR, intraverse directional; PERFV, perfective; POSSD, possessed; PRES, present; RDP.s/h, monomoraic reduplicant with coda $* h$ the penultimate stress accent. Based on fieldwork with native speakers, Amith described the phonological patterning of the new tones in the Nahuatl spoken in the villages of San Agustín Oapan and Ahuelicán. He postulated high tones on some, but not all, words and noted that it was possible to have multiple high tones in one word. He also noted that if these novel high tones were not present in a word, then only the expected penultimate stress accent was present. Amith described the tonal specifications in the village of Ahuelicán to have different tonal patterning from that in Oapan.

It will be our goal in the current paper to investigate both the claim that novel tones have been developed in the villages of Oapan and Ahuelicán and the origin of the postulated tones. Additionally, we will investigate the phonetic properties of the penultimate stress accents found in these villages and in the neighboring communities of Ameyaltepec and San Miguel Tecuiciapan, which do not manifest any tonal innovation (see Table 1).

Amith (unpublished ms.) has proposed that the novel high tones in Oapan are related to the position of a historical non-phrase-final coda $* h$ (which developed into [6] and was then lost in some subdialects). The high tone appears either on the syllable preceding the one with $* h$ or on the same syllable, depending on the location of the syllable with coda $* h$ within the word. In both cases, the historical $* h$ has been lost in Oapan. The Oapan words in (3) and (4) illustrate the postulated development of a high tone on a syllable preceding that with coda $* h$. Throughout this article, the historical forms, marked with '*', are shallow reconstructions of Balsas area Nahuatl based on correspondences with neighboring varieties and informed by evidence from Classical Nahuatl. The Oapan words in (5) and (6) illustrate the postulated development of a high tone on a vowel tautosyllabic to coda $* h$. Amith proposed that the original development was in the syllable preceding coda $* h$ (as in (3) and (4)) and that high tones on syllables with $* h$ (as in (5) and (6)) came about through later developments in Oapan that did not occur in Ahuelicán. ${ }^{5}$

$$
\begin{aligned}
& \text { (3) misttáso'tłaskeh <*mits tłasoh'tłaskeh }
\end{aligned}
$$

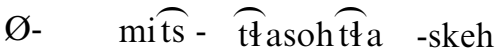

$$
\begin{aligned}
& \text { 3PL.S- 2SG.O- to.cherish -FUT.PL } \\
& \text { 'they will cherish you' }
\end{aligned}
$$

$\begin{array}{ll}\text { kipólo'tokeh } & <\text { kipoloh'tokeh } \\ \text { Ø- } \quad \text { ki- } & \text { poloh -tokeh } \\ \text { 3PL.S- } \quad \text { 3sG.O- } & \text { to.lose -DUR.PRES.PL } \\ \text { 'they are losing it' } & \end{array}$

${ }^{5}$ The examples in this section are based on transcriptions and consultation with native speakers of the respective subdialects. Words are transcribed as produced in an isolated context. The high tone mark ['] indicates a high tone and the stress mark ['] indicates a high F0 associated with the historical penultimate stress accent that may be found either on the penultimate syllable or the final syllable in the synchronic forms (i.e., those to the left of the ' $<$ '). The historical forms, to the right of the ' $<$ ' and marked with '*', are shallow reconstructions of Balsas area Nahuatl. 
Table 1

The four varieties of Nahuatl investigated in the study.

\begin{tabular}{lll}
\hline & $\begin{array}{l}\text { Penultimate } \\
\text { stress only }\end{array}$ & $\begin{array}{l}\text { Innovated } \\
\text { tones }\end{array}$ \\
\hline $\begin{array}{l}\text { Non-word-final *h retained } \\
\text { Non-word-final *h lost }\end{array}$ & $\begin{array}{l}\text { San Miguel Tecuiciapan } \\
\text { Ameyaltepec }\end{array}$ & $\begin{array}{l}\text { Ahuelicán } \\
\text { Oapan }\end{array}$ \\
\hline
\end{tabular}

Note: The Nahuatl varieties are indicated by the name of the village in which they are spoken. All villages are located along the Balsas River in the state of Guerrero, Mexico. The villages of Ahuelicán and Ameyaltepec were offshoots from the village of Oapan in pre-colonial times (Amith, 1995, 2005) and the Nahuatl in all three of these villages has certain differences from the Nahuatl spoken in San Miguel, which is phonologically more conservative, preserving the historical coda $* h$ and penultimate accent in all positions and cases.

(5)

mátła'pałli $\quad<*$ mahtła'palli
$\begin{aligned} & \text { mahtłapal } \\ & \text { (unbent or unjointed) wing }\end{aligned}$
$\begin{aligned} & \text { wing' } \\ & \text { - }\end{aligned}$

(6) mápil' tsiantłi mah hand/arm child $<*$ mahpil'tsi:nţi 'finger (diminutive)'

The words presented in (3)-(6) have penultimate stress accents that correspond to those of other varieties of Nahuatl. However, other words in Oapan, which have novel high tones on the penultimate or antepenultimate syllable, may have final, not penultimate, stress accents. Amith has proposed that the development of a high tone conditioned by $* h$ can cause the penultimate stress accent to shift to the final syllable. The words in (7) and (8) illustrate the change from penultimate to final stress accent (compare, especially, (4) and (8)). While we write the stress accent with the IPA stress mark and the tone with a hightone symbol, their interaction suggests that they may share some phonological specification. The shift may be either a metrical process, in which case the interaction may be a type of clash avoidance process (see, e.g., Hayes, 1995) or it may occur on a tonal tier, in which case it may be a type of dissimilation process. We will return to this point later on.

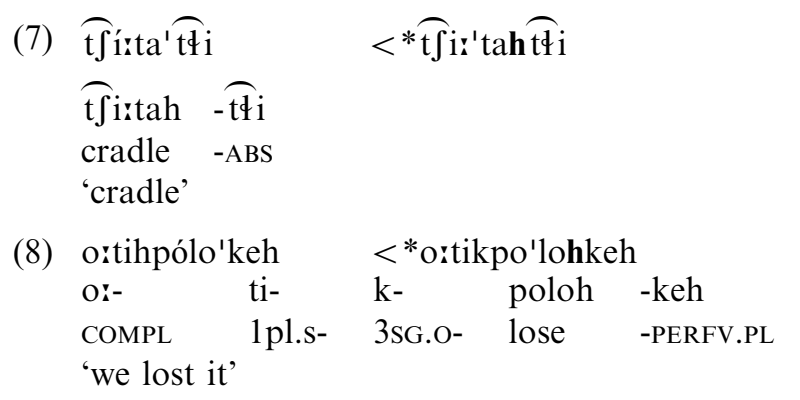

A preliminary analysis of the patterning of the novel tones in Ahuelicán, a different subdialect, reveals a more conservative pattern. First, historical $* h$ has not been lost and a high tone is apparently manifested only on the syllable preceding the one with coda $* h$. If there is no preceding syllable, then no tone was conditioned.

Moving back to a consideration of the origin of tone in Oapan and Ahuelicán, let us consider the effects of coda $/ \mathrm{h} /$ generally. We propose that the origin of the innovated tones may be in a lowering of F0 in the tautosyllabic vowel. Coda $/ \mathrm{h} /$ has been proposed as a conditioning environment for low or falling tone in many languages (Abramson, 2004; Manaster-Ramer, 1986; Matisoff, 1973; Ohala, 1973; Svantesson, 2001). Synthesizing work from several studies, Hombert, Ohala, and Ewan (1979) reported that coda /h/ lowers F0 across the preceding vowel by $25-50 \mathrm{~Hz}$ and that decreases in $\mathrm{F} 0$ as small as $10 \mathrm{~Hz}$ are perceptible to listeners. Recently, Thurgood (2002) has further refined our understanding of the effect of coda $/ \mathrm{h} /$ as a trigger for tonogenesis by proposing that coda $/ \mathrm{h} /$ can condition a low or falling tone when produced with breathy voicing. That is, a breathy-voiced [6], as opposed to a voiceless [h], lowers F0 and conditions tonal developments. This proposal is supported by the correlation between low F0 and breathy voicing in so-called 'register' distinctions in Southeast Asian languages (see, e.g., Thongkum, 1988). Breathy voicing is also known to be associated with lower F0 than modal voice cross-linguistically (Gordon \& Ladefoged, 2001).

In the case of the Nahuatl varieties in question here, we have the opportunity to investigate the conditioning effects of non-word-final coda $* h$ on the development of tone. ${ }^{6}$ In Ahuelicán, coda $* h$ is preserved and produced with breathy voicing (i.e., as [6]). There is also another village in the vicinity, San Miguel Tecuiciapan, which preserves coda $* h$ but has not innovated tone. If, indeed, breathy voicing has a lowering effect on F0, we should find relatively lower F0 for vowels in syllables with coda [f] in Ahuelicán and San Miguel. We also investigate the Nahuatl of another village in the Balsas River area called Ameyaltepec. This variety has lost coda $* h$ like Oapan, its parent village, though seemingly without innovating tone (or, perhaps having innovated a tone that was later lost). Here we do not expect $\mathrm{F} 0$ variations related to coda $* h$, as we have observed no coda $* h$-induced F0 effects in the synchronic form of this subdialect. Appendix A provides spectrograms and waveforms illustrating the synchronic production of segmentally matched syllables with and without historical coda $* h$ for the four villages. ${ }^{7}$

\footnotetext{
${ }^{6}$ Word-final $* h$ has not conditioned tonal innovation and is retained in all subdialects in phrase-final position. It may be elided in some phraseinternal positions but we have not yet systematically investigated this patterning.

${ }^{7}$ While Ameyaltepec and Oapan have lost non-word-final coda *h (historical $* h$ ), /h/ can be found in surface forms in both Oapan and Ameyaltepec. In Oapan and Ameyaltepec geminate $/ \mathrm{kk} /$ and $/ 1 \mathrm{l} />/ \mathrm{hk} /$ and $/ \mathrm{hl} /$ and in Oapan, among other sources of surface $/ \mathrm{h} /, / \mathrm{w} />/ \mathrm{h} /$ and $/ \mathrm{k} />/ \mathrm{h} /$ before all consonants. However, it is outside the scope of the current paper to investigate the phonetic nature of these $/ \mathrm{h} /$ productions, e.g., whether they are breathy or voiceless and whether they affect the F0 of the preceding vowel.
} 
These graphs clearly show that the $* h$ is produced with breathy voicing in the villages where it is preserved. Note that $* h$ is only found in coda, and not onset position. Table 1 provides a summary of the four varieties of Balsas Nahuatl investigated in the study.

\subsection{Overview of acoustic studies}

In the following sections, we present two studies that investigate the origins and acoustic correlates of the proposed tonal developments in Balsas Nahuatl, as well as the acoustic correlates to the penultimate stress accent. In the first study, we determine the effect of [6] on F0 to investigate the hypothesis that coda [6] can condition tonogenesis. We also investigate the F0 patterning of the hypothesized tones and stress accents. To gain a preliminary understanding of intonational uses of F0, we prompted Nahuatl consultants to produce words in two phrasal positions and we compared the F0 patterns of stress accents to the F0 patterns of tones in both phrasal positions. Though there may be some small variations, consistency in overall F0 patterns across phrasal position is expected for tonal specifications. In contrast, F0 patterns may vary by phrasal position for stress accents, as a result of different associations of intonational pitch accents in different phrasal positions.

After gaining an understanding of the F0 patterns in the first study, in the second study, we sought to determine whether there were other acoustic correlates to either stress accents or the hypothesized tones. Previous acoustic studies of hybrid stress and tone systems have reported that tone is coded by F0 and stress by other acoustic correlates such as amplitude, duration, or vowel quality, with F0 related to alignment of intonational pitch accents on stressed syllables (Everett, 1998; Remijsen, 2002; Remijsen \& van Heuven, 2005). We expected similar findings here, but also predicted that the stress accents in Oapan and Ahuelicán may be becoming more tonal, as evidenced by phonological interaction between the innovated tones and the historical stress accents.

\section{Study 1-F0 patterns of words in Balsas Nahuatl}

Here we investigated the production of $\mathrm{F} 0$ patterns in words with and without $* h$ spoken by inhabitants of the four villages as presented in Table 1 . We hypothesized that the realization of $* h$ as a breathy [ $\mathrm{h}$ ] in coda position conditioned tonogenesis in Oapan and Ahuelicán through a lowering of the fundamental frequency of the tautosyllabic vowel. The F0 patterns on innovated tones, as well as stress accents, were analyzed. Words were elicited in phrase-medial and phrase-final position in a preliminary attempt at dissociating intonational effects from word-level cues to stress.

\subsection{Method}

\subsubsection{Participants}

Twenty-four native speakers of Nahuatl were paid to participate in the study. The speakers had all lived in the Balsas River communities in central Guerrero, Mexico, since birth. All participants were second-language speakers of Spanish and reported normal hearing and no history of language or speech disorders. Six speakers were recorded from each of four villages: San Miguel, Ameyaltepec, Ahuelicán, and Oapan. The participants were 4 women and 2 men with an age range of 45-60 years old in San Miguel, 3 women and 3 men with an age range of 38-66 years old in Ameyaltepec, 4 women and 2 men with an age range of 43-65 years old in Ahuelicán, and 3 women and 3 men with an age range of 28-51 years old in Oapan.

\subsubsection{Materials and procedure}

Table 2 lists the phonetic transcription of the words recorded for this study. The first column presents a shallow reconstruction of the historical forms for Balsas River. The historical position of $* h$ is based on comparative evidence for modern dialects and for Classical Nahuatl. ${ }^{8}$ In the Balsas communities under study, where we reconstruct $* h$, San Miguel Tecuiciapan and Ahuelicán manifest [ $\mathrm{h}$ ] whereas Ameyaltepec and Oapan have no segment (though Oapan has, in these cases, innovated tone). The first section of Table 2 has words with coda $* h$ in the first of three syllables, the second section of the table has words with $* h$ in the second of three syllables, and the third section of the table has words with no coda $* h$. The tones and stresses are transcribed as heard by the researchers and confirmed by native speakers. Note that there are some syllables that have a coda $/ \mathrm{h} /$ in dialects that have lost $* h$ (see footnote 7 ). However, such a coda $/ \mathrm{h} /$ is a secondary development. Take for example, the $/ \mathrm{h} /$ in the second syllable of [kókoh'ke: tł] 'wood chopper' in Oapan, which derives from $*_{w}$ in $* k^{w} a h^{\prime} k^{w} a w k e: \overparen{t l}$. Note, finally, that in four cases the cognate to an elicitation word was not part of the lexicon of a particular subdialect. In two of these cases, a word with similar segmental content was substituted. In the two other cases a word with similar segmental content was not available and the data are missing.

All words were recorded in both phrase-medial and phrase-final positions. It was reasoned that if F0 patterns differed by phrasal position, the F0 effects could be attributed to intonational pitch accents related to phrasal position. In contrast, if the F0 patterns did not differ by position, they could either be attributed to word-level tone or stress accent, or to an intonational pitch accent present in both phrasal positions. Such a pitch accent may occur with words in pragmatic focus, as is likely to be the case for target words in elicited speech. In preliminary work with

\footnotetext{
${ }^{8}$ Classical Nahuatl had a glottal stop where most modern dialects have $/ \mathrm{h} /$.
} 
Table 2

List of words recorded for Study 1.

\begin{tabular}{|c|c|c|c|c|c|}
\hline Historical & San Miguel & Ameyaltepec & Ahuelicán & Oapan & Gloss \\
\hline \multicolumn{6}{|l|}{$* h$ in coda of first syllable } \\
\hline *ah'mo:lli & af'mo: $\overparen{\text { yli }}$ & a'mo: $\overparen{\text { Ali }}$ & af'mo: $\overparen{\text { tli }}$ & ámo: $\overparen{\text { lli }}$ & $\begin{array}{l}\text { Mexican jujube tree } \\
\text { (Ziziphus mexicana Rose, } \\
\text { in the Rhamnaceae family) }\end{array}$ \\
\hline *kih'kirske: $\overparen{t \mid}$ & kif'kisske: $\overparen{\mathrm{tq}}$ & ki'kisske: $\overparen{\mathrm{tf}}$ & kif'kisske: $\overparen{\mathrm{tq}}$ & kíkiske: $\overparen{t+}$ & partygoer \\
\hline *kwah'kwawker $\overparen{t \ddagger}$ & kof'kohke: $\overparen{\mathrm{tq}}$ & ku'kuwke: $\overparen{t \notin}$ & koh'kohke: $\overparen{\mathrm{tt}}$ & kókoh'ke: $\overparen{t \ddagger}$ & wood chopper \\
\hline *tłah'solli & tłaf'sołli & tła'sołli & tłaf'sołli & tłásoł'li & garbage/brush \\
\hline *kweh'tomatt & $\mathrm{k}^{\mathrm{w}}$ ef'toma $\overparen{\mathrm{tf}}$ & $\mathrm{k}^{\mathrm{w}} \mathrm{e}^{\prime}$ tomatt & $\mathrm{k}^{\mathrm{w}}$ efi'tomatł & kwéto'matf & pillow \\
\hline \multicolumn{6}{|c|}{$* h$ in coda of second syllable } \\
\hline 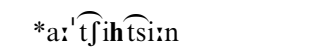 & a: ${ }^{\prime}$ tyifts inn & a:'tfits i:n & 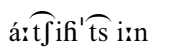 & á: $\overparen{t \int} i^{\prime} \overparen{t s}$ i:n & a little \\
\hline *mon'tah $\overparen{\mathrm{tf} i}$ & mon'taftti & mon'tatfi & móntaf' tti & mónta' $\widehat{\text { tłi }}$ & father-in-law \\
\hline * $\overparen{\mathrm{tq}}$ a'mahker $\overparen{\mathrm{tq}}$ & 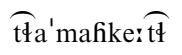 & támake: $\overparen{\mathrm{tq}}$ & - & 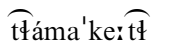 & hunter \\
\hline 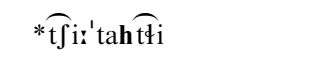 & 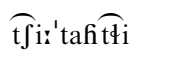 & $\overparen{\mathrm{t} \int \mathrm{i}} \mathrm{i}^{\prime} \mathrm{tat} \mathrm{t} i$ & tfírtaf' & tfísta'tłi & cradle \\
\hline *ka'mohtłi & ka'mohtłi & ka'motti & kámof' tłिi & kámo' tłi & sweet potato \\
\hline *to:'mohtfi & to:'moftłi & to:'mottii & tó:moh'tłi & tó:mo' tłi & prickly pear \\
\hline \multicolumn{6}{|l|}{ No $* h$} \\
\hline *a:'te:mpan/*a':te:yko & a:'termpan & $\mathrm{a}^{\prime}$ te:yko ${ }^{\mathrm{a}}$ & a:'termpan & a:'termpan & river's edge \\
\hline *pi'lisa:l & pi'lisa:4 & pi'lisa: 4 & pi'lisa: 4 & pi'lisa: 4 & blanket \\
\hline 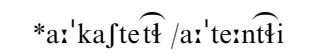 & 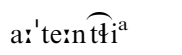 & $\mathrm{a} \mathbf{i}^{\prime} \mathrm{ka}$ te $\overparen{\mathrm{tq}}$ & - & 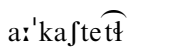 & stone bowl for giving water \\
\hline *mon'tsizntłi & mon'tsizntłi & mon'tsizntti & mon'tsiantłi & mon'tsiintti & $\begin{array}{l}\text { to animals (particularly pigs) } \\
\text { son-in-law (DIMIN.) }\end{array}$ \\
\hline *ko'ko ki & ko'ko $\mathrm{ki}$ & ko'kofki & ko'ko jki & ko'ko jki & sick person \\
\hline$* \overparen{t y}$ a'pets tłi & 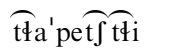 & 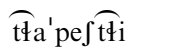 & 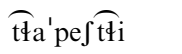 & 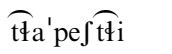 & bed \\
\hline * $\overparen{\operatorname{tq}} \mathrm{a}^{\prime} \operatorname{man} \overparen{\mathrm{tq} i}$ & $\overparen{t+a} a^{\prime} \operatorname{tantti}$ & $\overparen{\mathrm{tta}} \mathrm{a}^{\prime} \operatorname{mantfi}$ & $\overparen{t+a} a^{\prime} \operatorname{mantłi}$ & $\overparen{\text { tfa'mantfi }}$ & group \\
\hline$* \overparen{t \int i^{\prime} k i w t+1}$ & $\overparen{t \int} i^{\prime} k i c ̧ \widehat{t q i}$ & $\overparen{t \int} i^{\prime} k i r y t$ tłi & $\overparen{t \int} i^{\prime} k i k \overparen{t+i}$ & $\overparen{t \int i^{\prime} k i h t t_{1}}$ & basket \\
\hline *ka'mak $\overparen{\mathrm{tqi}}$ & ka'mak $\overparen{t ł i}$ & ka'mak $\overparen{t+i}$ & ka'mak $\widehat{\operatorname{tqi}}$ & ka'mahtti & mouth \\
\hline *to:'nalli & to:'na: & to:'nałli & to:'nałli & to:'nałli & sun \\
\hline *kwe'fomatt & $\mathrm{k}^{\mathrm{w}} \mathrm{e}^{\prime}$ Joma $\overparen{\mathrm{tq}}$ & $\mathrm{k}^{\mathrm{w}} \mathrm{e}^{\prime}$ Joma $\overparen{\mathrm{tt}}$ & $\mathrm{k}^{\mathrm{w}} \mathrm{e}^{\prime}$ Joma $\overparen{\mathrm{tf}}$ & $\mathrm{k}^{\mathrm{w}} \mathrm{e}^{\prime}$ Joma $\overparen{\mathrm{tf}}$ & wooden tray \\
\hline
\end{tabular}

${ }^{\mathrm{a}}$ Word not cognate with the words in the other dialects and with a different meaning than that expressed in the final column.

the participants, an attempt was made to shift the focus to and from the target word, as has been done in previous studies (e.g., Bruce, 1977; Remijsen \& van Heuven, 2005; Sluijter \& van Heuven, 1996a, 1996b). However, based on an auditory assessment, there were no apparent intonational cues to focus. Rather, it seems that in Balsas Nahuatl focus is indicated by word order and morphosyntactic marking (e.g., an emphatic pronoun). Further work will be needed to test this observation. In the current study, however, we will be able to compare the patterning of the innovated tones and stress accents by phrasal position. We predicted that the tones will show little variation in F0 by phrasal position, but that the stress accents may exhibit such variation.
Phrase-medially, the target words were embedded in the phrase [a:'mantsinn_ nikter'nerwas ${ }^{9}$ ] 'Now

will say'. Phrase-finally, the target words were added to the end of the phrase [a:'man tsian nikte:'nerwas ___ Now I will say __ Given the relatively flexible word order of Nahuatl, both of these phrases were judged to be natural by the participants. Note that the words in the carrier phrases contained no coda $* h$.

The words under investigation here were recorded as part of a larger list of words, some of which will be investigated in the second study reported in this paper.

\footnotetext{
${ }^{9}$ The verb [nikte:' ne:was] was pronounced as [nihte:'ne:was] by speakers in the village of Oapan.
} 
When recording the large list of words, a group of roughly 20 words was recorded in medial position and then the same group of words was recorded in final position. For this study, 936 productions were analyzed $(20$ words $\times 2$ phrasal positions $\times 4$ dialects $\times 6$ speakers -24 missing). The speakers were recorded in a quiet room in a home using a digital recorder $(44,100 \mathrm{~Hz}$ sampling rate) with a head-mounted microphone (Shure-SM10A). Two or three speakers, all from the same village, were recorded in a single session in the field in the respective villages; a second session was then conducted with the remaining speakers from the same village. Thus, inhabitants of the same village as the speaker were present during the recordings, along with the authors JDA and SGG.

Author JDA, a fluent non-native speaker of Balsas Nahuatl, produced the target word in isolation as a prompt. He attempted to produce the words in the subdialect of the village, when possible. However, he was more familiar with some subdialects than others. The participant then produced the target word in the appropriate carrier phrase. An aural prompt, rather than a written one, was used because most of the participants did not typically write or read in Nahuatl. It seems unlikely that the participants simply mimicked the aural presentation by the researcher for two main reasons. First, participants often produced the words in a different manner than the prompt, including both prosodic and segmental differences. Second, the participants discussed specific features of the experimenter's pronunciation and commented on how they said certain words differently in their village. They then proceeded to produce the words in the manner typical of their village and did not simply repeat the model presented by the experimenter. A similar recording technique has been used successfully by other researchers investigating the acoustic correlates to prosody in other less-studied languages (e.g., Martin \& Johnson, 2002).

\subsubsection{Analysis and predictions}

After completing the field recordings, we measured the $\mathrm{F} 0$ at the temporal midpoint of the vowel in each syllable in the target words with the software program Praat (Boersma \& Weenink, 2005), using the autocorrelation method with recommended settings (i.e., max. number of candidates: 15 ; silence threshold: 0.03 ; voicing threshold: 0.45; octave cost: 0.01 ; octave-jump cost: 0.35 ; voiced/ unvoiced cost: 0.14$)$. The pitch analysis range was set to accommodate the pitch range for each speaker. It is possible that the long and short vowels could have had different types of F0 patterns, namely long vowels have the potential for more tonal targets than short vowels. An inspection of the F0 tracks, however, indicated that F0 patterns were similar for long and short vowels and that there was no indication of multiple tonal targets on the long or short vowels. See Appendix B for example F0 tracks.

Several statistical tests were performed on the F0 data. The data from each of the four subdialects were analyzed separately. Prior to the analysis, the data from individual speakers were inspected and compared to other speakers of the same subdialect. Speakers of a given subdialect showed consistency in F0 patterning for each word type in each phrasal position. Accordingly, the data were pooled across the speakers in the statistical analyses. Inspection of the F0 patterns for the speakers from Oapan consistently revealed two distinct F0 patterns for words with $* h$ in the first syllable (top section in Table 2), depending on whether the second syllable had a long or short vowel. In the case of a long vowel in the second syllable a high F0 was found for the first two syllables and in the case of a short vowel in the second syllable, a high-low pattern across the first two syllables was found (compare, e.g., [kíkisketł] and [kókoh'ke: Tf] in Table 2). Thus, this word type will be split into two levels, depending on the length of the second vowel for the data from the Oapan speakers.

To test the effect of coda $* h$ and phrasal position on the production of $\mathrm{F} 0$ in the target words, the individual vowel midpoint F0 measurements for the speakers of a given subdialect were submitted to a multivariate analysis of variance (MANOVA). The dependent variables were F0 at midpoint for the first, second, and third syllable in the target words and the independent variables were Word Type as a between-subjects factor and Phrasal Position as a within-subjects factor. Word Type had three levels for San Miguel, Ameyaltepec, and Ahuelicán $(* h$ in the first syllable, $* h$ in the second syllable, and no $* h$ ) and four levels for Oapan $(* h$ in the first syllable with a long vowel in the second, $* h$ in the first syllable with a short vowel in the second, $* h$ in the second syllable, and no $* h$ ). This design compared the same speaker's productions to each other for each level. Thus, even though male and female speakers were entered together, each level of comparison had similar variance due to the fact that the same speakers were represented in the same proportion in each statistical cell. An alpha level of .05 was used for all statistical tests. A significant main effect of Word Type or an interaction of Word Type with Phrasal Position was investigated with Tukey's pair-wise comparisons. The F0 for each level of Word Type by each of level of Phrasal Position was compared in each of the syllables (first, second, third).

An influence of coda $* h$ on F0 was predicted to manifest a significant effect of Word Type. For subdialects preserving $* h$ as $[\mathrm{h}]$, vowels in syllables with coda [h] were predicted to have slightly lower F0 than vowels in syllables without coda [i]. The exact magnitude of the effect cannot be predicted from previous work by other researchers, but given the report of a relative $25-50 \mathrm{~Hz}$ drop across vowels followed by $/ \mathrm{h} /$ (Hombert et al., 1979), we expected that our midpoint measures would result in $5-25 \mathrm{~Hz}$ lowering effects (as midpoint effects would be smaller than F0 drops across the entire vowel). For subdialects with the proposed innovated tones, larger differences in F0 patterns (i.e., greater than $25 \mathrm{~Hz}$ ) by Word Type, depending on the placement of coda $* h$, were expected. Phrasal Position effects were not predicted on syllables with the proposed 
a

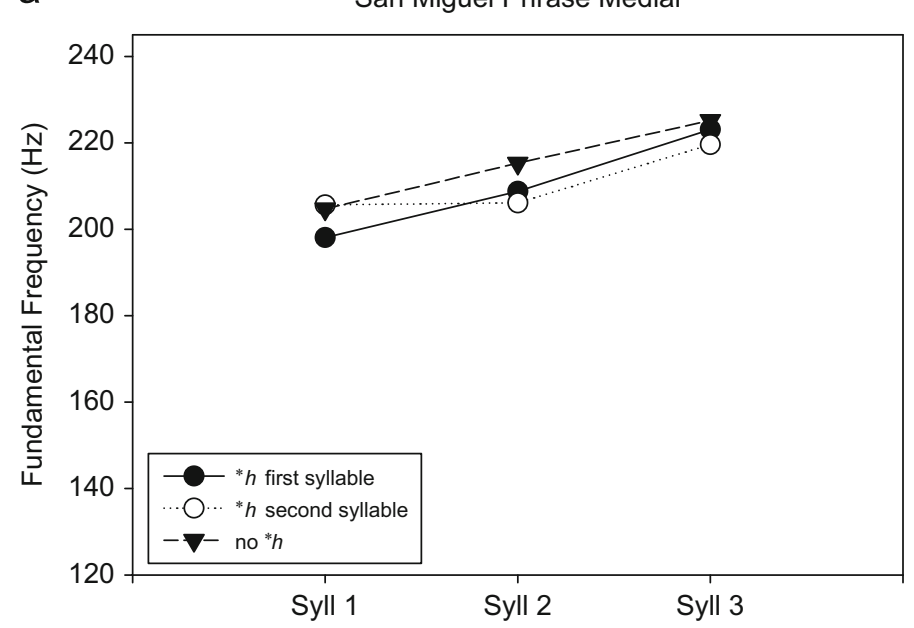

b

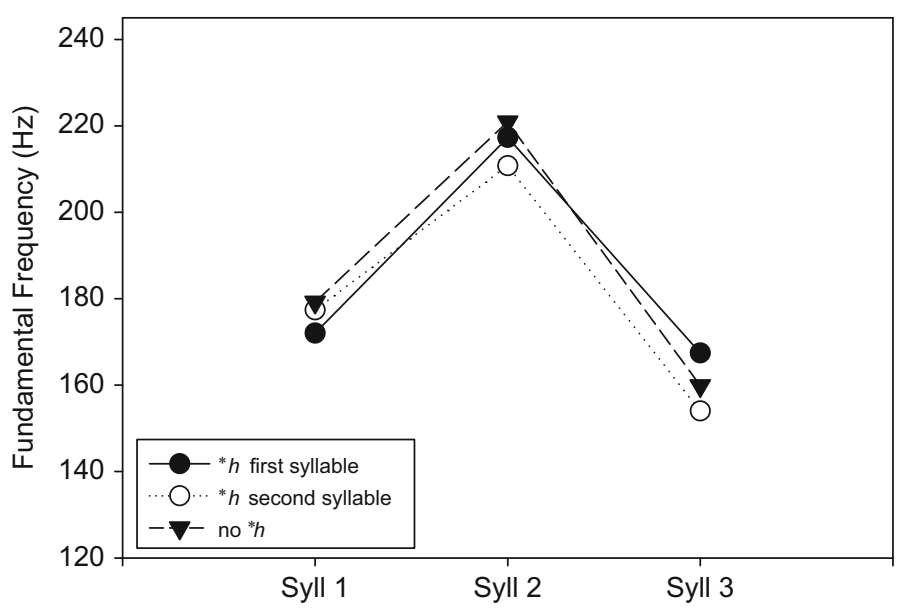

Fig. 1. Mean F0 at vowel midpoint for each syllable in the target words produced by six participants from San Miguel. Three types of words are presented, those with ${ }^{*} h$ in the first syllable, those with ${ }^{*} h$ in the second syllable, and those with no $* h$, in (a) phrase-medial and (b) phrase-final positions. Note that $* h$ is preserved in San Miguel as a breathy voiced [6].

innovated tones but penultimate stress accents were thought likely to show different patterns by phrasal position.

\subsection{Results}

\subsubsection{San Miguel (*h retained, penultimate stress only)}

Fig. 1 presents the mean F0 at vowel midpoint for each syllable in the words produced by the San Miguel participants. As this subdialect has not innovated tones and preserves the penultimate stress accent, we only expected to find large F0 excursions on the penultimate syllable, possibly affected by phrasal position. Additionally, the vowels preceding coda $[\mathrm{h}]\left(<^{*} h\right)$ were expected to have a slightly lower F0 than vowels in comparable position with no coda [h].

In Fig. 1(a) the target word was produced phrasemedially and in Fig. 1(b) the target word was produced phrase-finally. Note that, overall, the three word types (those with $* h$ in the first syllable, those with $* h$ in the second syllable, and those with no $* h$ ), exhibited the same general F0 patterns. In phrase-medial position, the F0 rose across the word and in phrase-final position, the $\mathrm{F} 0$ rose on the penultimate syllable and then fell on the final syllable. These results indicate that a high-low pattern beginning on the penultimate syllable is a phrase-final intonational pattern. The effect of Phrasal Position $[F(3,122)=103.16$, $\left.p<.001, \eta_{\mathrm{p}}^{2}=.72\right]^{10}$ was significant and did not interact with Word Type $[F(6,246)=0.30, p=.94]$. The Phrasal Position effect can be attributed to different F0 patterns associated

\footnotetext{
${ }^{10}$ The partial eta-squared $\left(\eta_{\mathrm{p}}^{2}\right)$ provides an estimate of the effect size. The eta-squared statistic describes the proportion of total variability attributable to a factor.
}

with the two phrase types: gradual rising in phrase-medial position and rising-falling in phrase-final position.

Moving on to the effects of [6], as can be seen in Fig. 1, vowels with a breathy coda have a relatively lower F0. Consider the words with [h] in the first syllable (filled circles). In these words, the first syllable had a relatively lower F0, regardless of the target word's position as phrase-medial or phrase-final. Likewise, words with [6] in the second syllable (empty circles) had a relatively lower F0 in the second syllable than words with no [f] (filled triangles) but not lower than those with [6] in the first syllable (filled circles). With words having coda $* h$ in the second syllable, the effect of this [G] on second syllable F0 was less pronounced overall (in comparison to the other two word types) than the comparative effect of F0 lowering on the first syllable when this syllable had a coda $* h$. We suggest that this is due to a continued effect on F0 in words with [f] in the first syllable, that is, with F0 lowering on the first syllable continuing into the second syllable.

The main effect of Word Type was significant but rather small $\left[F(6,246)=2.78, p=.01, \eta_{\mathrm{p}}^{2}=.06\right]$. Tukey's pairwise comparisons $(p<.05)$ revealed that, in the case of the first syllable of the target words, the syllable with coda [f] had a significantly lower F0 than the other two word types in phrase-medial position $(198 \mathrm{~Hz}$ vs. $204 \mathrm{~Hz}$ and $205 \mathrm{~Hz}$, i.e., $3 \%$ lower) and lower than the words with no [6] in phrase-final position ( $172 \mathrm{~Hz}$ vs. $180 \mathrm{~Hz}$, i.e., $4 \%$ lower). In the case of the second syllable of the target words, the syllable with coda [6] had a significantly lower F0 than words with no [6] in both phrase-medial $(205 \mathrm{~Hz}$ vs. $217 \mathrm{~Hz}$, i.e., $6 \%$ lower) and phrase-final positions $(211 \mathrm{~Hz}$ vs. $222 \mathrm{~Hz}$, i.e., $5 \%$ lower). There were no significant effects for the final syllable in the target words for either phrasemedial or phrase-final position. These differences, in which the syllable with [6] was approximately $6-12 \mathrm{~Hz}$ lower 
a

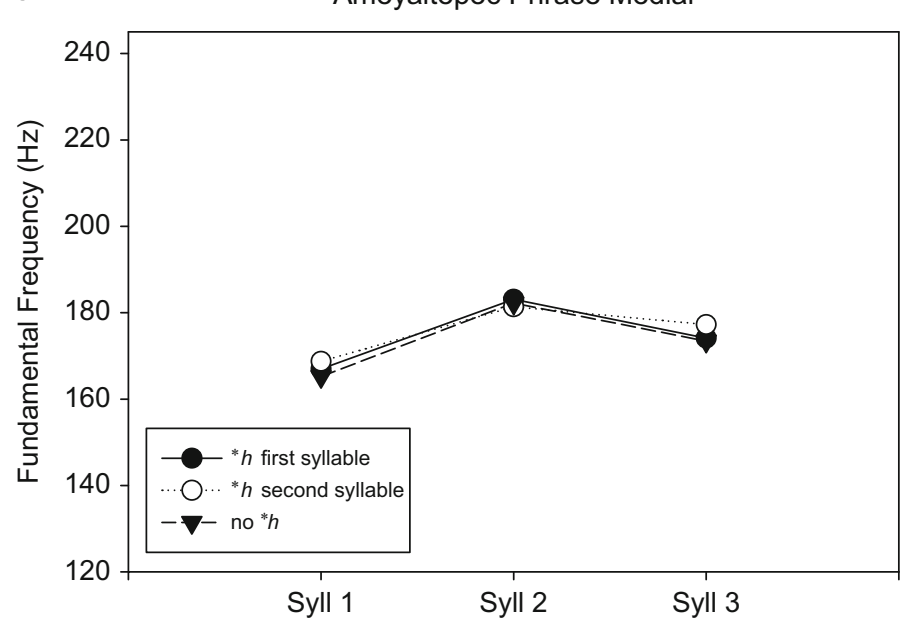

b

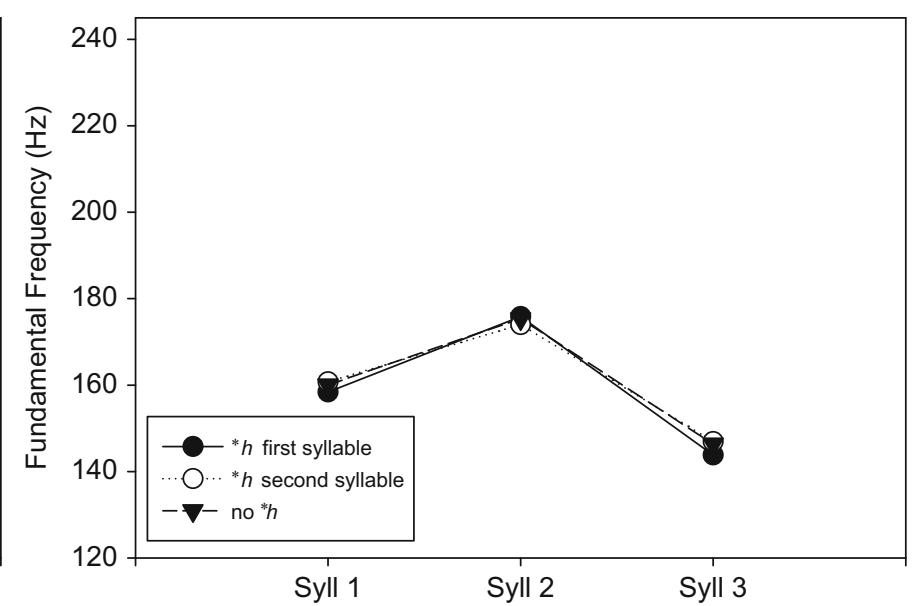

Fig. 2. Mean F0 at vowel midpoint for each syllable in the target words produced by six participants from Ameyaltepec. Three types of words are presented, those with $* h$ in the first syllable, those with $* h$ in the second syllable, and those with no $* h$, in (a) phrase-medial and (b) phrase-final positions. Note that $* h$ is lost in Ameyaltepec.

(i.e., 3-6\%), seem to reflect a local F0 perturbation conditioned by a coda breathy [h].

\subsubsection{Ameyaltepec (*h lost, penultimate stress only)}

Fig. 2 presents the mean F0 at vowel midpoint for each syllable in the words produced by the Ameyaltepec participants. As this subdialect has not innovated tones and preserves the penultimate stress accent, we only expected to find large F0 excursions on the penultimate syllable, possibly affected by phrasal position. Additionally, in this subdialect, $* h$ has been lost (i.e., there is no coda [ $\mathrm{h}]$ from $* h$ in non-word-final position). As the loss of $* h$ was not related to tonal development, no local lowering effects related to $* h$ were expected. We propose that the small, coarticulatory F0 lowering conditioned by a breathy coda segment will be lost unless phonologized as tone (as we propose in the case of Oapan). Note that in Ameyaltepec the three word types exhibit the same general F0 patterns. In both phrase-medial and phrase-final position, F0 was highest on the penultimate syllable. The fall from the penultimate was greater for target words in phrase-final position than in phrase-medial position. The main effect of Phrasal Position $[F(3,122)=32.67, p<.001$, $\left.\eta_{\mathrm{p}}^{2}=.45\right]$ was significant and did not interact with Word Type $[F(6,246)=0.60, p=.73]$. The Phrasal Position effect reflects the greater fall from the penultimate syllable found in the word-final position, as well as the overall lower F0 of target words in phrase-final position. The high F0 on the penultimate syllable in medial position differs from the findings for San Miguel, in which the F0 rose across the word in this phrasal position. This may be due to a high F0 correlate to stress accent in Ameyaltepec or to an intonational pitch accent associated with the stress accent due to focus on the target word in both phrasal positions in this subdialect. However, if the latter were to be the case, it is not clear why San Miguel would not have also exhibited such pitch accents related to focus.

As mentioned previously, the Ameyaltepec variety has lost non-word-final coda $* h$ but does not exhibit innovated tones. The F0 data presented in Fig. 2 indicate no residual effect of coda $* h$ on the F0 patterns. Unlike the data from San Miguel, where historical $* h$ is maintained as [h], syllables with a historical $* h$ in Ameyaltepec did not show a lowering of F0 vis-à-vis other word types. The effect of Word Type was not significant $[F(6,246)=0.99, p=.44]$.

\subsubsection{Ahuelicán (*h retained, proposed innovated tone)}

Fig. 3 presents the mean F0 at vowel midpoint for each syllable in the words produced by the Ahuelicán participants. We expected to find large F0 excursions on syllables preceding those with coda [h] $\left(<^{*} h\right)$ if our hypothesis of tonal innovation were correct for this subdialect. With regard to stress accent, large F0 excursions were expected on the penultimate syllable in cases with no tonal innovation and on the final syllable in cases where a high tone had been conditioned on the antepenultimate syllable, in which case the stress accent shifted to the final syllable. These F0 excursions may be affected by phrasal position. Additionally, the vowels in the same syllable as coda [6] were expected to have a slightly lower F0 than vowels in comparable position with no coda [f].

Notice that, overall, the word type with $* h$ in the second syllable displayed a different pattern than the other word types. The first syllable was high, the second low and the final high again regardless of phrasal position. In contrast, the F0 patterns for the other two types $(* h$ in the first syllable and no $* h$ ) varied by phrasal position. As in the case of San Miguel, the F0 gradually rose across the word phrase-medially and exhibited a high F0 on the penultimate syllable phrase-finally, indicating an intonational phrase-final effect. The main effects of Word Type 
a

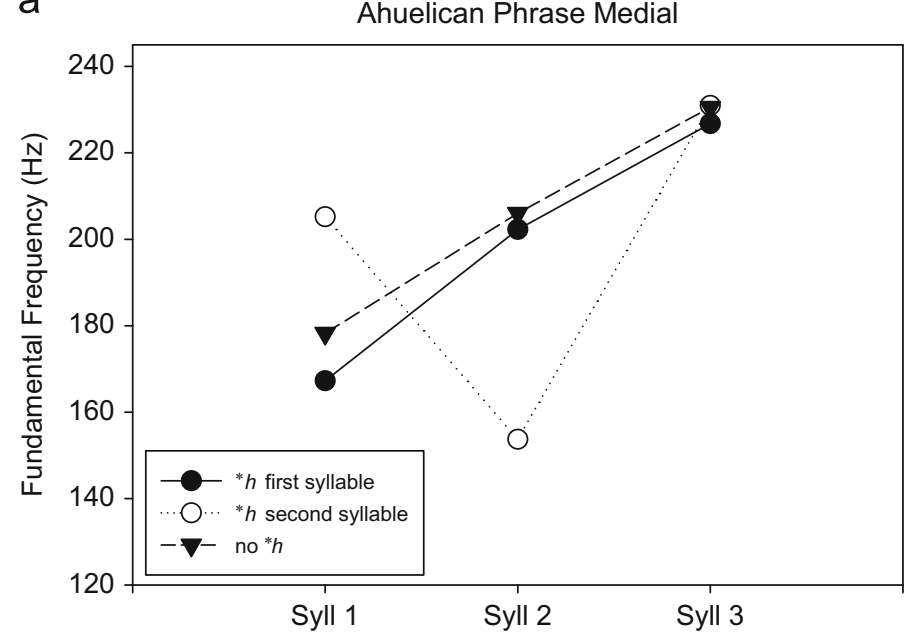

b

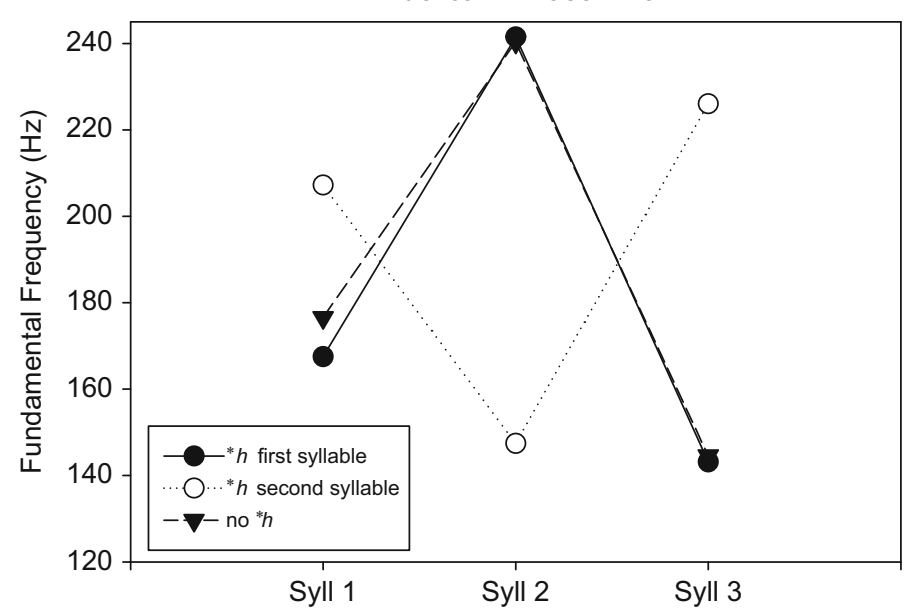

Fig. 3. Mean F0 at vowel midpoint for each syllable in the target words produced by six participants from Ahuelicán. Three types of words are presented, those with ${ }^{*} h$ in the first syllable, those with ${ }^{*} h$ in the second syllable, and those with no $* h$, in (a) phrase-medial and (b) phrase-final positions. Note that $* h$ is preserved in Ahuelicán as a breathy voiced [f], though somewhat more weakly realized than in San Miguel.

$\left[F(6,214)=25.41, p<.001, \eta_{\mathrm{p}}^{2}=.42\right]$ and Phrasal Position $\left[F(3,106)=91.54, p<.001, \eta_{\mathrm{p}}^{2}=.72\right]$ were significant, as was the interaction $\left[F(6,214)=13.04, p<.001, \eta_{\mathrm{p}}^{2}=.27\right]$. The interaction was due to the differential effect of Phrasal Position on the different levels of Word Type.

The interaction of the Word Type effect with the Phrasal Position effect was further investigated with Tukey's pairwise comparisons $(p<.05)$. The effect of Word Type for each of the syllables (first, second, third) for each of the phrasal positions was tested. First, let us consider differences between words with coda [h] in the second syllable (i.e., those with the novel F0 patterns) and the other two word types. In phrase-medial position, the first syllable of words with [6] in the second syllable was also significantly higher than the first syllable of the words of the other two types $(205 \mathrm{~Hz}$ vs. $167 \mathrm{~Hz}$ and $179 \mathrm{~Hz}$, i.e., $15 \%$ and $23 \%$ higher). Comparing the F0 of the second syllable, words with [h] in the second syllable were significantly lower than the other two word types $(153 \mathrm{~Hz}$ vs. $202 \mathrm{~Hz}$ and $207 \mathrm{~Hz}$, i.e., $24 \%$ and $26 \%$ lower). In the final syllable, there were no differences between the word types. In phrase-final position, the first syllable of words with $[\mathrm{h}]$ in the second syllable was significantly higher than the other two types $(207 \mathrm{~Hz}$ vs. $167 \mathrm{~Hz}$ and $177 \mathrm{~Hz}$, i.e., $24 \%$ and $17 \%$ higher). In the second syllable, words with [f] in the second syllable were significantly lower than the other two types $(147 \mathrm{~Hz}$ vs. $242 \mathrm{~Hz}$ and $242 \mathrm{~Hz}$, i.e., $39 \%$ lower). In the final syllable, words with [6] in the second syllable were again significantly higher than the other two types $(226 \mathrm{~Hz}$ vs. $144 \mathrm{~Hz}$ and $145 \mathrm{~Hz}$, i.e., $57 \%$ and $56 \%$ higher). These differences of 38 to $95 \mathrm{~Hz}$ (i.e., 15-57\%) are much larger than those expected due to a local F0 perturbation conditioned by [6] (i.e., 5-25 Hz). Thus, we suggest that the differences reported here reflect different F0 targets due to different tonal specifications across the words. Words with coda [h] in the second syllable have a high-low-high pattern in both phrase-medial and phrasefinal positions, whereas words with coda [f] in the first syllable or no [ $\mathrm{h}$ ] have similar global $\mathrm{F} 0$ patterns that are affected by phrasal position (but note the local effects, to be discussed below).

Second, let us consider differences between words with coda [ $\mathrm{h}]$ in the first syllable vs. words with no [f]. In phrasemedial position, words with [6] in the first syllable had a significantly lower first syllable F0 than words with no [6] $(168 \mathrm{~Hz}$ vs. $179 \mathrm{~Hz}$, i.e., 6\%). There were no differences between the two for the second and third syllables. In phrase-final position, again, words with [6] in the first syllable had a significantly lower first syllable F0 than words with no [6] $(167 \mathrm{~Hz}$ vs. $177 \mathrm{~Hz}$, i.e., 6\%) again with no differences between the two word types for the second and the third syllables. As in the case of San Miguel, these differences, in which the syllable with [h] is slightly lower (6-12 Hz in San Miguel and 10-11 Hz in Ahuelicán), seem to reflect a local F0 perturbation conditioned by a coda breathy [6]. Thus, it seems that although $* h$ in the first syllable has slightly lowered the F0 of the tautosyllabic vowel, it has not conditioned a phonological specification for tone. The presence of $* h$ in the second syllable, however, apparently has conditioned tonal changes, resulting in a high-low pattern ending on the tautosyllabic vowel.

\subsubsection{Oapan (*h lost, proposed innovated tone)}

Fig. 4 displays four different word types: $* h$ in first syllable and a long vowel in the second, $* h$ in the first syllable and a short vowel in the second, ${ }^{*} h$ in the second syllable, and no $* h$. We expected to find large F0 excursions on syllables preceding those with $* h$, and on initial syllables with $* h$ if our hypothesis of tonal innovation were correct for this subdialect. With regard to stress accent, large F0 excursions were expected on the penultimate syllable in cases with no tonal innovation; they were also found, 
a

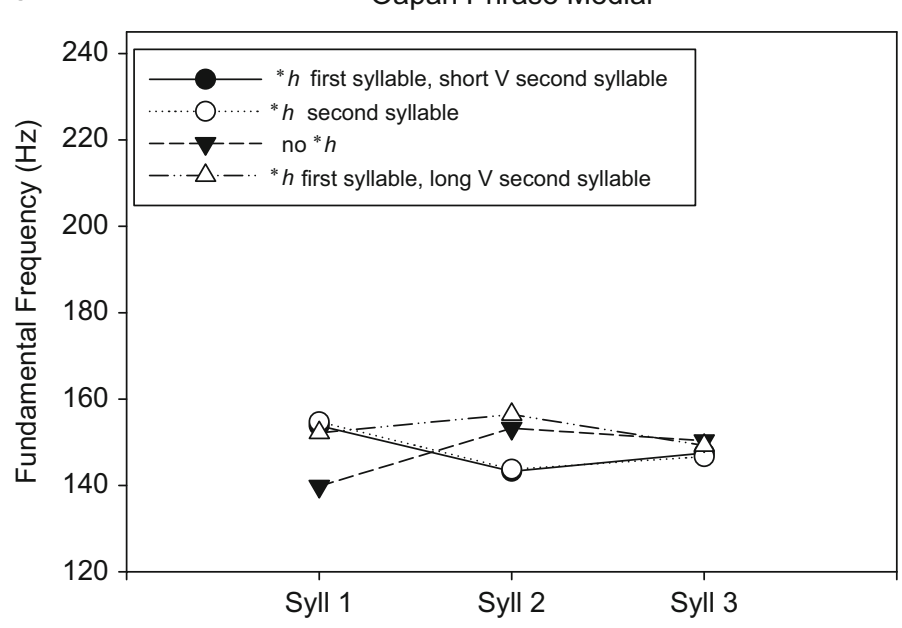

b

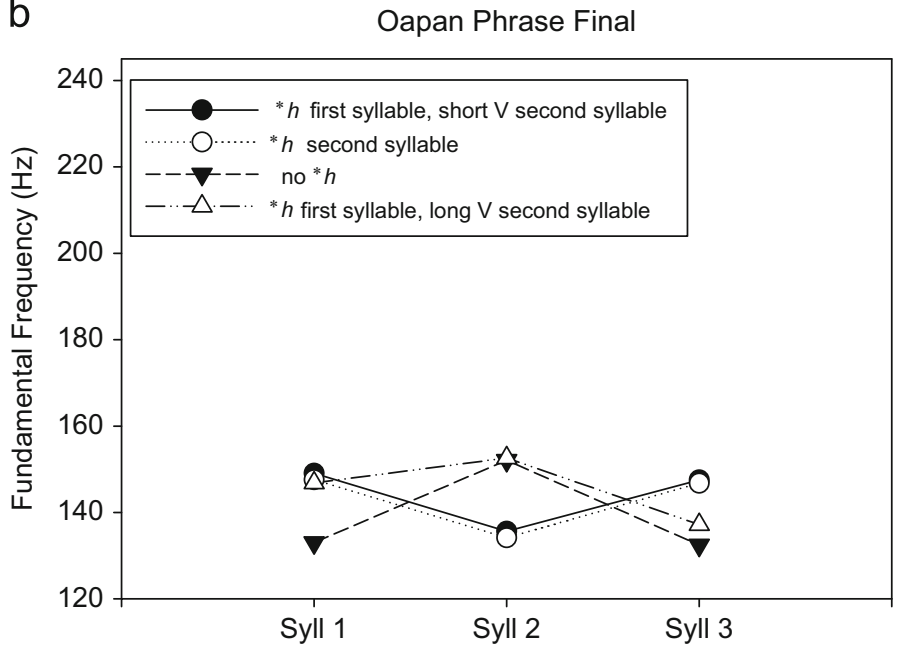

Fig. 4. Mean F0 at vowel midpoint for each syllable in the target words produced by six participants from Oapan. Four types of words are presented, those with $* h$ in the first syllable and a long vowel in the second syllable, those with $* h$ in the first syllable and a short vowel in the second syllable, those with $* h$ in the second syllable, and those with no $* h$, in (a) phrase-medial and (b) phrase-final positions. Note that coda $* h$ is lost in Oapan in all but phrase-final position.

somewhat unexpectedly, in cases with an innovated high tone on an initial syllable followed by a long vowel in the second syllable. Large F0 excursions were also noted on the final syllable in cases where a high tone had been conditioned on an initial syllable followed by a short vowel in the second syllable. These F0 excursions may be affected by phrasal position. The loss of $* h$ in the second syllable may have conditioned a low F0 on the tautosyllabic vowel, in addition to a high $\mathrm{F} 0$ on the preceding syllable, as was found to be the case in Ahuelicán.

There was a complex patterning by word type. First let us consider the words with no historical coda $* h$ (Fig. 4, filled triangles). These words displayed an F0 pattern similar to all the words in Ameyaltepec. There was a high F0 on the penultimate syllable in both phrasal positions, with a greater fall on the final syllable when the target word was in phrase-final position. Second, let us consider the words with coda $* h$ in the second syllable (open circles) and words with coda $* h$ in the first syllable and a short vowel in the second syllable (filled circles). Similar to the Ahuelicán words with $* h$ in the second syllable, these words exhibited a high-low-high pattern. In Oapan, however, the final syllable's F0 rose relatively more when the target word was in the final rather than the medial position. Finally, consider words with coda $* h$ in the first syllable and a long vowel in the second syllable (open triangles). A pattern unlike those found in any of the other dialects was seen. The first two syllables were relatively high and the third syllable lower. As with the other word types in Oapan, the final syllable has a relatively greater F0 movement away from the penultimate syllable when the target words were in phrase-final position. The main effects of Word Type $\left[F(9,351)=15.13, p<.001, \eta_{\mathrm{p}}^{2}=.28\right]$ and Phrasal Position $\left[F(3,115)=5.68, p<.001, \eta_{\mathrm{p}}^{2}=.13\right]$ were significant, as was their interaction $[F(9,351)=6.97$, $\left.p<.001, \eta_{\mathrm{p}}^{2}=.15\right]$. The interaction was apparently due to the greater relative change in $\mathrm{F} 0$ from the penultimate syllable to the final syllable in phrase-final position than in phrase-medial position. Even though the overall patterns were similar in both phrasal positions, a more extreme F0 movement was found for the final syllable (either higher or lower F0) in phrase-final position.

The effect of Word Type as modulated by Phrasal Position was further investigated with Tukey's pair-wise comparisons $(p<.05)$ for each of the syllables (first, second, third) for each of the phrasal positions. In the case of the first syllable in the target words, word types with $* h$ in the first or second syllable had higher F0 values than the words with no coda $* h$ (approx. 12\% higher on average). As for the second syllable in the target words, the words with $* h$ in the coda of the second syllable, as well as words with $* h$ in the first syllable followed by a short vowel in the second syllable, had a lower F0 than the other two types for both phrasal positions (approx. 11\% lower on average). Finally, for the third syllable, the effects varied by phrasal position. There were no significant differences between the groups for phrase-medial position. In phrase-final position, however, the words with $* h$ in the coda of the second syllable as well as words with $* h$ in the first syllable followed by a short vowel in the second syllable had a higher F0 than the other two types.

Words with $* h$ in the second syllable are similar to the cognate words in Ahuelicán in that they have a highlow-high pattern. The patterning of these words in both of these Nahuatl subdialects suggests that coda $* h$ has conditioned a tonal pattern in which the preceding syllable has a high F0 and the tautosyllabic syllable has a low F0. The two dialects differ, however, in the production of words with $* h$ in the first syllable. In Ahuelicán words with $* h$ in the first syllable and words with no $* h$ displayed similar F0 patterns (although the slight pitch depressing effect of $* h$ in 
the first syllable is clearly manifested): F0 rose across the word in phrase-medial position and had a low-high-low pattern when the word was in phrase-final position. In Oapan, however, words with $* h$ in the first syllable were different from words with no $* h$. In other words, the loss of $* h$ in the first syllable has had an effect on $\mathrm{F} 0$ production in these words. In cases where the second syllable had a short vowel, the pattern was the same as that found in words with coda $* h$ in the second syllable: specifically a high-low-high pattern across the three syllables of the word. In cases where the following second syllable had a long vowel, a high-high-low pattern was found. In neither of these cases can we attribute the high F0 of the first syllable to an effect of [6] $\left(<^{*} h\right)$. In the following discussion section, an explanation for the high F0 on these syllables will be proposed.

\subsection{Discussion}

The investigation of the F0 patterns revealed different behaviors for our hypothesized tonal patterns related to coda $* h$ from those related to the historical penultimate stress accent: F0 patterns varied by phrasal position for stress accent but not for innovated tone. High F0 was found on the preceding or same syllable as $* h$ in Oapan and on the syllable preceding $* h$ in Ahuelicán in both phrasemedial and phrase-final positions. This finding is consistent with the view that a high tone is part of the lexical specification of these words: it is consistently found, regardless of prosodic environment. The penultimate accent, on the other hand, varied in F0 pattern by phrasal location in some subdialects. In San Miguel and Ahuelicán, high F0 for the penultimate syllable was found only in phrase-final position. We suggest this is due to an intonational pitch accent associated with the final stressed syllable of the phrase, in this case the penultimate syllable. In Oapan and Ameyaltepec, the high F0 on the penultimate syllable of the target words was found in both phrasal positions. This may reflect an intonational pitch accent aligned with the stressed syllable on a focused word in both phrasal positions, as the target words represented new information in the same, repeated carrier phrase. This possibility would suggest that the other dialects implement focus differently. Alternatively, it may be that F0 is part of the implementation of stress accent in these subdialects, irrespective of discourse prominence. Further work using a methodology similar to Remijsen and van Heuven (2005), in which phrasal position and focus are orthogonally varied, would be needed to more thoroughly investigate the relationship of $\mathrm{F} 0$ to penultimate stress accent.

In the next section, the acoustic correlates of the penultimate stress accent and the putative tones will be further examined. It is possible that the consistency of the F0 patterning associated with the historical stress accents indicates a change to a tonal specification in some dialects. The presence or absence of other acoustic correlates often found for stress accent will be used to help shed light on this question.
Now let us turn to a discussion of tonogenesis and the effect of $* h$. Ameyaltepec has lost coda $* h$, seemingly without any effect on the prosodic system. In the village of San Miguel, which has not innovated tones, coda $* h$ is preserved as [h]. Here, vowels in syllables with coda [h] had a $6-12 \mathrm{~Hz}$ lower F0 value (i.e., 3-5\%) than matched syllables with no coda [h]. This suggests that the slight lowering effect of coda [h] on F0 may be the origin of the tonal developments in Oapan and Ahuelicán. We propose that this effect of coda [h] on F0 was reinterpreted as a lexically-specified tone and enhanced into a high tonal specification on the preceding syllable (and in some cases a low tone on the syllable with [f] — see discussion below) in Oapan and Ahuelicán.

Coda $/ \mathrm{h} /$ has been documented as conditioning a low or falling tone in a variety of languages (Matisoff, 1973; Ohala, 1973; Svantesson, 2001), and Thurgood (2002) has proposed that, specifically, a breathy laryngeal is indicated in these sorts of sound changes. The results reported here lend support to the proposal that a coda [ $\mathrm{h}]$ can condition a slightly lowered F0 on the tautosyllabic vowel that may be the origin of falling F0 contours. Note, however, that in San Miguel, there were no major effects of $* h$ on the prosodic system. Thus, it seems that this subdialect offers insight into the original conditioning environment of the tonal developments attested in other varieties of Balsas Nahuatl.

Providing more evidence for our proposed course of development, the village of Ahuelicán still has [G] as a reflex of $* h$, along with innovated tones. When there was a syllable preceding a syllable with a coda [6], a high-low patterning was found across the two syllables. In this case, the syllable with coda [f] was roughly $25-50 \%$ lower, and the preceding syllable roughly $15-24 \%$ higher than comparable syllables with no coda [h]. However, when there was no preceding syllable, the syllable with coda [6] had only a slight reduction in F0 (roughly $10 \mathrm{~Hz}$ or $6 \%$ ). Thus, in Ahuelicán, there is evidence for both the original locus of the innovated tones, as well as the segmental preconditioning of the tonogenesis.

In the village of Oapan, $* h$ has been lost and the tonal system has undergone developments beyond those found in Ahuelicán. First, as in Ahuelicán, when a syllable with a historical $* h$ was preceded within a root or stem by another syllable, a high-low patterning was evidenced across these two syllables. We suggest that Oapan went through a stage when $* h$ was pronounced as breathy voiced [6], which conditioned a slight lowering of the F0 of the tautosyllabic vowel due to the effects of breathy phonation. The preceding syllable, which would most likely not have been affected by the breathy voicing, would have had a relatively higher F0. This relatively higher F0 was then reinterpreted as a high-low F0 target yielding the pattern that we have documented (see, e.g., the first two syllables of the word in (9) and note that the penultimate stress accent has shifted to the final syllable). 
(9) Tłáso'ti <* đła'sohti (cf. Ahuelicán ţásof'ti)

Ø- tyasohti -Ø

3SG.S- to.be.dear -PRES.SG

'it is dear (or scarce)'

This high-low pattern is also found in both Ahuelicán and Oapan when a root- or stem-initial syllable has $* h$ in the coda and there is a prefix. Consider the word in (10) with the initial prefix no- 'my'.

$$
\begin{array}{lll}
\text { nókwe'ton } & <* \text { no'kwehton (cf. Ahuelicán } \\
& \multicolumn{2}{c}{\text { nókwef'ton) }} \\
\text { no- } & \text { kwehtom } & -\varnothing \\
\text { 1SG.POSSR- } & \text { pillow } & \text {-ALIEN.POSSD.SG } \\
\text { 'my pillow' } & &
\end{array}
$$

However, these two subdialects diverge in cases where the root- or stem-initial syllable has coda $* h$ but no preceding syllable. In these cases Oapan Nahuatl manifests a further, and what we consider subsequent, development that is absent in Ahuelicán. Specifically, there is a high tone on these initial syllables (11). Note that this prosodic pattern cannot be directly explained by the F0-lowering hypothesis of breathy-voiced [ $\mathrm{h}]$.

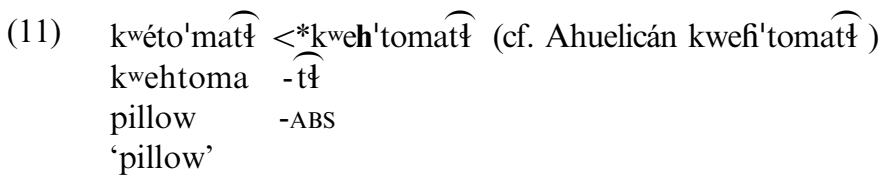

This suggests a stage beyond that found synchronically in Ahuelicán, in which tone is tied to the location of coda [6]. In Oapan, when coda [ $\mathrm{f}]$ was lost, the high-low tonal pattern may have come to be associated with the root itself. By this analysis, the high-low pattern would be produced on the root when the first syllable of an unprefixed root ended with a coda $* h$ (as seen with [kwéto'ma ty] in (11)). Consider also the forms in (12) and (13). The transitive verbal root * tyahpa'lowa 'to greet' has Oapan forms in which a high tone is found on the first syllable of the root, even when there is a prefix, as in (12). With prefixes having a long vowel, however, the high tone is found on the preceding syllable, as in (13).

$$
\begin{aligned}
& \text { kitłápa'lowa } \\
& <\text { kitłahpa'lowa }
\end{aligned}
$$

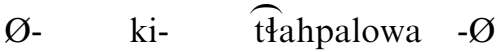

$$
\begin{aligned}
& \text { 3SG.S- 3SG.O- to.greet -PRES.SG } \\
& \text { 's/he greets him/her' }
\end{aligned}
$$

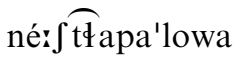

$$
\begin{aligned}
& <* \text { nertf tłahpa'lowa }
\end{aligned}
$$

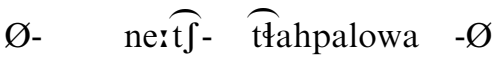

$$
\begin{aligned}
& \text { 3SG.S- 1SG.O- to.greet -PRES.SG } \\
& \text { 's/he greets me' }
\end{aligned}
$$

Thus, we hypothesize a second stage unique to Oapan. Once the coda $* h$ was lost, the innovated high tone was no longer tied to the syllable preceding the syllable with coda $* h$; it may also be located on a root-initial syllable with coda $* h$. This proposed set of events may be an example of the development of autosegmental tonal patterning in a language, as tones come to be associated with roots rather than the conditioning environment. Oapan has further developed in this regard and now has some morphological uses of tone (e.g., speakers in Oapan use a high tone for some meanings encoded by a reduplicant in other Balsas subdialects).

Now let us consider the second high in the highlow-high patterning found in Ahuelicán and Oapan for words with $* h$ in the second syllable. Two likely possibilities present themselves as to the origin of this second high. First is the proposal that the following high is a dissimilatory high, similar to the high preceding the syllable with $* h$, in that it arose in contrast to the low $\mathrm{F} 0$ of the syllable with coda $* h$. Another possibility, the one we support here, is that the following high is a reflex of the penultimate stress accent that has been displaced to the final syllable. Words with more than three syllables are needed to disambiguate these two possibilities, as a dissimilatory high would be present, whereas a displaced historical stress accent would not. Amith (unpublished ms.) proposes the second analysis and provides some example data to support this view.

Consider, for example, the word in (14). The first two syllables have a high-low pattern. However, there is no other high on the syllable immediately following the second syllable with a low. The next prominence is found on the penultimate syllable and does not seem to be related to the $* h$. Instead, this would seem to be the penultimate stress accent found throughout Nahuatl dialects. Contrast this to the accentual pattern in (15). Here there are two high-low tonal patterns related to the placement of $* h$. We suggest that the prominence on the final syllable in (15) is from the historical penultimate accent that has been moved to the final syllable in a shift process so that a stress accent does not immediately follow a high tone.

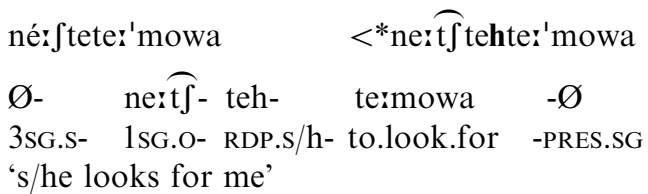

$$
\begin{aligned}
& \text { o:né:Steté:mo'keh <*o:ner t tehter'mohkeh } \\
& \text { o:- } \varnothing \text { - nert }
\end{aligned}
$$

The tonal patterning of words with $* h$ in the first syllable in Oapan may also be related to this analysis. Recall that words of this type with a short vowel in the second syllable had a high-low-high pattern but that words of this type with a long vowel in the second 
syllable had a high-high-low pattern (see Fig. 4). The historical penultimate stress accent may be retained on the long penultimate syllable even though, in so doing, the low of the high-low pattern is not produced. However, in the words with a short vowel, the historical penultimate stress accent is shifted to the following syllable. This suggests a weight or moraic factor is involved with the stress shift phenomenon.

In investigating the prosodic patterns of Balsas Nahuatl so far, we have focused on F0. However, we have hypothesized that the stress accents will be correlated with other types of acoustic cues, such as duration or spectral amplitude characteristics. We also hypothesized that the innovated tones will be exclusively correlated with F0. Yet given the phonological interaction between the innovated tones and the penultimate accents in Oapan and Ahuelicán, we also want to investigate the possibility that the historical stress accents are becoming tonal, in a shift to a tone language from a stress accent language, through a hybrid system.

\section{Study 2-Acoustic correlates of tone and stress accent in Balsas Nahuatl}

In this section, we present an investigation of the acoustic correlates of stress accent and putative tone in four subdialects of Balsas Nahuatl. The focus here is on the production of the vowel in (1) the penultimate syllable preserving the historical penultimate stress accent in all subdialects and (2) the syllable preceding a syllable with $* h$ in the subdialects with innovated tones (Oapan and Ahuelicán). These syllable types were selected because stress accents can be found on penultimate syllables in all subdialects and putative tone can be found on syllables preceding $* h$ in all the tonal subdialects, allowing for the examination of common syllable types across the subdialects. The vowels in these syllable types were compared to vowels in paired, unstressed syllables in order to compare vowels with high tone or stress accent to vowels unaffected by $* h$ and stress accent.

Three potential correlates to stress accent and tone were investigated here: fundamental frequency, vowel duration, and spectral balance. Stress accent in well-studied languages such as English and Dutch has been related to duration and perceived loudness for quite some time (e.g., Fry, 1955). More recently, Sluijter and van Heuven (1996a, $1996 \mathrm{~b}, 1997$ ) have argued that perceived loudness is related to the distribution of intensity across the spectrum (i.e., spectral balance), such that relatively greater energy in the higher frequencies is subjectively perceived as louder than relatively weaker energy in the higher frequencies. In contrast, the primary acoustic correlate to tone (in Hyman's sense) is F0 (Beckman, 1986; Gussenhoven, 2004; Hyman, 2006), although, to our knowledge, spectral balance correlates have not been investigated in tonal languages.

\subsection{Method}

\subsubsection{Participants}

The same 24 native speakers of Nahuatl, 6 each from four villages, who participated in Study 1 also participated in this study.

\subsubsection{Materials and procedure}

Tables 3 and 4 provide a phonetic transcription of the words recorded for this study. The vowel that was measured for the analysis is underlined in these tables. Table 3 lists the words recorded to investigate the production of penultimate stress accent. Words for which the stressed penultimate vowel was measured are listed in the upper part of Table 3. The lower part of Table 3 lists the words containing the paired, unstressed vowels. For example, the first word 'my spindle whorl wheel', pronounced as [nomala'kateç] in Oapan, was paired with 'meat (dim.)' [naka 'tsiintìi]. In two cases, Ahuelicán did not have a cognate word and thus there were two fewer word pairs for this dialect. Table 4 lists the words recorded to investigate the production of the high tone in syllables preceding a syllable with a coda $* h$. The varieties of Balsas Nahuatl spoken in the villages of Ahuelicán and Oapan are the only ones to have such tones. The upper part of Table 4 lists the words with high tone derived from coda $* h$ in the following syllable and the lower part lists the words containing the paired, unstressed syllables without high tone. For example, 'sweet potato' is pronounced as [kámof'tłi] in Ahuelicán. The underlined, target [a] was paired with the underlined [a] in [ka'makt ii] 'mouth'.

The vowels used for comparison to the stress-accented and high-toned vowels were paired as closely as possible, given the constraints of vocabulary and a fixed placement of the stress accent on the penultimate syllable in some subdialects. The criteria were as follows. First, as in the case of the target syllables, only the open vowel [a] was used. This was to control effects of vocal tract resonances on the amplitude of the harmonics and to control variation in vowel length and F0 due to vowel height. Second, all vowels were in open syllables. ${ }^{11}$ This was to control variation in duration due to syllable structure. Third, to the extent possible, we paired the voicing of the onset consonant. This was to control for microprosodic effects of onset consonant voicing on F0. For the stress accent comparisons, there are even numbers of voiced and voiceless onsets in the two conditions. In the high-tone comparisons, there is an imbalance by one word. Fourth, final syllables were not used in any of the comparisons. This was to control for durational effects caused by wordfinal lengthening and other potential confounds of word

\footnotetext{
${ }^{11}$ The vowels compared in the paired words [te: $\overparen{t \int w i:}$ 'kaskeh] and [kinakaska'na:was] found in Table 3 may be an exception to the open syllable criteria. However, given the fact that the vowels compared are both followed by a [sk] cluster, possible differences in syllabification were not expected to affect the results.
} 
Table 3

List of words with penultimate stress accent used in Study 2.

Historical Oapan Ahuelicán Ameyaltepec $\quad$ San Miguel Gloss

[a] with penultimate accent

\begin{tabular}{|c|c|c|c|c|c|}
\hline *nomala'katew/m & nomala'kąteç & nomala'katem & nomala'katem & nomala'kateh & my spindle whorl stone (or bead) \\
\hline *o:nowi:'kakeh & o:nowi:'kąkeh & o:nowi:'kakkeh & o:nowi:'kąkeh & o:nowi:'kąkeh & they left together \\
\hline *kinakaska'narwas & kinakaska'naiwas & kinakaska'na:was & kinakaska'na:was & kinakaska'na:was & $\mathrm{s} /$ he will thin its handles (lit. 'ears') out \\
\hline *mala'katet‡ & mala'katety & mala'katetł & mala'katetæ & mala'katety & spindle whorl stone (or bead) \\
\hline *o:mitsterkakeh & o:miste:' kakeh & o:miste:'kakeh & o:miste: 'kakeh & o:mitste:'kakeh & they lay you down \\
\hline *o:pepe' tłakak & o:pepe' tłakak & - & o:pepe' tłakak & o:pepe' tła $\underline{\text { akak }}$ & it glittered \\
\hline *pepe' tłakas & pepe' tłakas & - & pepe'tłakas & pepe' tłakas & it will glitter \\
\hline *ter $\overparen{\operatorname{tq}}$ ah' $\overparen{\text { tqatas }}$ & 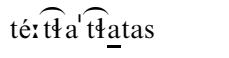 & 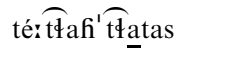 & te: $\overbrace{\text { tfa'tatas }}$ & 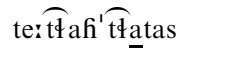 & $\mathrm{s} /$ he will have a good time watching things \\
\hline *o:nomo: 'tłakeh & o:nomo:' tłakeh & o:nomo:' tłakeh & o:nomo:' tłakeh & o:nomo:' tłakeh & they threw rocks at each other \\
\hline *te: $\overparen{t \int w i: ' k a s k e h}$ & te: $\overparen{t \int}$ wi: 'kaskeh & te: $\overparen{\mathrm{t} \int}$ wi: ${ }^{\prime}$ kaskeh & te: $\overparen{t \int}$ wi: kaskeh & te: $\overparen{t \int}$ wi: 'kaskeh & they will accompany us \\
\hline
\end{tabular}

[a] in paired unaccented syllable

\begin{tabular}{|c|c|c|c|c|c|}
\hline *naka' tsizntłi & naka' tsintti & naka' tsintti & naka' tsintti & naka' tsizntli & meat (DIMIN.) \\
\hline *mits t4apa'tili:s & mistłapa'tilizs & misttapa'tilizs & mistłapa'tilizs & mits $\overparen{t+a p a}{ }^{\prime}$ tiliss & $\mathrm{s} /$ he will exchange things for you \\
\hline *kitłaka:'wilizs & kitłaka:'wiliss & kitłaka:'wiliss & kittaka:'wiliss & kitfaka:'wiliss & $\mathrm{s} /$ he will leave things for him/her \\
\hline *ne: $\overparen{t \int t+a k o: ' w i r s k e h}$ & 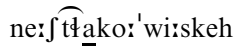 & ne: $\int \overbrace{\text { tłakko: wiskeh }}$ & 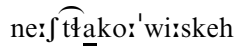 & nertf tłako:'wirskeh & they will strike me with a rod \\
\hline *kinakaska'na:was & kinakaska'na:was & kinakaską'na:was & kinakaska'na:was & kinakaska'na:was & $\mathrm{s} /$ he will thin its handles (lit. 'ears') out \\
\hline *o: tfa'parkkeh & o: tła'pa:hkeh & - & o: tła'pa:hkeh & o: tła'pa:hkeh & they washed clothes \\
\hline *nomala'katew/m & nomala'kateç & - & nomala'kate $\boldsymbol{x}$ & nomala'kateh & my spindle whorl stone (or bead) \\
\hline *o:ne: $\overbrace{\mathrm{t} \int \mathrm{t}}$ ater'milih & o:ne: $\int \overbrace{\text { tłater }}$ 'milih & o:ne: $\int \widehat{\text { tł }}$ ate:' milih & o:ne: $\int \widehat{t t}_{\text {ate: }}$ 'milih & o:ne: $\overparen{t \int} \overbrace{\text { tł }}$ ate:' milih & $\mathrm{s} /$ he filled things up for me \\
\hline 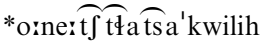 & 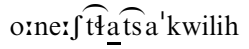 & 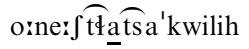 & 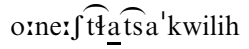 & o:ne: $\overparen{\mathrm{t} \int \mathrm{tq}}$ atsa'kwilih & $\mathrm{s} /$ he blocked my way \\
\hline *kinakaska'na:was & kinakaska'na:was & kinakaska'na:was & kinakaska'na:was & kinakaska'na:was & s/he will thin its handles (lit. 'ears') out \\
\hline
\end{tabular}

boundary such as change in voice quality or F0. Fifth, the comparison vowels were paired with stress-accented or high-toned vowels in terms of approximate position within the word: medial vowels were paired with medial vowels and initial vowels were paired with initial vowels. This was to partially control for durational effects related to position within the word. We must note, however, that in the stress accent comparisons, there was an unavoidable systematic difference in position - the paired vowel was always earlier in the word, and thus followed by more syllables within the word, than the penultimate stress-accented vowel. The greater number of syllables following the paired vowel than the stress-accented vowel may have conditioned more polysyllabic shortening (Lindblom \& Rapp, 1973; Nooteboom, 1972), presenting a potential confound to the durational measures in this case. Sixth, none of the paired vowels had a high tone or were stressed (including the stress relocated to the final syllable), nor was there an $* h$ in any of the paired words. This was to compare vowels with high tone or stress accent to vowels unaffected by $* h$ or stress.
The target words were recorded in both phrase-medial and phrase-final positions. The nouns were said in the same sentence frame used in Study 1. However, verbs were not accepted in this sentence frame by the speakers. Rather, verbs in the future tense were produced in the sentence frames ['morstia _ sa'niman] 'tomorrow _ early' and ['mo:stya sa'niman _ _ 'tomorrow early __ ' and those in the past tense were uttered in the sentence frames ['ja:łwa ___ sa'niman] 'yesterday _ early' and ['ja:łwa sa'niman _ _ ' 'yesterday early __.' The same recording procedure was used for the words in this study as that used in Study 1. For this study, 1248 productions were analyzed: 912 for the penultimate accent $(20$ words $\times 2$ phrasal positions $\times 4$ dialects $\times 6$ speakers -48 missing) and 336 for the innovated tone $(14$ words $\times 2$ phrasal positions $\times 2$ dialects $\times 6$ speakers).

\subsubsection{Acoustic analysis}

The sound files were downsampled to $22,050 \mathrm{~Hz}$ to facilitate the FFT spectral analysis performed for the amplitude measures. 
Table 4

List of words with tone from *h used in Study 2.

\begin{tabular}{|c|c|c|c|}
\hline Historical & Oapan & Ahuelicán & Gloss \\
\hline \multicolumn{4}{|c|}{ [a] with accent from following syllable with coda $* h$} \\
\hline *ka'mohtłi & kámo'tłi & kámoh'tłi & sweet potato \\
\hline$*(\overparen{\mathrm{ttah}}) \overparen{\mathrm{tta}} \mathrm{a}^{\prime} \mathrm{mahke}: \overparen{\mathrm{tt}}$ & tłáma'ke: & tłafţámaf'ke: & hunter \\
\hline *te:mat $\overparen{t}{ }^{\prime}$ tihke: $\overparen{\mathrm{tq}}$ & te:má $\mathrm{tti}^{\prime} \mathrm{ke}: \overparen{\mathrm{tq}}$ & te:mástif'ke: $\overparen{\text { tq }}$ & teacher \\
\hline$* \overparen{\mathrm{t} f}$ ala'lah $\overparen{\mathrm{tqi}}$ & 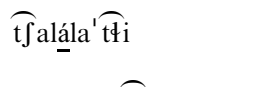 & tyalálah' tłi & $\begin{array}{l}\text { cuachalalate tree (Amphipterygium adstringens } \\
\text { (Schltdl.) Standl., in the Julianaceae family) }\end{array}$ \\
\hline *tamala'johtłi & tamalájo'tti & tamalájoh'tłi & variety of squash \\
\hline *a:' & á: & á: & a little \\
\hline$*_{\mathrm{o}}$ tłakwahtah'sikeh & o: tłákwata'sikeh & o:tłákwafitaf'sikeh & they ate upon arriving there \\
\hline \multicolumn{4}{|c|}{ [a] in paired unaccented syllable } \\
\hline *ka'mak $\overparen{\mathrm{tfi}}$ & 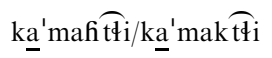 & ka'maktłi & mouth \\
\hline$*_{\text {mala'kate } \overparen{\mathrm{tq}}}$ & mala'kate $\overparen{t \neq}$ & mala'kate $\overparen{t 1}$ & spindle whorl stone \\
\hline *te:mal' tsi:n $\overparen{\text { tłi }}$ & te:maq'ts int $\overparen{\text { tqi }}$ & te:maq'ts int $\widehat{\text { tqi }}$ & puss (DIMIN.) \\
\hline *mala'kate $\overparen{t \ddagger}$ & mala'katet1 & mala'kate $\overparen{\text { tæ }}$ & spindle whorl stone \\
\hline *nomala'katew & nomala'kateç & nomala'katem & my spindle whorl wheel (or bead) \\
\hline 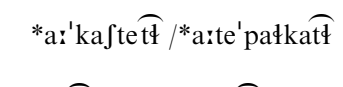 & $\underline{a}^{\prime} k a \int t e \overparen{t q}^{a}$ & $\underline{a}_{\text {ite'pałkatq }}{ }^{\mathrm{a}}$ & $\begin{array}{l}\text { stone bowl for giving water to animals } \\
\text { (particularly pigs) }\end{array}$ \\
\hline 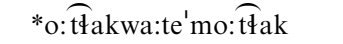 & o:tłakwa:te'mo:tłak & o:tłakwa:te'mo:tłak & $\mathrm{s} /$ he threw things at people's heads \\
\hline
\end{tabular}

${ }^{\text {a }}$ These words are not cognate, but do have the same syllable structure for the target vowel.

3.1.3.1. Duration measure. The duration of the target vowels was measured to determine whether there were systematic differences in duration related to stress accent or tone. The measures were made using waveform and spectrographic displays in Praat. The duration of the vowel was measured from the onset of the first full glottal pulse to the offset of the last full glottal pulse corresponding with the end of visible energy of, or a marked change in frequency of, the second formant in the spectrogram.

3.1.3.2. Fundamental frequency measure. Fundamental Frequency (F0) was measured at the temporal midpoint of the vowel using a Praat script with the autocorrelation method at the same settings as in Study 1. Through auditory assessment and visual inspection of the waveform for irregularities, creaky-voiced tokens were identified and the F0 measurements for those tokens were eliminated from the analysis. Twenty-one tokens (roughly $1 \%$ of the data) were eliminated by this procedure. Two tokens were eliminated for the high-tone vowels and one for their paired counterparts. Ten tokens were eliminated for the stressed vowels and eight for their paired counterparts.

3.1.3.3. Spectral balance measures. The spectral balance measures estimate differences between the amplitude of the first and second harmonic $(\mathrm{H} 1-\mathrm{H} 2)$ and the amplitude of the first harmonic and the second formant $(\mathrm{H} 1-\mathrm{A} 2)$. The $\mathrm{H} 1-\mathrm{A} 2$ measure gives an estimate of the overall spectral slope from the low to mid-range frequencies. It is thought that with increased vocal effort or more creaky phonation (not necessarily associated with vocal effort) the harmonic amplitudes in the mid- to high-frequency range (over $500 \mathrm{~Hz}$ ) increase more than those in the lower part of the spectrum. This is due to the more rapid closure of the glottis during phonation, producing a change in spectral balance (Gauffin \& Sundberg, 1989; Glave \& Rietveld, 1975; Liénard \& Di Benedetto, 1999). The H1-H2 measure provides an estimate of the open quotient, or the ratio of the time that the vocal folds are open to the complete duration of the glottal cycle: the greater the open quotient, the greater the H1-H2 difference (Hanson, 2001; Stevens \& Hanson, 1995). Additionally, the open quotient has been found to be negatively correlated with vocal effort (Holmberg, Hillman, Perkell, Guiod, \& Goldman, 1995). Thus, greater vocal effort is thought to be correlated with smaller $\mathrm{H} 1-\mathrm{A} 2$ and $\mathrm{H} 1-\mathrm{H} 2$ differences, though we do not know that vocal effort is the cause of spectral balance changes in stress-accented vowels.

The amplitude of the source harmonics, as well as the amplitude and bandwidths of vocal tract resonances, varies as a function of formant frequencies (Fant, 1960). Thus, vowels with essentially the same formant frequencies must 
be compared, or normalizing procedures must be used (e.g. Hanson, 1997; Hanson \& Chuang, 1999) for spectral balance measures. For this reason, the formant frequencies of the paired vowels will be compared prior to the analysis of the $\mathrm{H} 1-\mathrm{H} 2$ and $\mathrm{H} 1-\mathrm{A} 2$ measures analyzed in this study.

Using PCQuirer, software by Scicon Research and Development, both narrowband FFT and LPC (26 coefficients) spectra were calculated and plotted in a single spectral window. A Hamming window was centered at the temporal midpoint of the vowel to calculate a narrowband FFT spectrum $(1024$ point, $21 \mathrm{~Hz})$. The amplitude, in decibels, of the first and second harmonics was measured by hand with a cursor on a frequency-expanded screen. The location of the first harmonic in the frequency range was verified against the F0 measurement to guard against spurious harmonic measurements, as the FFT spectrum would sometimes find a peak below the $\mathrm{H} 1$ for voices with high fundamental frequencies. The amplitude of the second formant was measured as the most prominent harmonic from the narrowband FFT spectrum that was found to be clearly within the second formant band defined by the LPC tracing. These measures only approximate the amplitude of the second formant, as the most prominent harmonic may or may not be at the central frequency of the resonance.

3.1.3.4. First and second formant frequency measures. Before proceeding with the analysis of the spectral balance measures, we report the formant frequency comparisons for the paired vowels of each group.

The first and second formant frequencies (F1 and F2) were measured at the temporal midpoint of the vowel using a Praat script. LPC analysis was used to determine the formant frequencies. The LPC analysis was obtained using the values recommended by the authors of Praat: 5 formants (10 coefficients) and a $25 \mathrm{~ms}$ Gaussian window, and pre-emphasis from $50 \mathrm{~Hz}$. The analysis range was set at 5500 for female and 5000 for male speakers to approximate the relative difference in format spacing between genders. The LPC tracks were superimposed on a broadband spectrogram calculated from 0 to $5000 \mathrm{~Hz}$ with a $5 \mathrm{~ms}(260 \mathrm{~Hz})$ Gaussian window. The F1 and F2 measurements were automatically recorded at the vowel's temporal midpoint. These measurements were verified by visual inspection of the spectrogram. Knowledge of the typical formant structure for an [a] vowel, as well as of the [a] vowel for a given speaker, was employed and spurious formant measures were discarded. The LPC formant tracking values that corresponded to visible formants on the spectrogram were recorded manually to replace the spurious values.

The individual data points for each speaker for the F1 and F2 measures were submitted to separate repeated measures ANOVAs with the factors of Phrasal Type (medial and final) and Stress (stress accented and unstressed) or Tone (high tone and no tone). An alpha level of .05 was used for all tests. The results indicated that F1 and F2 did not significantly vary by phrasal position. The main effect of Phrasal Type and the interaction of Stress or Tone and Phrasal Type were not significant for any of the $\mathrm{F} 1$ or $\mathrm{F} 2$ comparisons $[F$-values ranged from $>0.01$ to 3.43 ].

F1 and F2 were also unaffected by stress accent. There was no significant effect on F1 for San Miguel [stressaccented mean $695 \mathrm{~Hz}$ vs. unstressed mean $680 \mathrm{~Hz}$, $F(1,59)=1.78, p=.19]$, Ameyaltepec [662 Hz vs. $649 \mathrm{~Hz}$, $F(1,59)=1.89, p=.17]$, Ahuelicán $[711 \mathrm{~Hz}$ vs. $688 \mathrm{~Hz}$, $F(1,46)=1.83, p=.18]$, or Oapan $[621 \mathrm{~Hz}$ vs. $643 \mathrm{~Hz}$, $F(1,57)=1.89, p=.17]$. Neither was the effect of Stress on F2 significant for San Miguel [stress-accented mean $1669 \mathrm{~Hz}$ vs. unaccented mean $1647 \mathrm{~Hz}, F(1,59)=$ $0.94, p=.34]$, Ameyaltepec $[1603 \mathrm{~Hz}$ vs. $1584 \mathrm{~Hz}$, $F(1,59)=2.08, p=.15]$, Ahuelicán $[1589 \mathrm{~Hz}$ vs. $1558 \mathrm{~Hz}$, $F(1,46)=3.11, p=.08]$, or Oapan $[1568 \mathrm{~Hz}$ vs. $1547 \mathrm{~Hz}$, $F(1,57)=1.69, p=.20]$.

Likewise, F1 and F2 were unaffected by the presence or absence of high tone. There was no significant effect on F1 for either of the tonogenetic villages: Oapan [high-tone mean $658 \mathrm{~Hz}$ vs. no tone mean $665 \mathrm{~Hz}, F(1,40)=0.27$, $p=.60]$ or Ahuelicán $[710 \mathrm{~Hz}$ vs. $728 \mathrm{~Hz}, F(1,41)=3.20$, $p=.08]$. Neither was the effect of Tone on F2 significant for Oapan [high-tone mean $1486 \mathrm{~Hz}$ vs. no tone mean $1495 \mathrm{~Hz}, F(1,40)=0.21, p=.65]$ or Ahuelicán $[1537 \mathrm{~Hz}$ vs. $1498 \mathrm{~Hz}, F(1,41)=3.06, p=.09]$.

Given the finding that formant frequencies were not significantly affected by either stress accent or tone, the analysis of the $\mathrm{H} 1-\mathrm{H} 2$ and $\mathrm{H} 1-\mathrm{A} 2$ measures will proceed without normalization in the sections below.

\subsubsection{Predictions and statistical analysis}

The data from individual speakers were first inspected and compared to other speakers of the same subdialect. Speakers of a given dialect showed consistency in F0 patterning for each word type in each phrasal position. Accordingly, the data have been pooled across the speakers in the statistical design described below.

The comparisons for the paired vowels were made by subdialect. In San Miguel and Ameyaltepec, stressaccented vowels were compared to vowels in paired, unstressed syllables (see Table 3). In Ahuelicán and Oapan, the stress accent comparisons were made, as well as comparisons of vowels with high tone (due to coda $* h$ in the following syllable) to vowels with no tone (due to lack of $* h$ in the following syllable; see Table 4).

For the stress accent comparisons, at least some of the acoustic correlates potentially associated with stress accent (duration, $\mathrm{H} 1-\mathrm{H} 2$, and $\mathrm{H} 1-\mathrm{A} 2$ ) were anticipated and, if found, were expected to be constant across the phrasal conditions. We thought it possible, however, that the correlates to stress accent would be different or weaker for the tonal subdialects (Ahuelicán and Oapan) than the other subdialects due to the possibility that in the tonal dialects stress accent is in the process of transitioning to tone. We 
did not have specific expectations for F0 patterns on the stress-accented vowels, as the focus on the target words may or may not have conditioned an intonational pitch accent: a higher F0 on stress-accented words in both phrasal positions may reflect a correlate of stress accent or of a focus-related pitch accent. However, a higher F0 in phrase-final position only would most likely reflect a phrase-final intonational pattern.

For the tonal comparisons, F0 differences between hightoned and paired syllables were the only expected effects. The other measures (duration, $\mathrm{H} 1-\mathrm{H} 2$, and $\mathrm{H} 1-\mathrm{A} 2$ ) were not expected to vary by tonal specification. Additionally, the F0 effects were expected to be found in all phrasal conditions, as the tones are thought to be word-level specifications.

For both the stress accent and tone comparisons, the individual data points for each speaker were submitted to separate repeated measures ANOVAs for each of four measures (duration, $\mathrm{H} 1-\mathrm{H} 2, \mathrm{H} 1-\mathrm{A} 2$, and $\mathrm{F} 0$ ) with the within subject factors of Phrasal Type (medial and final) and Stress (stress accented and unstressed) or Tone (high tone and no tone). This statistical design tested the effect of Stress or Tone on the four acoustic measures and allowed for an assessment of the interaction of the effect with Phrasal Position. All factors were repeated measures for which a given speaker's productions were compared with their own productions across the conditions. Thus, even though both male and female speakers were in each group, the variance in the cells to be compared was similar, as they contained productions from the same speakers. An alpha level of .05 was used for these tests. Only the statistics for significant main effects and interactions are reported. Significant interactions were investigated by conducting two repeated-measures ANOVAs testing the effect of Stress or Tone on each phrasal position separately (alpha level was adjusted to .025 for two comparisons).

\subsection{Results}

\subsubsection{San Miguel (*h retained, penultimate stress only)}

Fig. 5 presents the results for San Miguel speakers comparing penultimate stressed vowels to unstressed vowels. The F0 of stress-accented vowels was higher than that of unstressed vowels in both phrasal positions, but the effect was stronger for the final than the medial position (5a). The effect of Stress was significant $[F(1,54)=94.75$, $\left.p<.001, \eta_{\mathrm{p}}^{2}=.64\right]$ and it interacted with Phrasal Type $\left[F(1,54)=19.76, p<.001, \eta_{\mathrm{p}}^{2}=.27\right]$. The main effect of Phrasal Type was not significant. There was a significant effect of Stress for both positions, with a larger effect size for the final position [medial: $F(1,57)=25.57, p<.001$, $\eta_{\mathrm{p}}^{2}=.31$, final: $\left.F(1,56)=123.34, p<.001, \eta_{\mathrm{p}}^{2}=.67\right]$.

For the measure of duration, in phrase-final position stressed vowels tended to have longer durations than paired, unstressed vowels. Also, there was a marginal trend for vowels to be longer overall in phrase-final position (5b).
The effect of Stress was significant $[F(1,59)=10.82$, $\left.p=.002, \eta_{\mathrm{p}}^{2}=.16\right]$ and it interacted with Phrasal Type $\left[F(1,59)=5.41, p=.02, \eta_{\mathrm{p}}^{2}=.08\right]$. The main effect of Phrasal Type was marginally significant $[F(1,59)=3.97$, $p=.051]$. The effect of Stress was significant for the final position $\left[F(1,59)=18.08, p<.001, \eta_{\mathrm{p}}^{2}=.24\right]$, but not the medial position $[F(1,59)=1.81, p=.18]$.

The spectral balance measurements $(\mathrm{H} 1-\mathrm{H} 2$ and H1-A2) were affected by stress accent in both phrasal positions (5c-d). Additionally, the H1-A2 measure tended to increase in phrase-final position across the Stress conditions. The main effect of Stress was significant $\left[\mathrm{H} 1-\mathrm{H} 2: F(1,54)=28.38, p<.001, \eta_{\mathrm{p}}^{2}=.34\right.$ and $\mathrm{H} 1-\mathrm{A} 2$ : $\left.F(1,54)=47.32, p<.001, \eta_{\mathrm{p}}^{2}=.47\right]$. There was also a main effect of Phrasal Type for the H1-A2 measure $\left[F(1,54)=6.63, p=.013, \eta_{\mathrm{p}}^{2}=.11\right]$. No other main effects or interactions were significant for these measures.

As predicted, correlates to stress accent were found for the penultimate syllables in San Miguel: spectral balance measures $\mathrm{H} 1-\mathrm{H} 2$ and $\mathrm{H} 1-\mathrm{A} 2$ indicated a flatter spectral slope and smaller open quotient in stress-accented than unstressed vowels in both phrasal conditions. Durational differences, on the other hand, were only found phrasefinally. The effect of F0 was found to vary by phrasal position.

\subsubsection{Ameyaltepec (*h lost, penultimate stress only)}

Fig. 6 presents the results for Ameyaltepec speakers comparing penultimate stress-accented vowels to paired, unstressed vowels. The F0 of stressed vowels was higher than that of unstressed vowels in both phrasal positions (6a). The main effect of Stress was significant $\left[F(1,52)=26.46, p<.001, \eta_{\mathrm{p}}^{2}=.34\right]$ and did not interact with Phrasal Type.

The duration of stress-accented vowels was longer in phrase-final position than that of unstressed vowels (6b).The effect of Stress was significant $[F(1,59)=21.82$, $\left.p<.001, \eta_{\mathrm{p}}^{2}=.27\right]$ and it interacted with Phrasal Type $\left[F(1,59)=14.97, p<.001, \eta_{\mathrm{p}}^{2}=.20\right]$. The effect of Stress on duration was significant for phrase-final position $\left[F(1,59)=30.75, p<.001, \eta_{\mathrm{p}}^{2}=.34\right]$, but not for phrasemedial position.

Finally, the stress-accented vowels had smaller $\mathrm{H} 1-\mathrm{H} 2$ and $\mathrm{H} 1-\mathrm{A} 2$ differences than the unstressed vowels in both phrasal positions ( $6 \mathrm{c}$ and $\mathrm{d}) . \mathrm{H} 1-\mathrm{H} 2$ was significantly smaller $\left[F(1,52)=19.40, p<.001, \eta_{\mathrm{p}}^{2}=.27\right]$, as was $\mathrm{H} 1-\mathrm{A} 2$ $\left[F(1,52)=9.90, p=.003, \eta_{\mathrm{p}}^{2}=.16\right]$ in stress-accented than unstressed vowels. These main effects did not interact with Phrasal Type.

As in San Miguel, correlates typical of stress accent were found for the penultimate syllables: spectral balance measures ( $\mathrm{H} 1-\mathrm{H} 2$ and $\mathrm{H} 1-\mathrm{A} 2)$ were affected by Stress type in both phrasal conditions. Additionally, in this dialect, F0 differences were found to be equally strong in both phrasal conditions. Durational differences, on the other hand, were only found phrase-finally. 
a

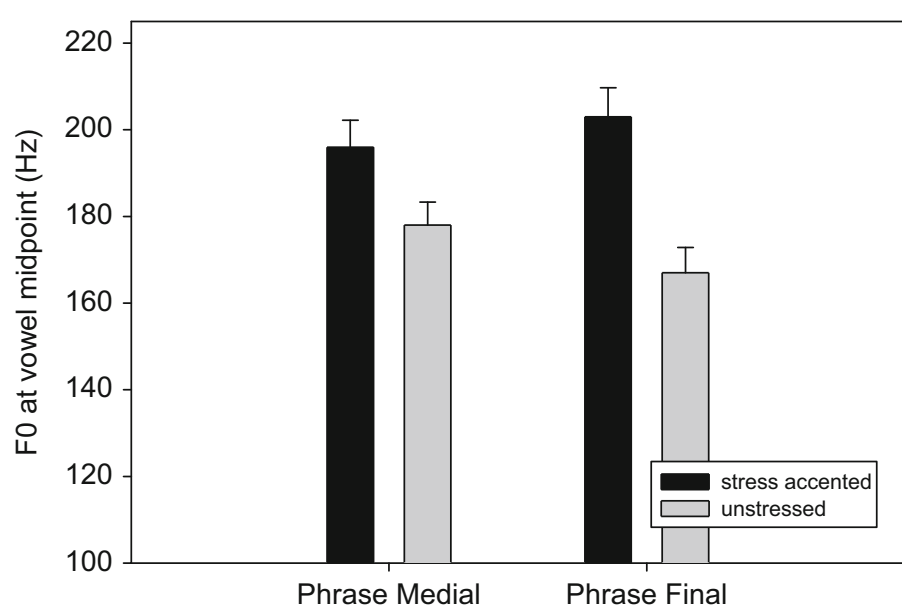

C

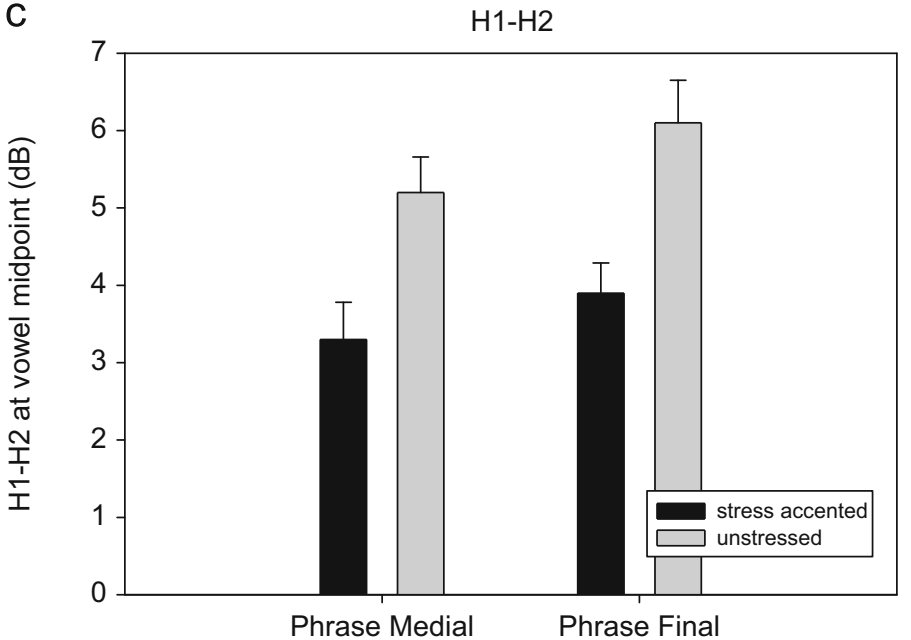

b

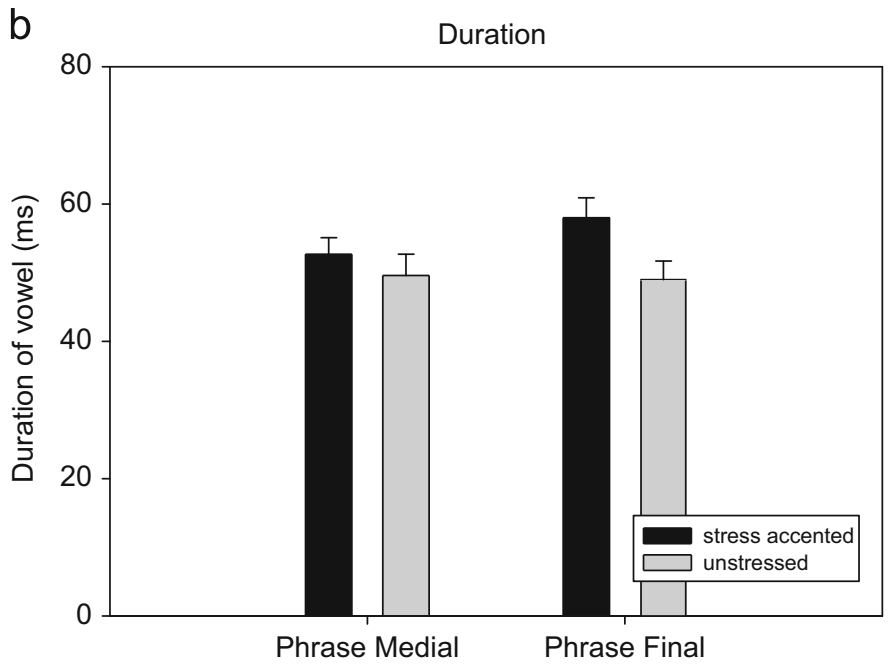

d

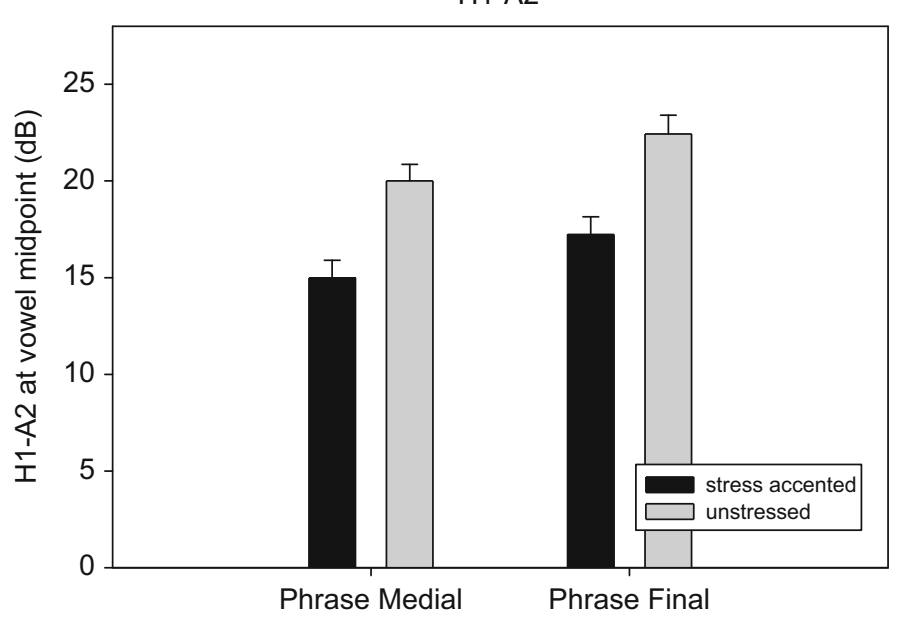

Fig. 5. Mean and standard error at vowel midpoint for the measures of (a) fundamental frequency, (b) vowel duration, (c) difference between the first and the second harmonic, and (d) difference between the first harmonic and the amplitude of the second formant for vowels stressed on the penultimate syllable and for unstressed vowels. Data were produced by six participants from San Miguel.

\subsubsection{Ahuelicán (*h retained, innovated tone)}

Fig. 7 presents the results for Ahuelicán speakers comparing penultimate stress-accented vowels to unstressed vowels. The stress-accented vowels have a higher F0 than unstressed vowels, especially in phrase-final position (7a). The effects of Stress $[F(1,44)=53.43$, $\left.p<.001, \eta_{\mathrm{p}}^{2}=.55\right]$ and Phrasal Type $[F(1,44)=24.43$, $\left.p<.001, \eta_{\mathrm{p}}^{2}=.36\right]$ were significant, as was their interaction $\left[F(1,44)=28.81, p<.001, \eta_{\mathrm{p}}^{2}=.40\right]$. The effect of Stress on F0 was significant for the phrase-final position $\left[F(1,44)=60.11, p<.001, \eta_{\mathrm{p}}^{2}=.58\right]$ and marginally significant for the phrase-medial position $[F(1,44)=5.38$, $\left.p=.025, \eta_{\mathrm{p}}^{2}=.11\right]$.

Duration and $\mathrm{H} 1-\mathrm{H} 2$ measures seem to be roughly the same for the stressed and unstressed vowels $(7 b-c)$. The effects of Stress and Phrasal Type were not significant for these measures. However, stressed vowels had a smaller H1-A2 difference (7d), indicating a flatter spectral slope without a change in open quotient. Only the main effect of Stress was significant $[F(1,44)=8.62, p=.005$, $\left.\eta_{\mathrm{p}}^{2}=.16\right]$.

Fig. 8 presents the results for Ahuelicán speakers comparing vowels with high tone to vowels with no tone. F0 was the only measure found to differentiate vowels with high tone from vowels with no tone. Furthermore, F0 differences were found in both phrase-medial and phrase-final positions (8a). The effect of Tone was significant for the measure of $\mathrm{F} 0 \quad[F(1,41)=55.93$, $\left.p<.001, \eta_{\mathrm{p}}^{2}=.58\right]$ and did not interact with Phrasal Type. No significant main effects or interactions were observed for the measures of duration, $\mathrm{H} 1-\mathrm{H} 2$, or $\mathrm{H} 1-\mathrm{A} 2$.

Thus, stress accent was coded in both phrasal conditions with one known correlate of stress accent, H1-A2, in indicating a flatter spectral slope, but without any indication of a change in open quotient. F0 was only correlated with stress accent in phrase-final position. 


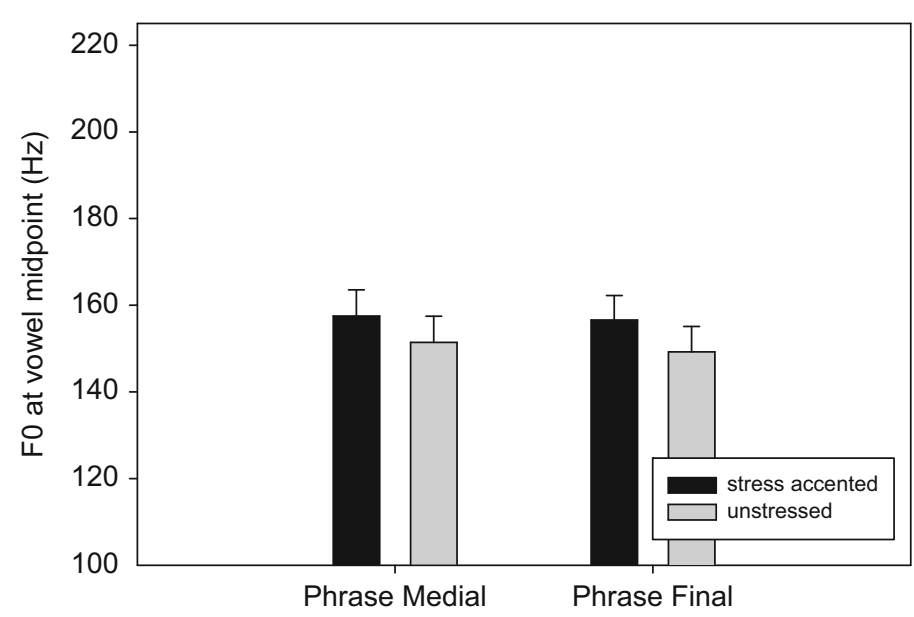

C

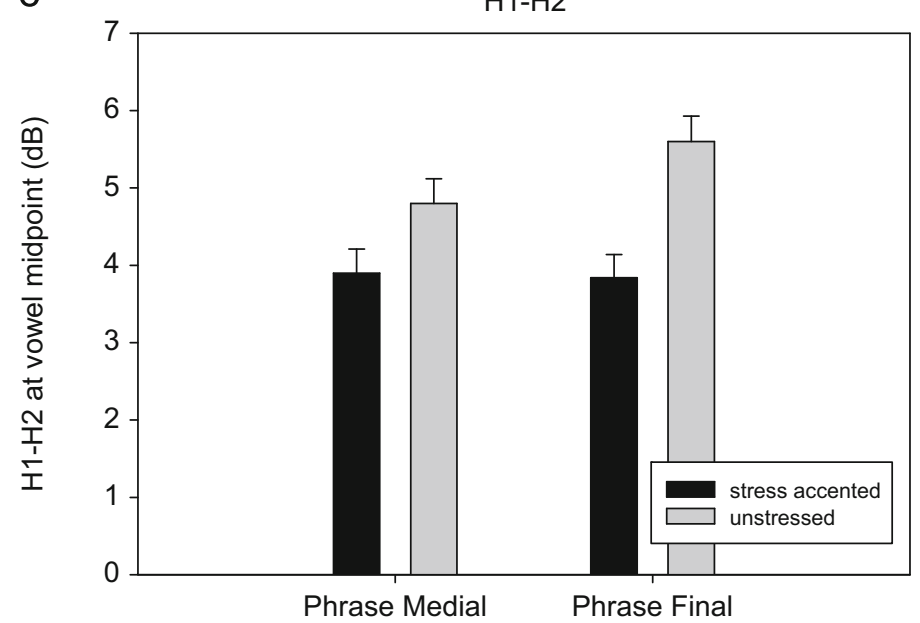

b

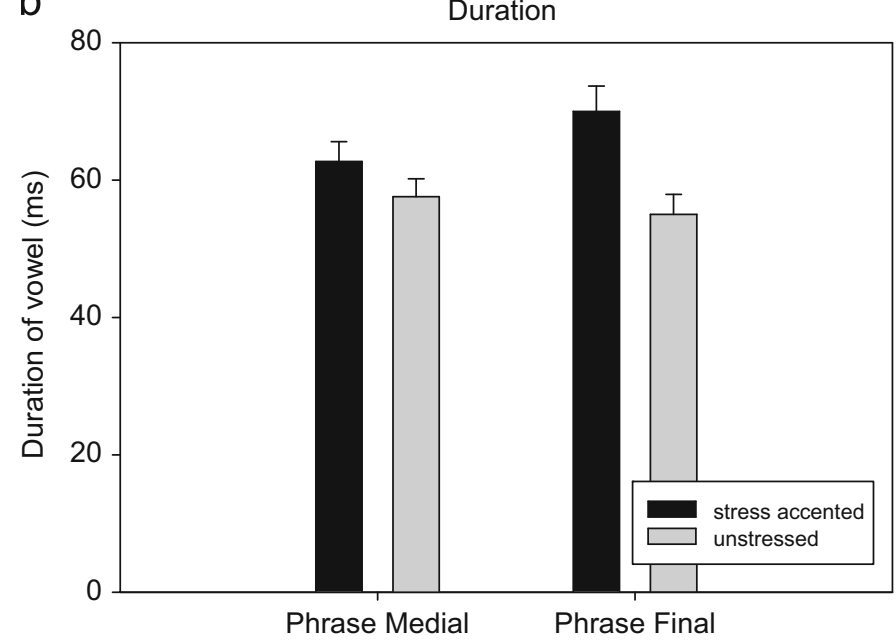

d

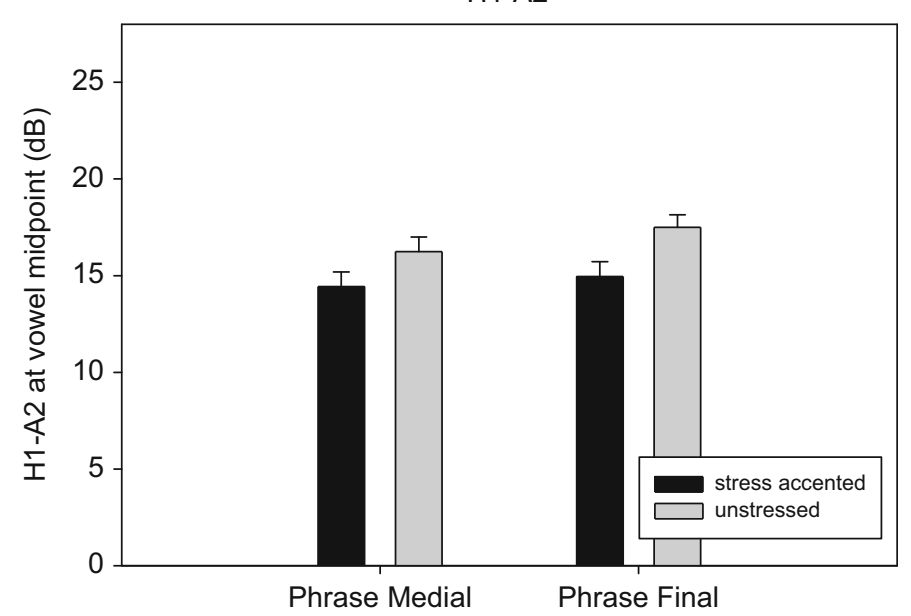

Fig. 6. Mean and standard error at vowel midpoint for the measures of (a) fundamental frequency, (b) vowel duration, (c) difference between the first and the second harmonic, and (d) difference between the first harmonic and the amplitude of the second formant for vowels stressed on the penultimate syllable and for unstressed vowels. Data were produced by six participants from Ameyaltepec.

Conversely, as predicted, the innovated tones were solely correlated with F0 in both phrasal positions.

\subsubsection{Oapan (*h lost, innovated tone)}

Fig. 9 presents the results for Oapan speakers for stress accent comparisons. The penultimate stress-accented vowels had a higher F0 than unstressed vowels in both phrasal positions but the difference was greater in phrasefinal position (9a). The effect of Stress was significant $\left[F(1,53)=80.18, p<.001, \eta_{\mathrm{p}}^{2}=.60\right]$ and it interacted with Phrasal Type $\left[F(1,53)=13.30, p=.001, \eta_{\mathrm{p}}^{2}=.20\right]$. The effect was significant for both phrasal positions [medial: $F(1,58)=38.25, p<.001, \eta_{\mathrm{p}}^{2}=.40$, final: $F(1,53)=104.75$, $\left.p<.001, \eta_{\mathrm{p}}^{2}=.66\right]$ but simply stronger in phrase-final position.

Duration of the stress-accented vowels was also longer in both positions (9b). The effect of Stress was significant $\left[F(1,58)=15.10, p<.001, \eta_{\mathrm{p}}^{2}=.21\right]$ and did not interact with Phrasal Type.
Finally, H1-H2 and H1-A2 were not correlated with penultimate stress accent in either position $(9 \mathrm{c}-\mathrm{d})$. Neither the main effect of Stress, nor its interaction with Phrasal Type, was significant for either of these measures. However, there was a tendency, based on the H1-A2 measure, for increased spectral tilt across the board phrase finally. There was a marginal main effect of Phrasal Type for the H1-A2 measure $[F(1,53)=4.11, \quad p=.048$, $\left.\eta_{\mathrm{p}}^{2}=.07\right]$.

Fig. 10 presents the results for tone comparisons. The only significant effect of Tone was found for the F0 measure, and it was found for both phrasal positions (10a). Vowels with high tone have significantly higher F0 than vowels with no tonal specification $[F(1,39)=102.12$, $\left.p<.001, \eta_{\mathrm{p}}^{2}=.72\right]$. Additionally there was a Phrasal Type effect without interaction for F0. Phrase-final words (both those with high tone and those with no tonal specification) had lower F0 than phrase-medial words $[F(1,39)=15.21$, $\left.p<.001, \eta_{\mathrm{p}}^{2}=.28\right]$. No other significant main effects or 
a

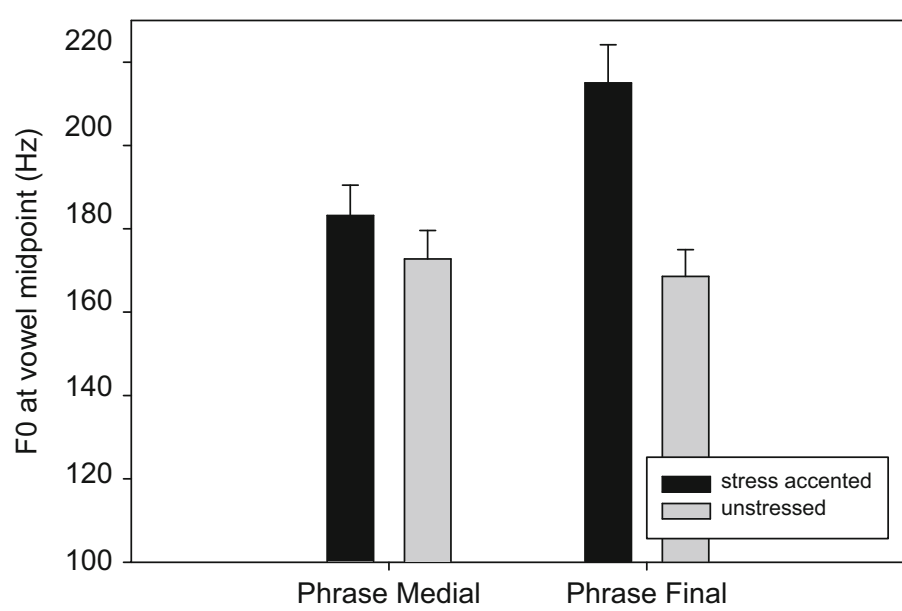

C

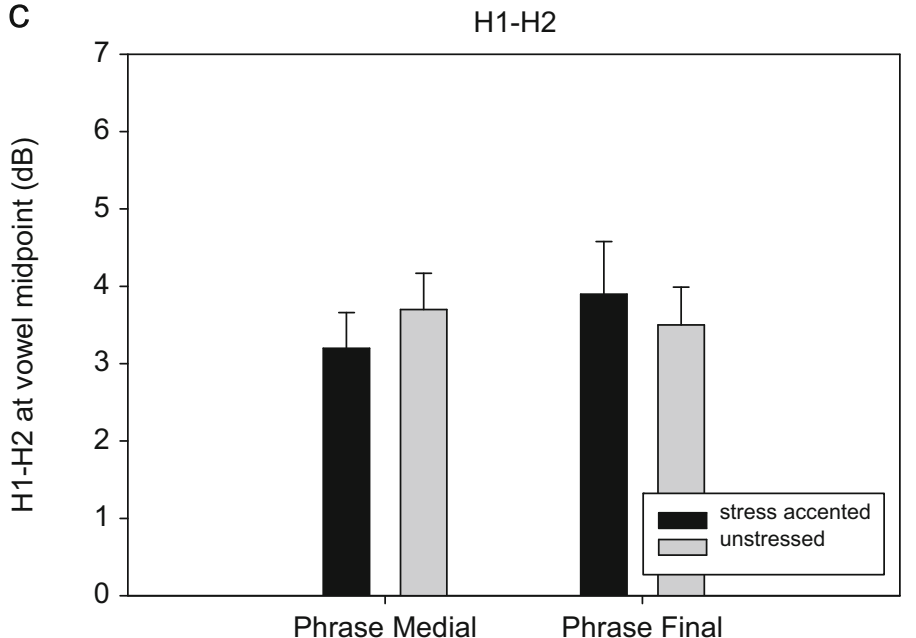

b

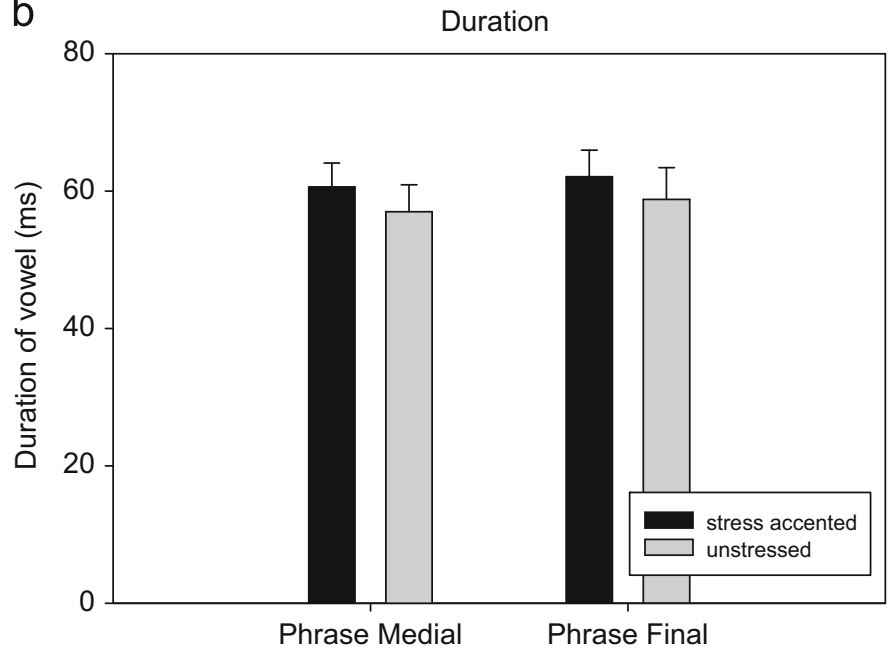

d

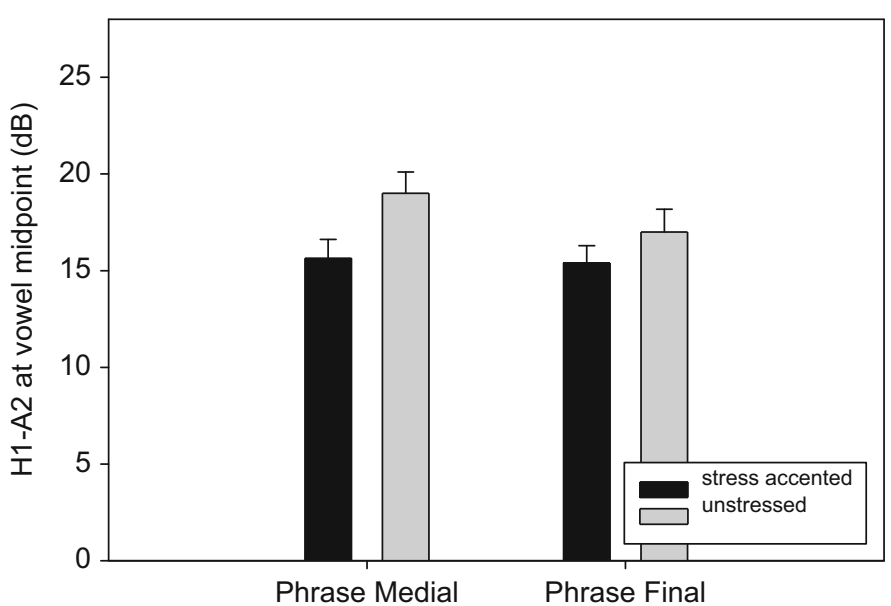

Fig. 7. Mean and standard error at vowel midpoint for the measures of (a) fundamental frequency, (b) vowel duration, (c) difference between the first and the second harmonic, and (d) difference between the first harmonic and the amplitude of the second formant for vowels stressed on the penultimate syllable and for unstressed vowels. Data were produced by six participants from Ahuelicán.

interactions were observed for any of the other measures (10c-d).

As was the case in Ahuelicán, stress accent was coded in both phrasal conditions with one known correlate of stress accent, but in this case it was duration. Contrastively, the innovated tones were only correlated with F0 and the effect was similar in phrase-medial and phrase-final positions, although the F0 of phrase-final words was lower across the board.

\subsection{Discussion}

This second study investigated potential acoustic correlates to stress and tone: F0, duration, and the spectral balance measures $\mathrm{H} 1-\mathrm{H} 2$ and $\mathrm{H} 1-\mathrm{A} 2$. In San Miguel and Ameyaltepec, two villages where historical penultimate stress accent is preserved and no tone innovated, smaller
$\mathrm{H} 1-\mathrm{H} 2$ and $\mathrm{H} 1-\mathrm{A} 2$ differences reliably distinguished stress-accented from unstressed syllables in both phrasemedial and phrase-final positions. Vowels with penultimate stress accent were also longer than unstressed vowels, but this trend was only significant in phrase-final position. In Ameyaltepec, higher F0 reliably distinguished stress accented from unstressed syllables in both phrase-medial and phrase-final positions but in San Miguel the F0 effect was only strongly evidenced phrase-finally. Note that the F0 results concur with the data reported in Study 1.

Taken together, these results indicate that San Miguel and Ameyaltepec have a word-level stress accent primarily correlated with acoustic effects of spectral balance. Duration was at best a weak correlate phrase internally. The relatively longer duration in the phrase-final than phrase-internal position may be due to an overall utterance-final lengthening in which the penultimate stress-accented syllable was lengthened to a greater degree 
a

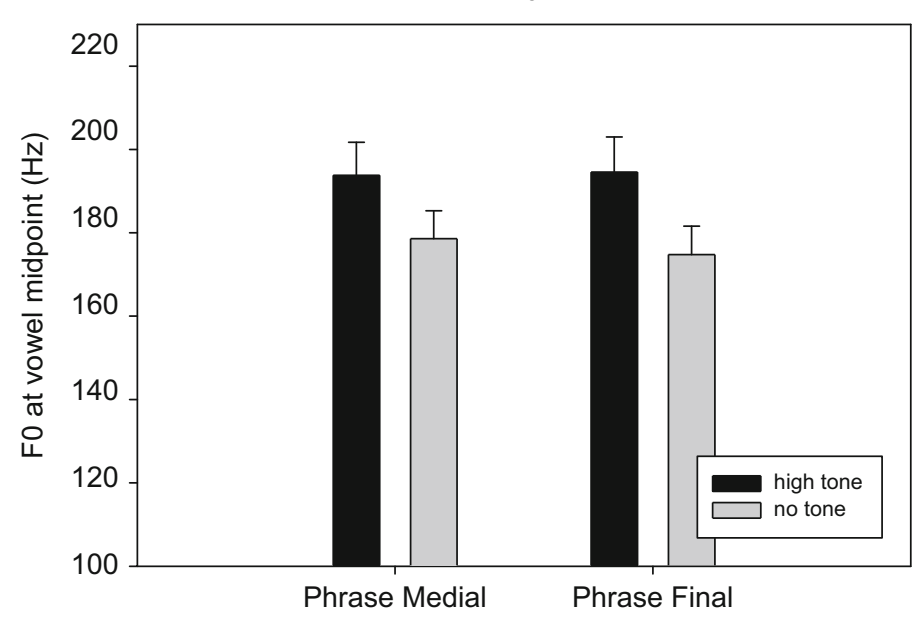

C

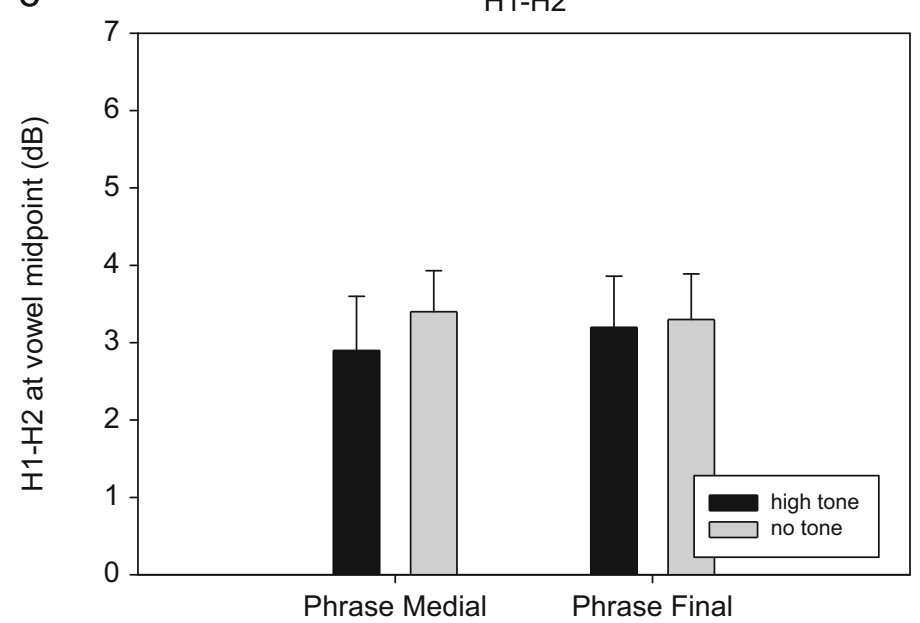

$\mathrm{b}$

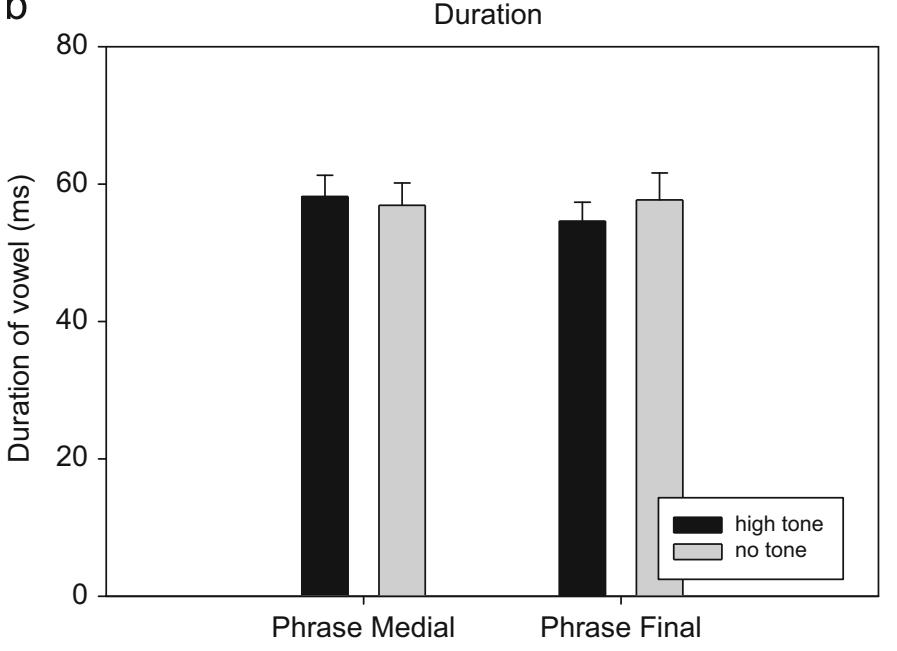

d

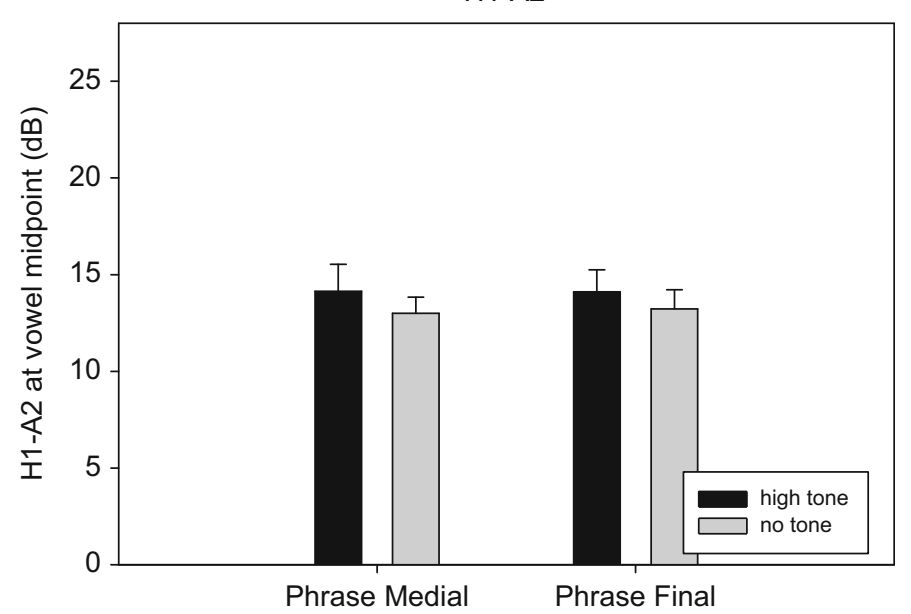

Fig. 8. Mean and standard error at vowel midpoint for the measures of (a) fundamental frequency, (b) vowel duration, (c) difference between the first and the second harmonic, and (d) difference between the first harmonic and the amplitude of the second formant for vowels with high tone from the effect of $* h$ in the coda of the following syllable and for vowels without tone. Data were produced by six participants from Ahuelicán.

than the more word-internal paired vowel. F0 may also be a correlate to stress accent in Ameyaltepec. However, as mentioned previously, further work manipulating the discourse context is needed to disassociate intonational from stress accent effects.

Now let us turn to the results from the villages which have developed high tone on syllables preceding $* h$ : Oapan and Ahuelicán. These varieties also preserve penultimate stress accent in some words. Thus, it was of interest to determine differences in the realization of stress accent and tone. As seen in the results of Study 1, syllables with high tone had higher F0. In this second study, the possibility of other acoustic correlates to the high tone was investigated. However, the only acoustic measure found to correlate to tone in both subdialects and in both phrasal positions was F0.

In both Oapan and Ahuelicán, the acoustic correlates of penultimate stress accents differed from those of tone. In
Ahuelicán, the penultimate stress accents were produced with a flatter spectral slope (smaller $\mathrm{H} 1-\mathrm{A} 2$ differences) in both phrasal positions. A higher F0 was only reliably found in phrase-final position. Thus, a flatter spectral slope appears to be the primary acoustic correlate to penultimate stress in Ahuelicán; the high F0 appears to be a characteristic of phrase-final intonational prosody. In Oapan, penultimate stress accents were produced with higher F0 and longer duration in both phrasal positions. Therefore, greater duration, and possibly higher F0, appear to be the primary acoustic correlates to stress in Oapan.

Thus, the penultimate stress accents exhibited acoustic characteristics typical of stress in both villages: flatter spectral slope in Ahuelicán and longer duration in Oapan. However, in neither village did penultimate stress-accented vowels exhibit smaller $\mathrm{H} 1-\mathrm{H} 2$ differences, which would indicate smaller open quotients. Thus these varieties may 
a

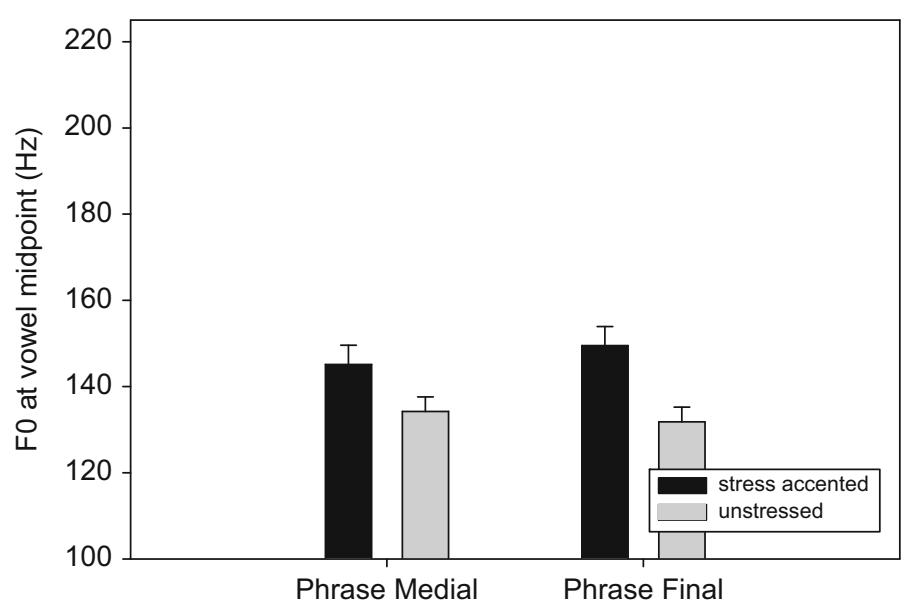

C

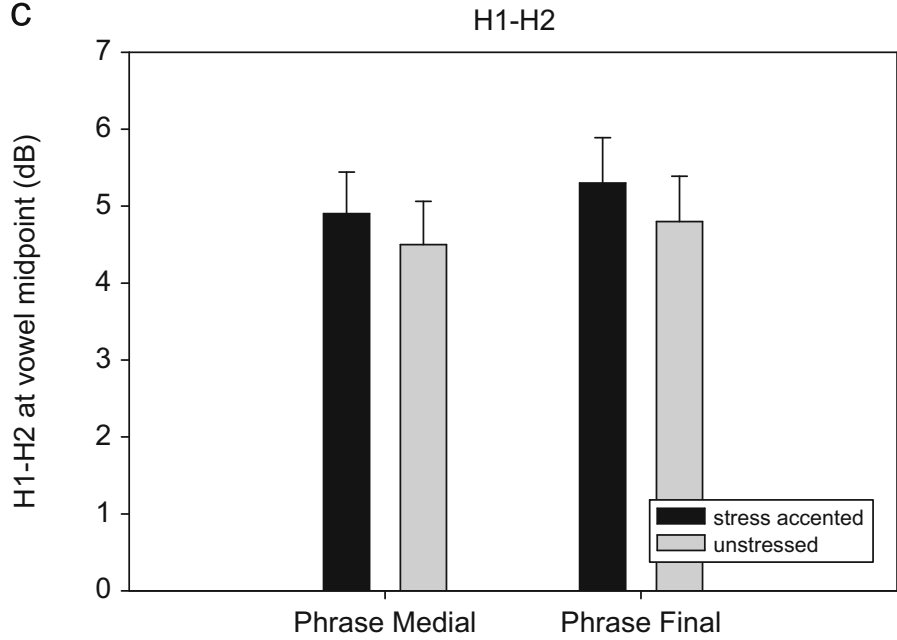

b

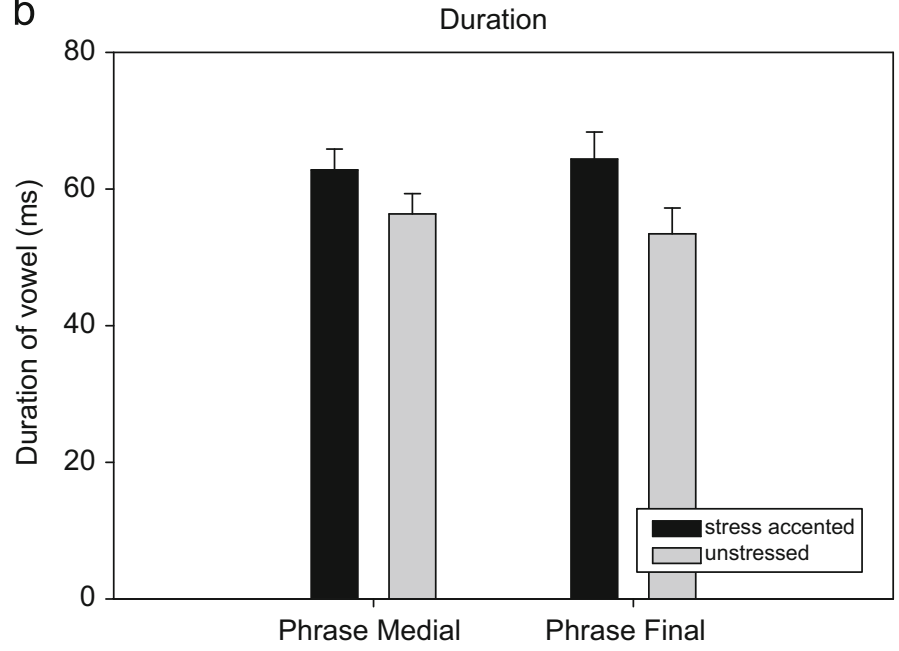

d

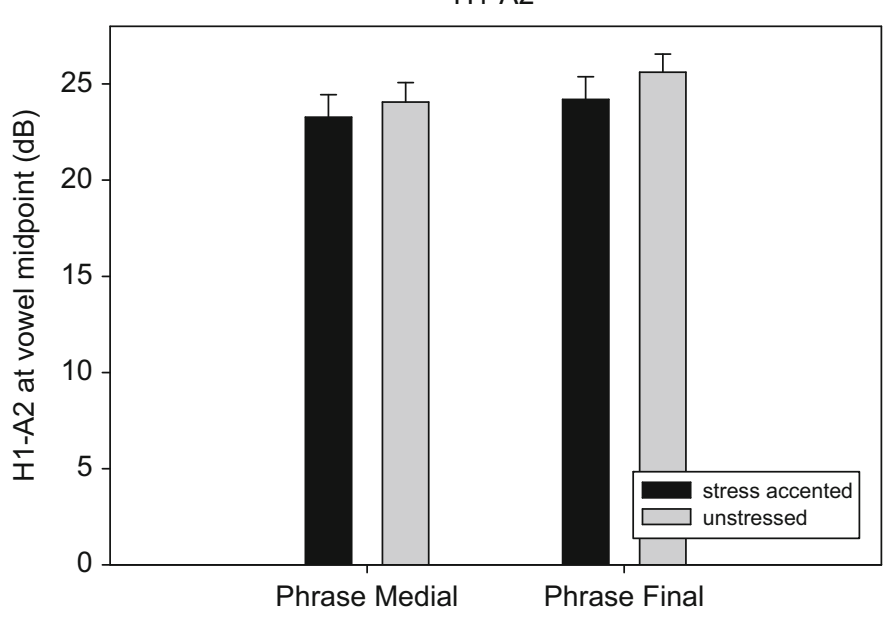

Fig. 9. Mean and standard error at vowel midpoint for the measures of (a) fundamental frequency, (b) vowel duration, (c) difference between the first and the second harmonic, and (d) difference between the first harmonic and the amplitude of the second formant for vowels stressed on the penultimate syllable and for unstressed vowels. Data were produced by six participants from Oapan.

use less creaky or tense voicing in producing penultimate stress than the San Miguel and Ameyaltepec varieties.

\section{General discussion and conclusion}

The results of the studies presented here have provided evidence about the origin and development of tone in the Nahuatl subdialects of Oapan and Ahuelicán. Tone seems to have originated in a small lowering of $\mathrm{F} 0$ conditioned by a non-final coda breathy $[6](<* h)$. We proposed that tone developed as a reinterpretation of the relatively higher F0 on the syllable preceding a syllable with [6]. A high-low F0 contour across the two syllables was phonologized, producing a high tone on the preceding syllable. This account of the sound change may be captured by John Ohala's notion of hypo-correction (see, e.g., Ohala, 1993), in which listeners fail to normalize coarticulatory effects (such as the effect of breathy voicing on F0) and interpret the coarticulatory effects as intended by the speaker. Although, the conditioning environment was not necessarily lost as a result of the hypo-correction in this case.

Given this analysis, the development of tone in Balsas Nahuatl is similar to the development of low or falling tonal contours found in other languages (Matisoff, 1973; Ohala, 1973; Svantesson, 2001), including the related UtoAztecan language Hopi (Manaster-Ramer, 1986). The results also provide support for Thurgood's (2002) proposal that breathy voicing is the relevant conditioning element in such developments.

Furthermore, once the conditioning environment (i.e., the coda [f]) was lost and the F0 patterns were phonologized as lexical tones, they were no longer tied to their original location. Thus in Oapan high tones are now found on syllables other than those immediately preceding a syllable with coda $* h$ (see examples (5) and (6) in which a high tone is found on a syllable with $* h$ ). This historical development may be the origin of autosegmental tonal 
a

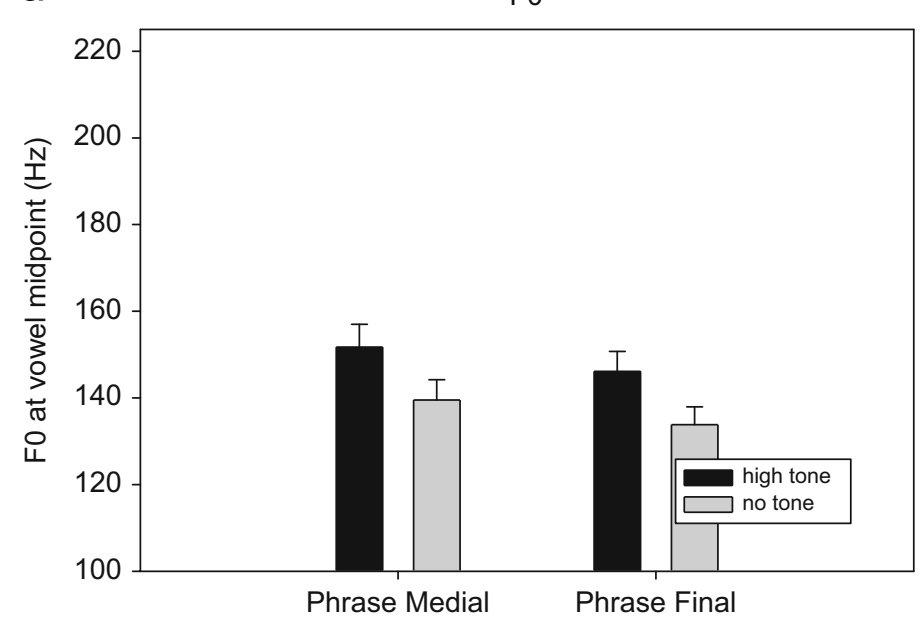

C
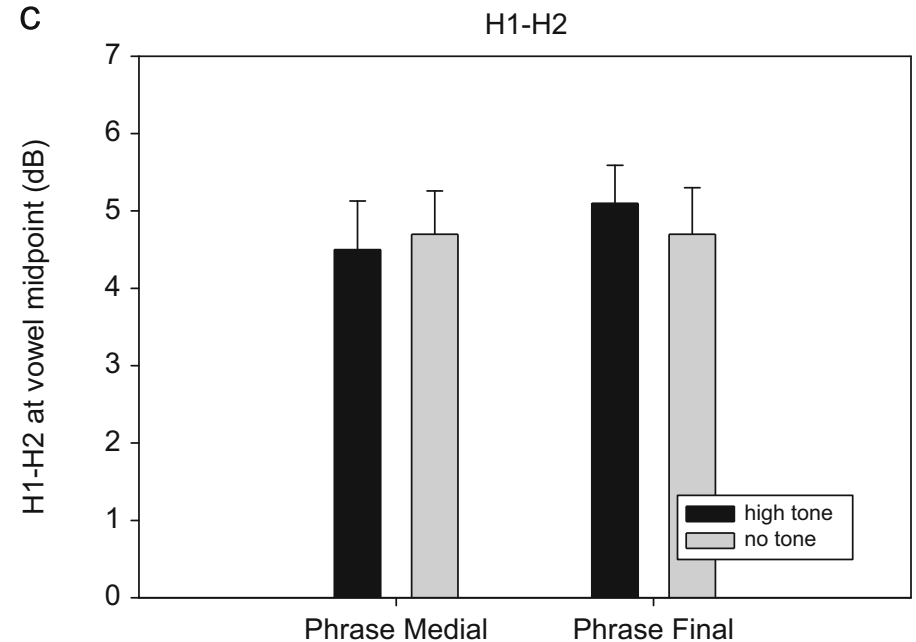

b

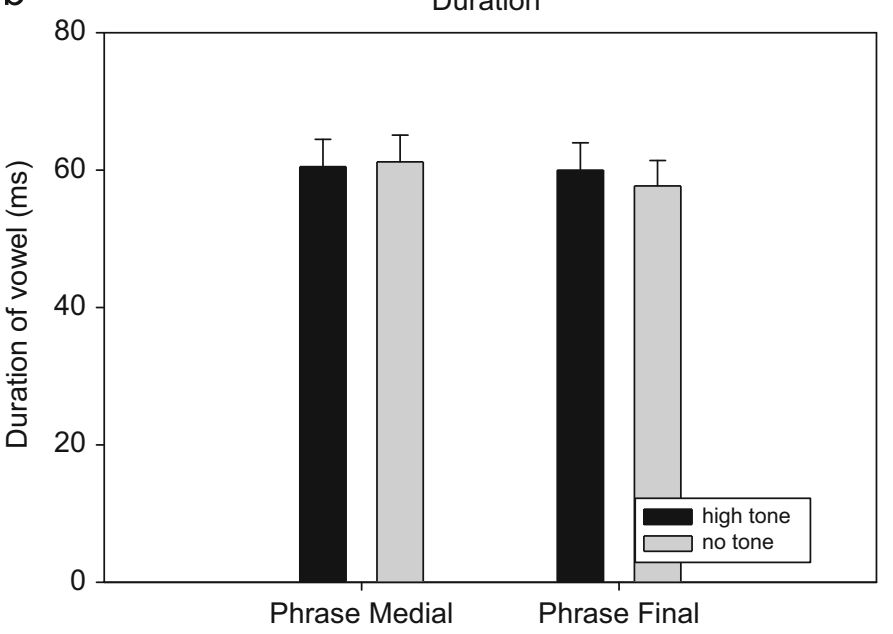

d

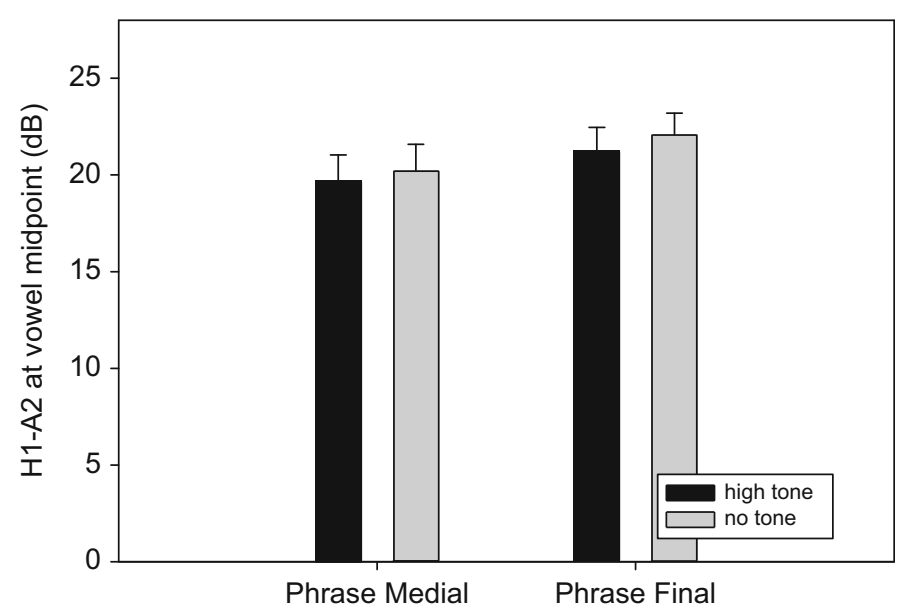

Fig. 10. Mean and standard error at vowel midpoint for the measures of (a) fundamental frequency, (b) vowel duration, (c) difference between the first and the second harmonic, and (d) difference between the first harmonic and the amplitude of the second formant for vowels with high tone from the effect of $* h$ in the coda of the following syllable and for vowels without tone. Data were produced by six participants from Oapan.

phenomena in Oapan Nahuatl, in which accents are not tied to certain syllables, but exhibit morphologicallyconditioned variation. Consider the variation illustrated in examples (9) through (15) in which tonal patterns appear to be associated with roots and vary in their placement depending on affixation. The lack of variation in tonal placement in Ahuelicán indicates that the conditioning environment may need to be lost before variation may enter into the system.

In both the tonal subdialects, the historical penultimate stress accents interact with the innovated tones. As can be seen in Figs. 3 and 4 and in the examples (9)-(11), when a high tone is developed on the antepenultimate syllable, the historical stress accent shifts from the penultimate to the final syllable (except in Oapan when the penult has a long vowel and retains the stress accent). This indicates that the innovated tones and the historical stress accents interact with each other so that, in some sense, they must form part of the same word-level prosodic system. Whether this interaction is autosegmental at the tonal level or a metrical, accentual phenomenon, is not clear at the present stage of analysis. However, the interaction would seem to require some sort of phonological specification on the same tier or domain for both the innovated tones and historical stress accents.

Although the hybrid stress-tone systems reviewed in the introduction exemplified cases in which stress and tonal systems were independent of each other, there are cases in which stress and tone interact. For example, Van der Hulst and Smith (1988) review many cases of hybrid systems in which tone is dependent on stress or vice versa. Tonal information may be limited to stressed syllables in Scandinavian languages and dialects of Dutch, German, and Croatian. In other cases, such as Kimatuumbi and Ayutla Mixtec, stress placement may be limited to syllables with certain tonal specifications. However, we have not yet found a report of a hybrid system in which tone and stress accent interact in a clash avoidance or dissimilatory process, as is the case in the Nahuatl subdialects studied here. 
The finding of phonological interaction between stress accent and tone led us to question whether the historical stress accents were themselves becoming tonal. Thus, we investigated the phonetic realization of tone and penultimate stress accent. Tone was found to be uniquely correlated with F0, whereas stress accent was found to be correlated with different acoustic characteristics, depending on subdialect. In subdialects that had not developed tone, stress accent was correlated primarily with spectral balance measures. In dialects that had developed tone, spectral balance measures were less strongly associated with stress accent. In Oapan, spectral balance measures were not correlated with stress accent and duration had developed into the primary correlate. In Ahuelicán, spectral balance correlates had been diminished but no new features had been added. Thus, we propose that in these subdialects, stress is changing in its phonetic realization as it interacts with tone. To better determine the precise direction of change, however, the association of F0 with these historical stress accents will need further investigation in more controlled prosodic environments.

The development of duration as a correlate to stress in Oapan is a bit puzzling. If stress were becoming more tonelike, why would a new correlate typical of stress accent be recruited? Likewise, it is a bit puzzling why none of the other subdialects use duration as a major correlate of stress accent. To tackle these questions, let us begin from a typological context. In many languages characterized as
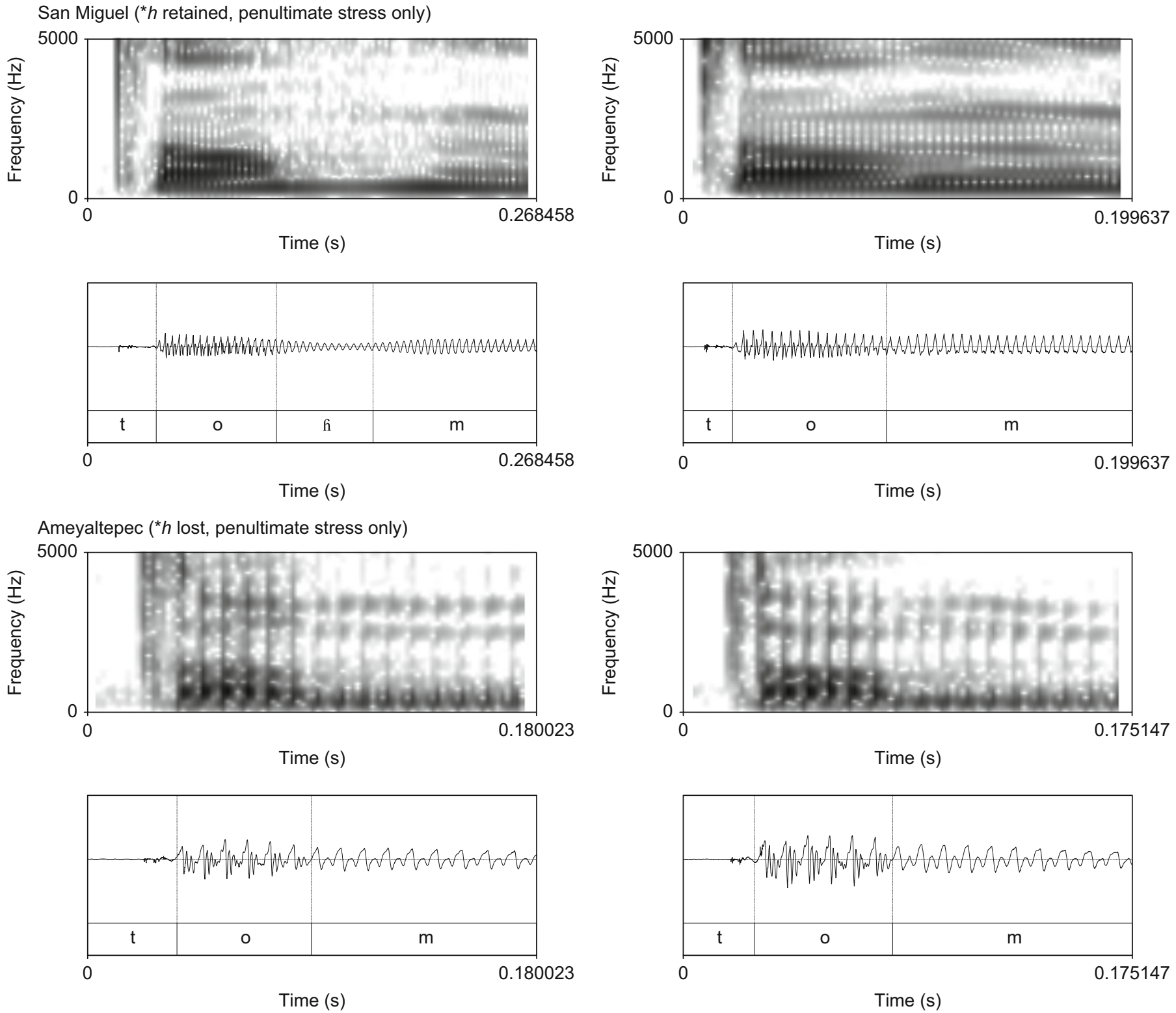

Fig. A1. 

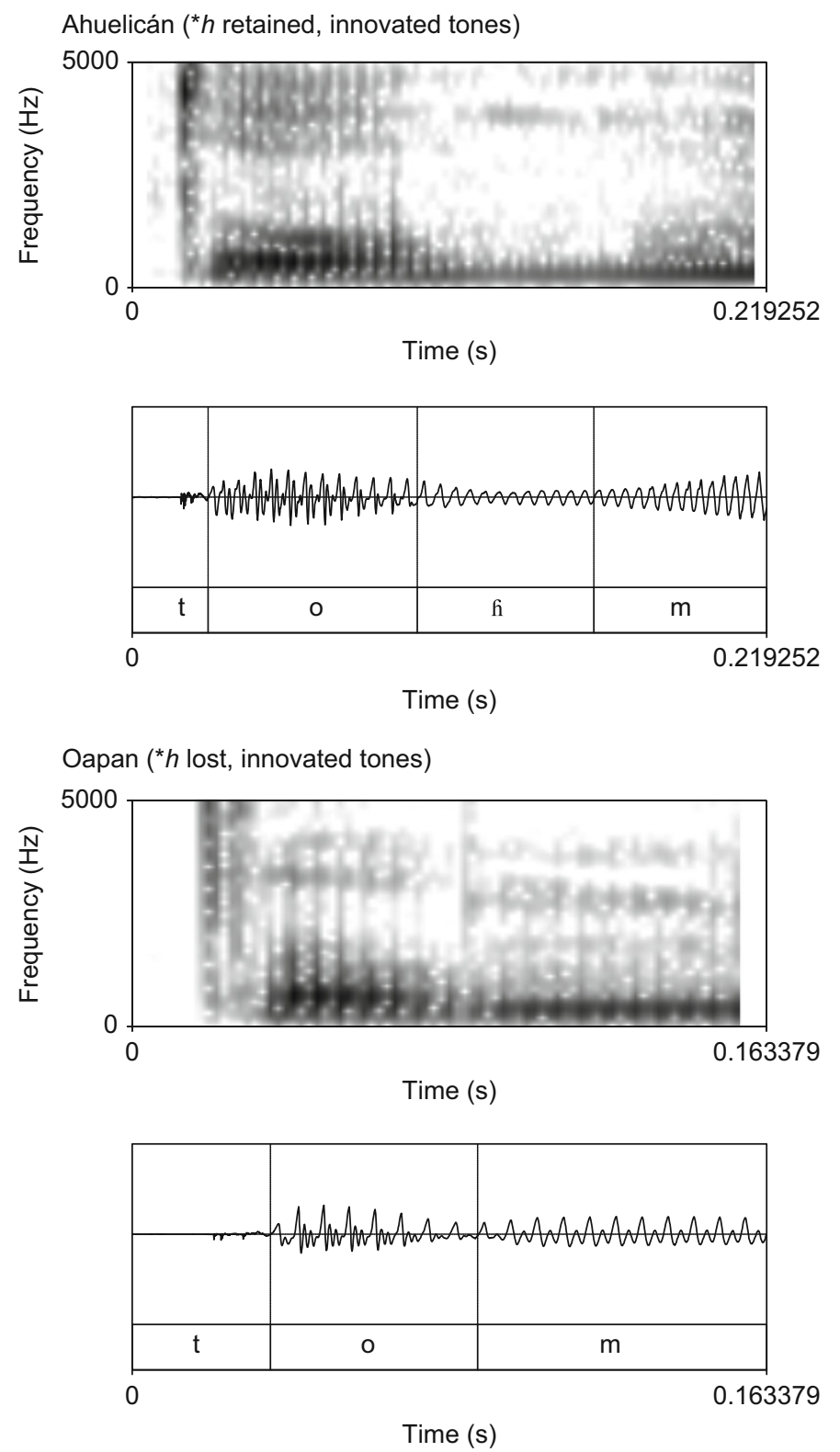
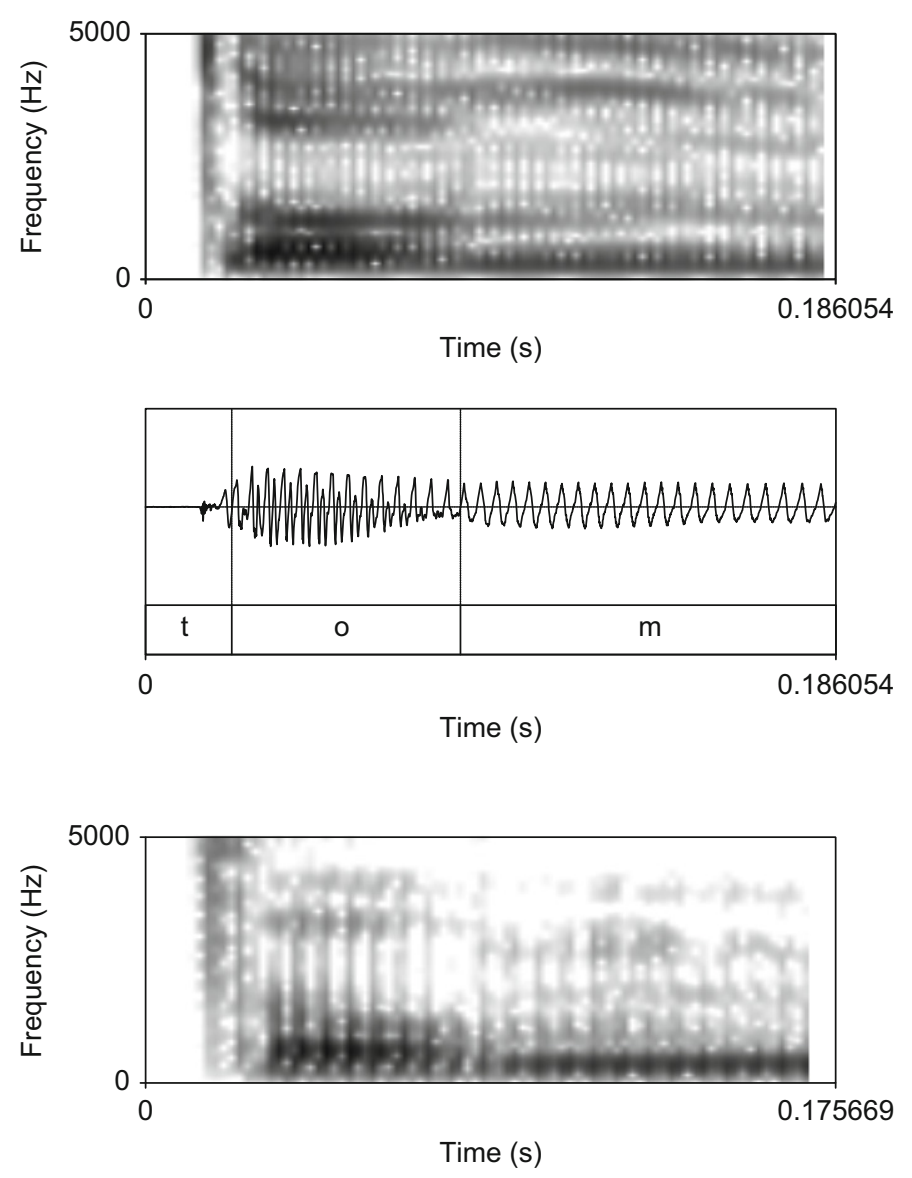

Fig. A1. (Continued)

having stress accent, longer duration is considered to be a primary correlate to stress (see, e.g., Beckman, 1986; Gussenhoven, 2004 and references therein). However, not all languages have been found to use duration as a cue to stress. Berinstein (1979) found that speakers of the Mayan language Q'eqchi' which has phonemic vowel length, did not use duration in stress production, nor did they use it as a cue to perception. However, the speakers of the related language Kakchiquel, as well as Spanish and English-none of which have phonemic vowel length--did use duration as a cue to perception. Thus, as Berinstein proposed, the presence of phonemic vowel length may modulate the use of duration as a cue to stress. It should be noted that at least some languages with durational contrasts have duration as a correlate to word-level stress (e.g., Finnish, as described by Suomi and Ylitalo, 2004).
Three of the four Nahuatl subdialects investigated here follow Berinstein's generalization. Only Oapan, which has lost the correlate of spectral balance, employs duration. We suggest that duration, a less common correlate to stress accent in languages such as Nahuatl that have phonemic length, was developed in Oapan only after the loss of the spectral balance stress correlates.

The loss of certain correlates to stress accent and the shift to others may indicate some instability in the word-level prosody of these hybrid systems. It may be that we are witnessing the transition from a tone and stress hybrid system to a purely tonal system. It may also be that the recruitment of duration while other correlates to stress are being lost has reinforced the encoding of stress and served to maintain and resolidify the hybrid system. Though hybrid systems are rare, 

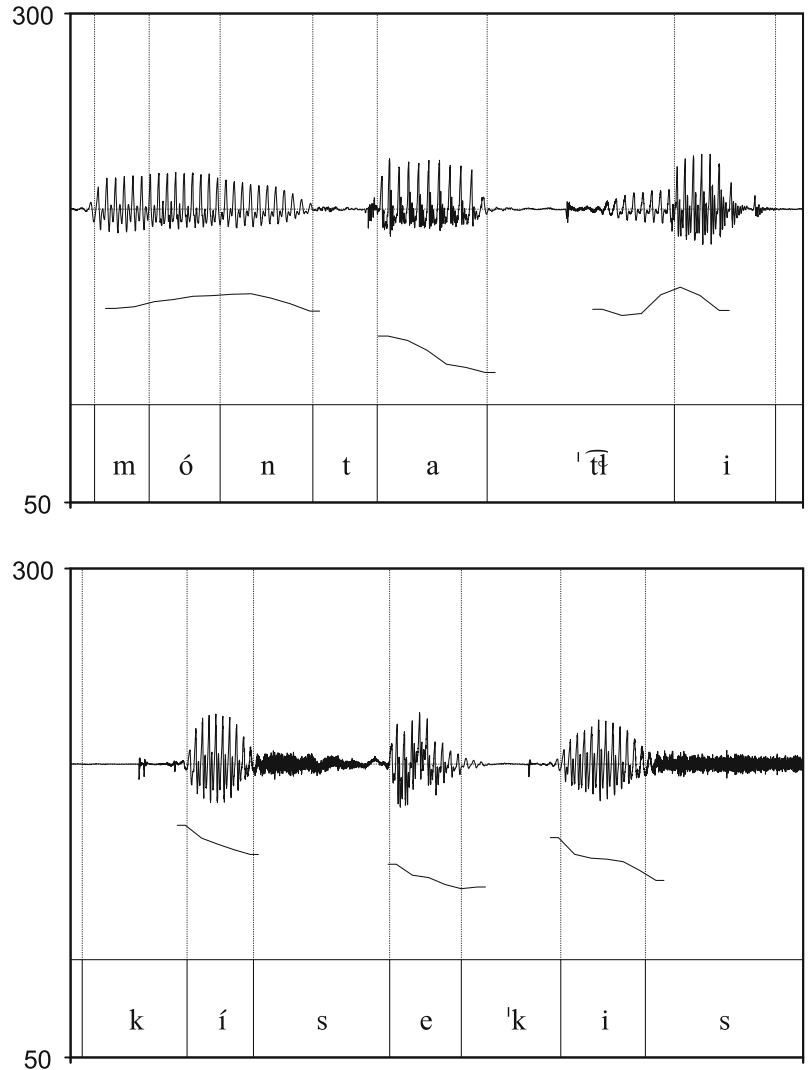
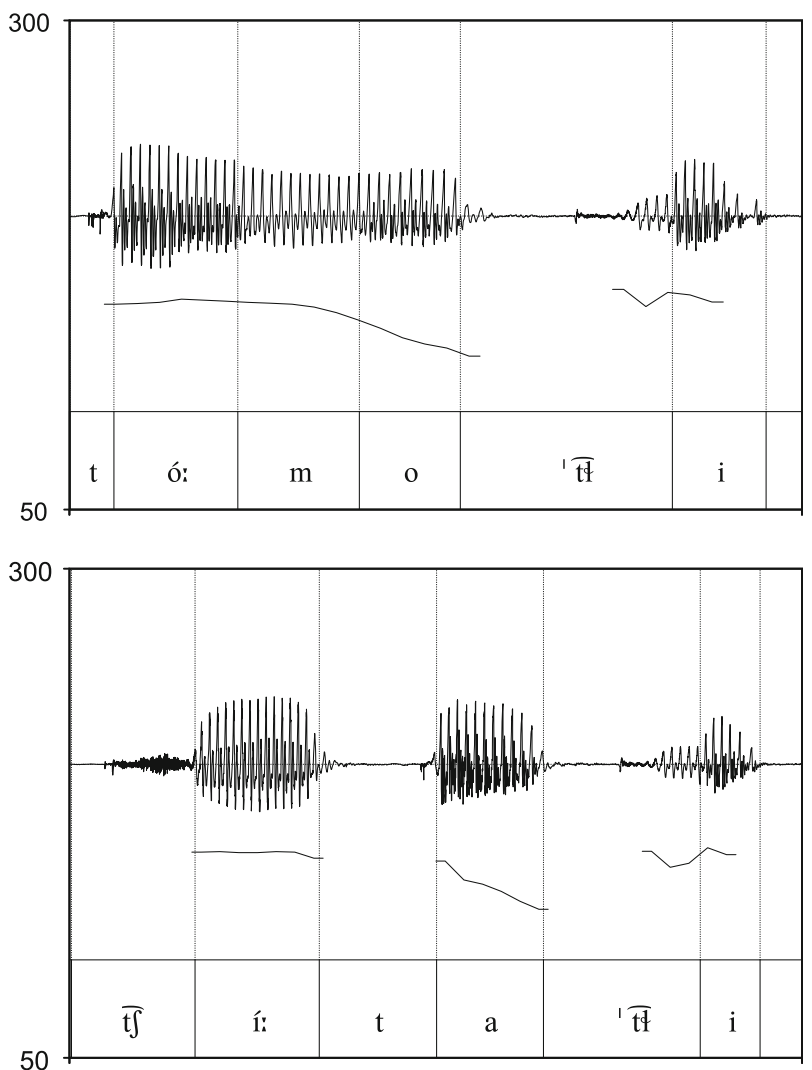

Fig. B1.

there has been enough documentation of them (see Introduction for review) to consider them a viable prosodic class.

Let us turn now to a consideration of the origin of tone and stress hybrid systems. Earlier we proposed a tentative developmental course for hybrid systems in which tone is acquired through the reanalysis of a segmental contrast in a stress accent language. The stress then remains, as well as the innovated tones. In such languages tones will not necessarily be present on all lexical items, just those containing the earlier phonological contrast. The Nahuatl subdialects investigated here provide another example of such a developmental course.

Overall, the data presented here provide further support for hybrid systems from a typological perspective, though they also indicate that such systems are perhaps rather unstable. Future work is needed to provide a more complete understanding of how word-level hybrid systems interact with phrase-level prosody and how such systems change over time.

\section{Acknowledgements}

The research reported here was supported by the National Science Foundation, award number 0504164; the US Department of Education, International Research and Studies Program, grant P017A010051, and the Ford Foundation, grants 1025-1428 and 1065-0692. We are indebted to the Nahuatl speakers who participated in this research and to the communities of Oapan, Ahuelicán, San Miguel, and Ameyaltepec for their hospitality and support. We also thank three anonymous reviewers and Alice Turk for their thoughtful suggestions and comments; responding to them has greatly benefited the presentation of this work.

\section{Appendix A}

Fig. A1 illustrates the production of a word with a nonword-final coda $* h$ and a matched word spoken by one speaker from each village under investigation. The illustrations on the left are example productions of the beginning of the word *tohmits 'body hair' and those on the right, of *tomi:n 'money'. For clarity of presentation, just the beginning of the word through the $[\mathrm{m}]$ is illustrated. Note that in San Miguel and Ahuelicán the historical *h is preserved and produced as a breathy voiced [f] in [tofmitł] $<*$ tohmitt . There is a clear period of voicing with reduced amplitude at the end of the syllable. Note also that the breathy voicing extends to the beginning of the [m] in these dialects. This can be contrasted with the production of [tominn] $<*$ tomi:n, which has no breathy voicing at the end of the syllable. In contrast, the 
subdialects that have lost $* h$, Ameyaltepec and Oapan, produce [tomit1] $<*$ tohmitt with no breathy voicing at the end of the syllable and the production is quite similar to that of [tomi:n] $<*$ tomi:n.

While these figures are representative of all the speakers from each village, it should be noted that the breathy phonation period in speakers from Ahuelicán is sometimes shorter than that in speakers from San Miguel. In San Miguel, the breathy voicing sometimes transitions to voicelessness toward the end of the syllable. Thus, while San Miguel speakers always have a breathy-voiced portion as a reflex of $* h$, they sometimes have a voiceless period after that. So, for example, the word illustrated here could sometimes be produce as [tofimity] and sometimes be produced as [tôhimitt].

\section{Appendix B}

As F0 was measured at the temporal midpoint in this study, the possibility that long vowels had more than one tonal target was considered. A thorough examination of long vowels produced by all speakers in all dialects did not reveal any differences in the F0 patterns between long and short vowels that would indicate two tonal targets for long vowels and one tonal target for short vowels. Here, we give representative F0 tracks for one speaker from Oapan. Compare the short, high tone [ó] in the first syllable of [mónta't1i] ('father-in-law') to the long, high tone [ó:] in the first syllable [tó:mo'tłi] ('prickly pear') and the short high tone [í] in the first syllable of [kíse'kis] ('s/he will toast it on a griddle') to the long, high tone [í] in [t fíta'tłi] ('cradle') in Fig. B1.

\section{References}

Abramson, A. S. (2004). The plausibility of phonetic explanations in tonogenesis. In G. Fant, H. Fujisaki, J. Cao, \& Y. Xu (Eds.), From traditional phonology to modern speech processing: Festschrift for professor Wu Zongji's 95th birthday (pp. 17-29). Beijing: Foreign Language Teaching and Research Press.

Amith, J. D. Tone and tonogenesis in Balsas Nahuatl: Accentual patterns from coda $* h$. Unpublished manuscript

Amith, J. D. (1995). The history of the Balsas River basin Nahuatl communities. In J. D. Amith (Ed.), The amate tradition: Innovation and protest in Mexican art (pp. 129-144). Mexico City: La Casa de las Imágenes; Chicago: Mexican Fine Art Center Museum.

Amith, J. D. (2005). The Möbius strip: A spatial history of colonial society in Guerrero, Mexico. Stanford, CA: Stanford University Press.

Andrews, J. R. (1975). Introduction to Classical Nahuatl. Austin, TX: University of Texas Press.

Beckman, M. E. (1986). Stress and non-stress accent. Dordrecht: Foris.

Beller, R., \& Beller, P. (1979). Huasteca Nahuatl. In R. W. Langacker (Ed.), Studies in Uto-Aztecan grammar. Vol. 2: Modern Aztec grammatical sketches (pp. 199-306). Dallas: Summer Institute of Linguistics; Arlington: University of Texas at Arlington.

Berinstein, A. E. (1979). A cross-linguistic study on the perception of and production of stress. UCLA Working Papers in Phonetics, 47.

Boas, F. (1917). El dialecto mexicano de Pochutla, Oaxaca. International Journal of American Linguistics, 1, 9-44.
Boersma, P., \& Weenink, D. (2005). Praat: Doing phonetics by computer (version 4.3.36) [Computer program]. Retrieved December 11, 2005, from $\langle$ http://www.praat.org/ $\rangle$.

Brewer, F., \& Brewer, J. G. (1971). Vocabulario mexicano de Tetelcingo, Morelos. Castellano-mexicano, mexicano-castellano. Mexico City: Instituto Lingüístico de Verano.

Brockway, E. (1979). North Puebla Nahuatl. In: R.W. Langacker (Ed.), Studies in Uto-Aztecan grammar, Vol. 2: Modern Aztec grammatical sketches (pp. 141-198). Dallas: Summer Institute of Linguistics; Arlington: University of Texas at Arlington.

Brockway, E., Brockway, T. H., \& Valdés, L. S. (2000). Diccionario náhuatl del norte del estado de Puebla. Mexico City: Instituto Lingüístico de Verano.

Bruce, G. (1977). Swedish word accents in sentence perspective. Lund: Glerrup.

Clark, M. (1988). An accentual analysis of the Zulu noun. In H. van der Hulst, \& N. Smith (Eds.), Autosegmental studies on pitch accent (pp. 51-79). Dordrecht: Foris.

Clements, G. N., \& Ford, K. C. (1979). Kikuyu tone shift and its synchronic consequences. Linguistic Inquiry, 10, 179-210.

Everett, K. E. (1998). The acoustic correlates of stress in Pirahã. Journal of Amazonian Linguistics, 1, 104-162.

Fant, G. (1960). Acoustic theory of speech production. The Hague: Mouton.

Fry, D. B. (1955). Duration and intensity as physical correlates of linguistic stress. Journal of the Acoustical Society of America, 27, 765-768.

Gauffin, J., \& Sundberg, J. (1989). Spectral correlates of glottal voice source waveform characteristics. Journal of Speech and Hearing Research, 32, 556-565.

Gordon, M., \& Ladefoged, P. (2001). Phonation types: A cross-linguistic overview. Journal of Phonetics, 29, 383-406.

Glave, R. D., \& Rietveld, A. C. M. (1975). Is the effort dependence of speech loudness explicable on the basis of acoustical cues? Journal of the Acoustical Society of America, 58, 875-879.

Graden, D. (1966). Consonantal tone in Jeh phonemics. The Mon Khmer Studies Journal, 2, 41-53.

Gussenhoven, C. (2004). The phonology of tone and intonation. Cambridge: Cambridge University Press.

Hanson, H. M. (1997). Glottal characteristics of female speakers: Acoustic correlates. Journal of the Acoustical Society of America, 101, 466-481.

Hanson, H. M. (2001). Towards models of phonation. Journal of Phonetics, 29, 451-480.

Hanson, H. M., \& Chuang, E. S. (1999). Glottal characteristic of male speakers: Acoustic correlates and comparison with female data. Journal of the Acoustical Society of America, 106, 1064-1077.

Haraguchi, S. (1988). Pitch accent and intonation in Japanese. In H. van der Hulst, \& N. Smith (Eds.), Autosegmental studies on pitch accent (pp. 123-150). Dordrecht: Foris.

Hayes, B. (1995). Metrical stress theory. Chicago: University of Chicago Press.

Holmberg, E. B., Hillman, R. E., Perkell, J. S., Guiod, P. C., \& Goldman, S. L. (1995). Comparisons among aerodynamic, electroglottographic, and acoustic spectral measures of female voice. Journal of Speech and Hearing Research, 38, 1212-1223.

Hombert, J.-M., Ohala, J., \& Ewan, W. (1979). Phonetic explanations for the development of tones. Language, 55, 37-58.

Hyman, L. M. (2006). Word-prosodic typology. Phonology, 23, 225-257.

Ladd, D. R. (1996). Intonational phonology. Cambridge: Cambridge University Press.

Lastra de Suárez, Y. (1981). Stress in modern Nahuatl dialects. In F. Karttunen (Ed.), Nahuatl studies in memory of Fernando Horcasitas. Texas Linguistic Forum, Vol. 18 (pp. 119-128). Austin: Department of Linguistics, University of Texas at Austin.

Liénard, J.-S., \& Di Benedetto, M.-G. (1999). Effect of vocal effort on spectral properties of vowels. Journal of the Acoustical Society of America, 106, 411-422. 
Lindblom, B., \& Rapp, K. (1973). Some temporal regularities of spoken Swedish. Papers from the Institute of Linguistics, 21, University of Stockholm.

Manaster-Ramer, A. (1986). Genesis of Hopi tones. International Journal of American Linguistics, 52, 154-160.

Martin, J. B., \& Johnson, K. (2002). An acoustic study of "tonal accent" in Creek. International Journal of American Linguistics, 68, 28-50.

Matisoff, J. A. (1973). Tonogenesis in Southeast Asia. In L. Hyman (Ed.), Southern California occasional papers in linguistics, no 1: Consonant types and tone (pp. 71-95). Los Angeles: Linguistics Program, University of Southern California.

Munro, P. (1977). Towards a reconstruction of Uto-Aztecan stress. In L. M. Hyman (Ed.), Southern California occasional papers in linguistics, no. 4 (pp. 303-326). Los Angeles: Department of Linguistics, University of Southern California.

Nooteboom, S. G. (1972). The production and perception of vowel duration. Doctoral Dissertation, University of Utrecht.

Ohala, J. J. (1973). The physiology of tone. In L. Hyman (Ed.), Southern California occasional papers in linguistics, no 1: Consonant types and tone (pp. 1-14). Los Angeles: Linguistics Program, University of Southern California.

Ohala, J. J. (1993). The phonetics of sound change. In C. Jones (Ed.), Historical linguistics: Problems and perspectives (pp. 237-278). New York: Longman.

Pierrehumbert, J. B. (1980). The phonology and phonetics of English intonation. Doctoral Dissertation, Massachusetts Institution of Technology.

Pierrehumbert, J. B., \& Beckman, M. E. (1988). Japanese tone structure. Cambridge, MA: Massachusetts Institute of Technology Press.

Pike, E. V. (1986). Tone contrasts in Central Carrier (Athapaskan). International Journal of American Linguistics, 52, 411-418.

Ramírez de Alejandro, C., \& Dakin, K. (1979). Vocabulario náhuatl de Xalitla, Guerrero. Cuadernos de la Casa Chata, Vol. 25. Mexico City: Centro de Investigaciones Superiores del Instituto Nacional de Antropología e Historia.

Remijsen, B. (2002). Lexically contrastive stress accent and lexical tone in Ma'ya. In C. Gussenhoven, \& N. Warner (Eds.), Laboratory phonology, Vol. 7 (pp. 585-614). Berlin: Mouton de Gruyter.

Remijsen, B., \& van Heuven, V. J. (2005). Stress, tone and discourse prominence in the Curaçao dialect of Papiamentu. Phonology, 22, $205-235$.

Shaul, D. L. (2000). Comparative Tepiman: Phonological change and inflectional categories. In E. H. Casad, \& T. L. Willett (Eds.), UtoAztecan: Structural, temporal and geographic perspectives: Papers in honor of Wick R. Miller by the friends of Uto-Aztecan (pp. 319-356). Hermosillo: Universidad de Sonora.
Sischo, W. (1979). Michoacán Nahuatl. In R.W. Langacker (Ed.), Studies in Uto-Aztecan grammar, Vol. 2: Modern Aztec grammatical sketches (pp. 307-380). Dallas: Summer Institute of Linguistics; Arlington: University of Texas at Arlington.

Sluijter, A., \& van Heuven, V. J. (1996a). Spectral balance as an acoustic correlate of linguistic stress. Journal of the Acoustical Society of America, 100, 2471-2485.

Sluijter, A., \& van Heuven, V. J. (1996b). Acoustic correlates of linguistic stress and accent in Dutch and American English. In Proceedings of the fourth international conference on spoken language, Vol. 2, Philadelphia (pp. 630-633).

Sluijter, A., \& van Heuven, V. J. (1997). Spectral balance as a cue in the perception of linguistic stress. Journal of the Acoustical Society of America, 101, 503-513.

Suomi, K., \& Ylitalo, R. (2004). On durational correlates of word stress in Finnish. Journal of Phonetics, 32, 35-63.

Stevens, K. N., \& Hanson, H. M. (1995). Classification of glottal vibration from acoustic measurements. In O. Fujimura, \& M. Hirano (Eds.), Vocal fold physiology: Voice quality control (pp. 147-170). San Diego: Singular.

Svantesson, J.-O. (2001). Tonogenesis in Southeast Asia-Mon-Khmer and beyond. In S. Kaji (Ed.), Proceedings of the symposium crosslinguistic studies of tonal phenomena: Tonogenesis, Japanese accentology, and other topics (pp. 45-58). Tokyo: Institute for the Study of Language and Cultures of Asia and Africa, Tokyo University of Foreign Studies.

Thongkum, T. L. (1988). Phonation types in Mon-Khmer languages. In O. Fujimura (Ed.), Voice production: Mechanisms and functions (pp. 319-333). New York: Raven Press.

Thurgood, G. (2002). Vietnamese and tonogenesis: Revising the model and the analysis. Diachronica, 19, 333-363.

Tuggy, D. H. (1979). Tetelcingo Nahuatl. In R. W. Langacker (Ed.), Studies in Uto-Aztecan grammar, Vol. 2: Modern Aztec grammatical sketches (pp. 1-140). Dallas, Arlington: Summer Institute of Linguistics, University of Texas at Arlington.

Van der Hulst, H., \& Smith, N. (1988). The variety of pitch accent systems: Introduction. In H. van der Hulst, \& N. Smith (Eds.), Autosegmental studies on pitch accent (pp. ix-xxiv). Dordrecht: Foris.

Wayland, R. P., \& Guion, S. G. (2005). Sound changes following the loss of $/ \mathrm{r} /$ in Khmer: A new tonogenetic mechanism? Mon-Khmer Studies, $35,55-82$.

Wolgemuth, C. (2002). Gramática náhuatl (mela’tájtol) de los municipios de Mecayapan y Tatahuicapan de Juárez, Veracruz. 2a edition. Mexico City, Instituto Lingüístico de Verano. 